\begin{tabular}{|c|c|c|}
\hline Beitr. Ent. & Keltern & ISSN 0005-805X \\
\hline $\mathbf{5 8}(2008) 2$ & S. $267-355$ & 15.11 .2008 \\
\hline
\end{tabular}

\title{
Aulacidae of the southwestern United States, Mexico, and Central America
}

\section{(Hymenoptera)}

With 183 figures

\section{DAVID R. SMITH}

\begin{abstract}
Summary
Forty-two species of Aulacidae are recorded from the southwestern United States (southern Texas, New Mexico, Arizona), Mexico, and Central America, including 11 species of Aulacus Jurine and 31 species of Pristaulacus Kieffer. Eight species are known from southwestern United States, 27 from Mexico, one from Guatemala, three from Honduras, one from Nicaragua, 11 from Costa Rica, and two from Panama. Taxa included are: Aulacus maculosus, n. sp. (Costa Rica); A. ochreus Smith, 2005 (Costa Rica); A. fascius, n. sp. (Mexico); A. veracruz, n. sp. (Mexico); $A$. costaricensis, n. sp. (Costa Rica); $A$ heredia, n. sp. (Costa Rica), A. elongatus, n. sp. (Panama, Costa Rica); A. leon, n. sp. (Mexico); A. whartoni, n. sp. (Mexico); A. aneurus Walkley, 1952 (US: New Mexico); A. dispilis Townes, 1950 (US: Texas); Pristaulacus argutus, n. sp. (Mexico); P. tria, n. sp. (Costa Rica); P. maculatus (Schletterer, 1889) (Costa Rica, Nicaragua, Panama); P. ruficollis (Cameron, 1887) (Guatemala, Honduras, Mexico); P. auricomus, n. sp. (Honduras, Mexico, US: Arizona); P. virga, n. sp. (Mexico); P. punctum, n. sp. (Costa Rica); P. decorus, n. sp. (Mexico); P. aquilus, n. sp. (Mexico); P. torridus (Bradley, 1908) (US: Texas); P. anteala, n. sp. (Costa Rica); P. triclora, n. sp. (Mexico); P. nigricoxae, n. sp. (Mexico); P. unimacula, n. sp. (Mexico); P. postala, n. sp. (Mexico); P.stangei, n. sp. (Mexico); P. tenuis, n. sp. (Mexico); P. decolorus, n. sp. (Mexico); P. singulus, n. sp. (Costa Rica); P. candidus, n. sp. (Mexico); P. omninoniger, n. sp. (Mexico); P. townesi, n. sp. (Mexico), P. arizonicus (Townes, 1950) (US: Arizona); P. rufitarsis (Cresson, 1864) (US: Arizona, California, New Mexico); P. ruficruris, n. sp. (Mexico, US: Texas); P. parkeri, n. sp. (Mexico); P. mexiuni, n. sp. (Mexico, US: Arizona, Texas); P. totoferrugineus, n. sp. (Mexico); P. hespenheidei, n. sp. (Mexico); P. tamaulipas, n. sp. (Mexico); P.annulatus KiefFer, 1911 (Mexico). Aulacus hyalinipennis Westwood, 1841, is placed in species incertae sedis of Aulacidae.
\end{abstract}

\section{Zusammenfassung}

Für das Gebiet der südwestlichen USA (südliches Texas, New Mexico, Arizona), Mexiko und Mittelamerika werden 42 Aulacidae-Arten festgestellt, von denen 11 zu Aulacus Jurine und 31 zu Pristaulacus Kiefrer gehören. Aus den südwestlichen USA sind 8 Arten bekannt, 27 aus Mexiko, eine aus Guatemala, drei aus Honduras, eine aus Nicaragua, 11 aus Costa Rica und zwei aus Panama. Die folgenden Taxa werden behandelt: Aulacus maculosus, n. sp. (Costa Rica); A. ochreus Sмiтн, 2005 (Costa Rica); A. fascius, n. sp. (Mexiko); A. veracruz, n. sp. (Mexiko); A. costaricensis, n. sp. (Costa Rica); A heredia, n. sp. (Costa Rica), A. elongatus, n. sp. (Panama, Costa Rica); A. leon, n. sp. (Mexiko); A. whartoni, n. sp. (Mexiko); A. aneurus Walkley, 1952 (USA: New Mexico); A. dispilis Townes, 1950 (USA: Texas); Pristaulacus argutus, n. sp. (Mexiko); P. tria, n. sp. (Costa Rica); P. maculatus (Schletterer, 1889) (Costa Rica, Nicaragua, Panama); P. ruficollis (Cameron, 1887) (Guatemala, Honduras, Mexico); P. auricomus, n. sp. (Honduras, Mexico, USA: Arizona); P. virga, n. sp. (Mexiko); P. punctum, n. sp. (Costa Rica); P. decorus, n. sp. (Mexiko); P. aquilus, n. sp. (Mexiko); P. torridus (Bradley, 1908) (USA: Texas); P. anteala, n. sp. (Costa Rica); 
P. triclora, n. sp. (Mexiko); P. nigricoxae, n. sp. (Mexiko); P. unimacula, n. sp. (Mexiko); P. postala, n. sp. (Mexiko); P. stangei, n. sp. (Mexiko); P. tenuis, n. sp. (Mexiko); P. decolorus, n. sp. (Mexiko); P. singulus, n. sp. (Costa Rica); P. candidus, n. sp. (Mexiko); P. omninoniger, n. sp. (Mexiko); P. townesi, n. sp. (Mexiko), P. arizonicus (Townes, 1950) (USA: Arizona); P. rufitarsis (Cresson, 1864) (USA: Arizona, California, New Mexico); P. ruficruris, n. sp. (Mexico, USA: Texas); P. parkeri, n. sp. (Mexiko); P. mexiuni, n. sp. (Mexiko, USA: Arizona, Texas); P. totoferrugineus, n. sp. (Mexiko); P. hespenheidei, n. sp. (Mexiko); P. tamaulipas, n. sp. (Mexiko); P. annulatus Kiefrer, 1911 (Mexiko). Aulacus hyalinipennis Westwood, 1841, wird innerhalb der Aulacidae als species incertae sedis betrachtet.

\section{Key Words}

parasitic wasps, Arizona, Texas, New Mexico, Mexico, Guatemala, Honduras, Nicaragua, Costa Rica, Panama, Cerambycidae, Buprestidae

\section{Introduction}

The Aulacidae occur in all regions of the world but are most diverse in the Oriental, Australian, and Neotropical regions. Sмiтн (2001) cataloged 157 species in three genera, of which Aulacus Jurine, 1807, and Pristaulacus Kieffer, 1900, are worldwide and Panaulux Benoit, 1954, is restricted to Africa. The catalog apparently stimulated some interest in the family; subsequently, 28 species have been added to the world fauna from Australia (Jennings et al. 2004a, b), New Guinea (Jennings and Austin 2006), New Caledonia (Jennings et al. 2004c), China (He et al. 2002; Turrisi 2005; Sun and Sheng 2007a, b), Africa (Turrisi 2006), the Palearctic Region (Turrisi 2007), and South America (Smith 2005a, b).

The aulacid fauna of Mexico and Central America has never been studied. SMIтH (2001) listed only three species, Aulacus hyalinipennis Westwood from Mexico, Pristaulacus ruficollis (CAmeron) from Guatemala, and P. annulatus (Kieffer) from Mexico. Smith (2005) added two species from Central America, Aulacus ochreus Smith from Costa Rica and Pristaulacus maculatus (Schletterer) from Costa Rica, Nicaragua, and Panama. Here, I treat 42 species from this region, including several from southwestern United States that could occur in Mexico.

Members of Aulacidae may be recognized by their characteristic habitus (Fig. 168). Though ichneumonid-like in appearance, the broad costal cell, metasoma inserted high on the propodeum, the somewhat dome-shaped head, and elongated "neck" are typical. They can be separated from the other two families of Evanioidea, Evaniidae and Gasteruptiidae, by the presence of vein $2 \mathrm{~m}$-cu in the forewing (Figs 4, 163), the antennae inserted low on the face, near the lower margin of the eyes (as in Fig. 18), lack of a jugal lobe in the hind wing, and elongate propleuron (as in Fig. 154). For a guide to separation of Aulacidae from other Evanioidea and Hymenoptera, see the books by Hanson and Gauld (2006) and Fernández and Sharkey (2007) and the chapters therein by Smith (2006, 2007), Mason (2006), and Gauld and Hanson (2006).

Aulacids are endoparasitic koinobionts of wood-boring insects, primarily Cerambycidae, Buprestidae (Coleoptera) and Xiphydriidae (Hymenoptera). Xiphydriids in this region are rare, only one species being known from Costa Rica (Sмiтн 1988); thus, most, if not all the species of aulacids are probably parasitoids of wood-boring beetles. Clues to probable hosts are indicated on label data for only five species: Aulacus aneureus (WALKLEY) reared from trees infested with Dendroctonus (Scolytidae); A. digitalis Townes emerging from wood of Celtis and Pithecellobium; Pristaulacus maculatus (SCHLETTERer) taken on fallen branches of Pentaclethra, and one specimen labeled "ex Trachysomus thomsoni" (Cerambycidae); P. decorus, n. sp., ex Vitex, Oxalis, and Scoparia (though probably swept while visiting those plants); and P. ruficruris, n. sp., ex Acacia rigidula. 


\section{Materials and Methods}

This study is based on approximately 200 specimens from the following collections. Acronyms used in the text are as follows:

\begin{tabular}{|c|c|}
\hline AEI & American Entomological Institute, Gainesville, FL (D. WAHL) \\
\hline AMNH & American Museum of Natural History, New York, NY. (J. CARPENTER) \\
\hline ANSP & Academy of Natural Sciences, Philadelphia, PA (D. Azuma) \\
\hline $\mathrm{BMNH}$ & The Natural History Museum, London, U.K. (C. TAYLOR, K. Goodger) \\
\hline CAS & California Academy of Sciences, San Francisco, CA (W. Pulawski) \\
\hline CDA & California Department of Agriculture, Sacramento (J. SoREnSEN) \\
\hline $\mathrm{CHAH}$ & Collection Henry A. Hespenheide, University of California, Los Angeles \\
\hline $\mathrm{CNC}$ & Canadian National Collection of Insects, Ottawa, Canada (J. Huber) \\
\hline CSU & Colorado State University, Fort Collins (H. E. Evans, B. Kondratieff) \\
\hline FSCA & Florida State Collection of Arthropods, Gainesville (L. A. Stange, J. WiLEY) \\
\hline HUM & Instituto Humboldt, Villa de Aleyva, Colombia (F. Fernández) \\
\hline INBio & $\begin{array}{l}\text { Instituto Nacional de Biodiversidad, Santa Domingo de Heredia, Costa Rica (J. A. UGaLdE, } \\
\text { C. Godoy) }\end{array}$ \\
\hline LACM & The Natural History Museum of Los Angeles County, CA (R. R. SnelLing) \\
\hline MCZ & Museum of Comparative Zoology, Harvard University, Cambridge, MA (S. Cover) \\
\hline MSU & Michigan State University, East Lansing (F. W. Stehr, G. L. PArsons) \\
\hline OSU & The Ohio State University, Columbus, OH (N. Johnson) \\
\hline TAMU & Texas A\&M University, College Station, TX (E. G. RILEY) \\
\hline UCB & University of California, Berkeley, CA (C. BARR) \\
\hline UCRC & University of California, Riverside (D. YANEGA) \\
\hline UCD & University of California, Davis, CA (L. Kimsey, S. HeYdon) \\
\hline UGA & University of Georgia, Athens (C. L. Sмітн) \\
\hline UKAN & University of Kansas, Lawrence (R. W. BROoKs, Z. H. FALIN) \\
\hline UMINN & University of Minnesota, St. Paul (P. J. Clausen) \\
\hline USNM & National Museum of Natural History, Smithsonian Institution, Washington, DC \\
\hline USU & Utah State University, Logan (W. J. Hanson) \\
\hline ZMUC & Zoologisk Museum, Universitetspaarken 15, Copenhagen, Denmark (B. Petersen) \\
\hline
\end{tabular}

I have examined types of all species except for Aulacus hyalinipennis Westwood, which could not be located (see incertae sedis). See SMITH (2001) for generic synonymy. Terminology follows that of Huber and Sharkey (1993). Locality data for holotypes are quoted from the labels, and data for paratypes and material examined are given essentially as they appear on the labels.

So far as is known, sexual dimorphism is not significant in Aulacidae. Therefore, some species, Aulacus heredia, Pristaulacus aquilis, P. tenuis, P. declorus, P. singularis, P. omninoniger, and P. townesi, are described only from males. Females, when encountered, should not be difficult to associate with these males.

Explanations of and characters used for species discrimination are as follows.

\section{Measurements:}

Length is the length of the body from the front of the head to the end of the metasoma and excludes the ovipositor. Ovipositor length is from the base of the ovipositor to the apex. These 
are sometimes difficult to measure because of the position of the head and abdomen in pinned specimens (turned up or down) and the curled ovipositor and sheath.

Head:

Antennae are filiform, with 12 flagellomeres in the female and 11 in the male. Antennal length is contrasted to the head width, which is the widest point of the head, including the eyes, in dorsal view. The scape is globular, much broader than the pedicel and flagellomeres (as in Fig. 28). Both the scape and first flagellar segment are longer than the pedicel; this is not contrasted in the descriptions because differences are very slight, if any.

The lower interocular distance and length of malar space in relation to the eye height and the length of the head behind the eyes in dorsal view are useful for species separation. The occipital carina is absent in all species of Aulacus, but present in varying degrees in all species of Pristaulacus from very narrow to broad and flangelike. The clypeus of all species has a central anteriorly projecting tooth. All species have a subantennal groove which extends from the base of the antenna through the malar area. The type of sculpture on the vertex, gena, and frons is significant for species discrimination.

\section{Mesosoma:}

Sculpture of all parts is significant. The propleuron has a short longitudinal to slightly diagonal carina posterolaterally; this did not seem to differ between species. The anterior margin of the pronotum is simple in all Aulacus and some Pristaulacus, but may have one or more anteriorly projected teeth in many species of Pristaulacus. One group of Pristaulacus has the anterolateral corners of the mesoscutum produced anteriorly into toothlike prominences (as in Figs 61, 62); the anterior margin of the pronotum is rounded, sometimes lobelike, in other species of the family (as in Figs 65, 66). The notauli of Aulacus may meet posteriorly before reaching the transscutal articulation (as in Fig. 9) or meet separately on the transscutal articulation (as in Fig. 25); in Pristaulacus, though sometimes faint, the notauli meet posteriorly before or at the transscutal articulation (as in Figs 105, 172).

The tarsal claws of most Aulacus are simple, but one species, $A$. whartoni, has a long, broad inner tooth at its base (Fig. 38); all claws of Prisaulacus are comblike, with three to six teeth (including the outer tooth) and sometimes a basal lobe (as in Fig. 82). The number of teeth can be difficult to determine; sometimes the basal tooth is hidden and difficult to see, and it may be mistaken for a basal lobe, which may be acute and toothlike.

Examples of forewing venation are illustrated throughout. Vein $2 \mathrm{r}-\mathrm{m}$ is present or faint in species of Aulacus (Fig. 4), but always absent in species of Pristaulacus (e.g., Fig. 157). All species of Aulacus have a short vein separating cells $1 \mathrm{M}$ and 1 Rs (Fig. 4); this is not repeated in the species descriptions. In Pristaulacus, the length of vein Rs+M between cells $1 \mathrm{M}$ and $1 \mathrm{Rs}$ varies. The two cells may be contiguous (as in Figs 110,119) or separated by a long or short vein Rs+M (as in Fig. 97). The hind wing venation is reduced. In all Aulacus, the venation consists of only the costa and $S_{c}+\mathrm{R}$ with the rest of the veins absent or very faint (as in Fig. 157). In Pristaulacus, the veins may be absent as in Aulacus or consisting of the costa, $\mathrm{Sc}+\mathrm{R}$ and veins $\mathrm{m}+\mathrm{cu}, 1 \mathrm{r}-\mathrm{m}, \mathrm{M}$, and $\mathrm{cu}+\mathrm{cu}-\mathrm{a}$ in an "X" pattern (as in Figs 81, 110, 97, 104). Cells $\mathrm{R} 1+\mathrm{Rs}$ and $\mathrm{Cu}$ may be contiguous, without a short vein M separating them (as in Figs 81, 110) or separated by a short vein M (as in $97,104)$. There are normally three hamuli on the hind wing, two stout, apical, down-curved ones and one more slender, laterally directed basal one. Almost all species have this combination. For a few species (Pristaulacus tria, P. aquilis, P. tricolor, P. unimacula, P. singulus, and P. hespenheidei), however, I did not see the more slender basal one, and it may be either absent or possibly broken off in the specimens examined. 
The length of the hind basitarsus in relation to the length of the remaining hind tarsal segments combined is sometimes helpful and is indicated for each species. The shape of the hind coxa varies and may be stout or long and slender; lengths and widths are measured from the longest and broadest points. An ovipositor guide is present on the inner surface of the hind coxa. This is usually perpendicular or diagonal and may be of various depths. In Aulacus, the ovipositor guide is usually near the base or center; in Pristaulacus it is usually near the apex. All Aulacus species treated here have a perpendicular to diagonal ovipositor guide, not a longitudinal guide, and all species have the apex of the hind coxa simple, not with an extension, the latter character states being found only in some Holarctic species (apparently confined to the parasitoids of Xiphydriidae).

\section{Metasoma:}

A typical, characteristic shape is shown in Fig. 168. Some may be stouter, others more elongate and slender, with various degrees of intermediates. The length of the ovipositor sheath is significant for species identification, and is measured in relation to the length of the forewing. Almost all are curled and difficult to measure accurately.

\section{Results}

\section{Key to Genera}

1. Tarsal claws simple or with minute inner tooth (one species with one large inner tooth, Fig. 38); occipital carina absent; forewing with vein 2r-m Present (Fig. 4), sometimes faint; pronotum without anteriorly projecting tooth Aulacus

- Tarsal claws comblike, with 3 or 4 teeth (Fig. 82); occipital carina distinct; forewing with vein $2 \mathrm{r}-\mathrm{m}$ absent; pronotum with (as in Figs 51, 175 or without one or more anteriorly projecting teeth

Pristaulacus

\section{Key to Species of Aulalcus}

1. Forewing hyaline with apex and cell 2Cu black (Fig. 4); head and mesosoma orange; head punctured (Figs 1, 2); mesonotum with transverse carinae (Fig. 3) ....... maculosus, n. sp. Forewing hyaline, only apex black and sometimes faint spot under stigma; other characters variable

2. Head and mesoscutum punctate, punctures separated by broad, flat shining interspaces, transverse carinae absent (Figs 5-10, 26-29)

Head with large punctures or smooth and shining, lacking punctures; mesoscutum with transverse carinae

3. Head extremely long behind eyes (Figs 27, 28); head red, mesosoma black; large, about $11.5 \mathrm{~mm}$ long elongatus, n. sp.

Head short and sharply narrowing behind eyes (Fig. 5); entirely yellow orange; small, about $6 \mathrm{~mm}$ long ochreus SMITH 
4. Head and body black, tarsi or band on ovipositor sheath may be white 5

Head, mesosoma, and/or metasoma red, orange, or yellowish .. 6

5. Head with fine microsculpture (Figs 39, 40); mesoscutum with fine transverse carinae (Fig. 41); ovipositor sheath black; small, about $6 \mathrm{~mm}$ long aneureus WALKLEY Head smooth, shining, without sculpture (Figs 18, 19); mesoscutum with coarser, more widely separate transverse carinae (Fig. 21); ovipositor sheath with white band; large, $9.5 \mathrm{~mm}$ or more in length costaricensis, n. sp.

6. Tarsal claws with one long inner tooth near base, slightly longer than outer tooth (Fig. 38); head shining, without sculpture (Figs 34, 35); black, clypeus and malar area orange, metasoma red, legs orange; hind coxa shining, without sculpture (Fig. 36)

whartoni, n. sp.

Tarsal claws simple; head usually with large, separated punctures (Figs 12, 15, 19, 31, 43), or lacking punctures (Fig. 23); head red or orange; hind coxa usually punctate or with transverse carinae fascius, n. sp.

7. Flagellum with white band at center; body entirely orange 7

- $\quad$ Flagellum completely brownish or black; body entirely orange or with considerable black on mesosoma 8

8. Mesosoma orange or with some black mainly on propleuron or propodeum; hind coxa smooth, shining, without sculpture; hind tibia uniform black 9

Mesosoma orange with pleura and sterna black; hind coxa with punctures or some transverse carinae; hind tibia white at base 10

9. Length, $14 \mathrm{~mm}$; propleuron orange, propodeum black; shallow, separated punctures on head (Figs 14, 15) veracruz, n. sp.

Length, $6.0 \mathrm{~mm}$; propleuron black, propodeum orange; head smooth, shining, lacking sculpture (Figs 22, 23) heredia, n. sp.

10. Ovipositor sheath with white band; mesonotum orange; propodeum black; most of pleura black; ovipositor length subequal to forewing length leon, n. sp. Ovipositor sheath black; mesosoma orange with black confined to lower portions of mesoand metapleura; ovipositor length $1.2 \mathrm{X}$ forewing length dispilis Townes

\section{Key to Species of Pristaulacus}

1. Pronotum with acute anterolateral projections (Figs 47, 48, 51, 52, 57, 58, 61, 62) ...

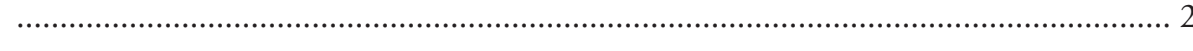

- Pronotum rounded anterolaterally (as in Figs 65, 66, 69, 70) …............................. 5

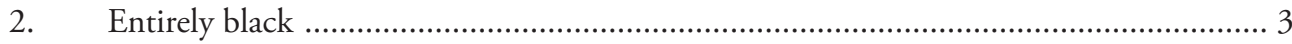

Head or mesosoma partly red, antenna black; ovipositor sheath with white band ......... 4 
3. Ovipositor sheath with white band; pronotum with one anteriorly projecting tooth (Figs 58, 61) argutus, n. sp.

Ovipositor sheath black; pronotum with three anteriorly projecting teeth (Fig. 51)

tria, n. sp.

4. Head red; mesosoma black maculatus (SCHLETTERER) Head black; mesosoma anterior to transscutal articulation red ruficollis (CAMERON)

5. Wings with black and hyaline pattern or uniformly infuscate, without distinct black spots under stigma or at apex of forewing (Figs 71, 76, 82, 91, 97, 110, 119)

- Wings entirely hyaline or hyaline with black spot under stigma and usually at apex of forewing (Figs 165, 174) 18

6. Head and mesosoma with golden pubescence (Figs 63-66); head and mesosoma black with yellow maculae as in Figs 63-66; anterior half of wings darkly infuscate, as in Fig. 91; ovipositor length 1.2X forewing length auricomus, n. sp.

Pubescence white, if present; head and body red or orange and black; infuscate pattern of wings various; ovipositor length subequal to or shorter than forewing length 7

7. Wings banded, black at base, center, and apex with hyaline bands between (Figs 71, 76, 81) 8

Wings entirely darkly infuscate, or infuscate anteriorly or posteriorly, sometimes with various hyaline spots (Figs 85, 91, 97, 110, 119) 10

8. Entirely orange; pronotum without anteriorly projecting tooth (Fig. 69); mesoscutum with transverse carinae (Fig. 70); ovipositor length subequal to forewing length ....virga, n. sp. Orange, with black pattern on head and mesosoma; dorsal margin of pronotum with anteriorly projecting tooth (Figs 78, 83); mesoscutum pitted (Figs 79, 84); ovipositor length shorter than forewing length 9

9. Mesosoma entirely black; coxae black; black on head extends half length of vertex (Fig. 73) punctum, n. sp.

Mesosoma with propleuron, pronotum, and usually propodeum orange (a few specimens have some black on these parts); coxae usually orange; black on head extends just past posterior ocelli (Fig. 78) decorus, n. sp.

10. Wings entirely black 11

Forewing with some hyaline or paler areas contrasting with dark areas (Figs 91, 97, $110,119)$ 12

11. Orange with ocellar area and most of meso- and metapleura black; legs orange, tarsi yellowish; tarsal claws with 6 teeth; hind wing with cells $\mathrm{Cu}$ and $\mathrm{R} 1+\mathrm{Rs}$ separated by short vein $M$ (as in Figs 97, 104) aquilus, n. sp. Black, part of metasoma red to orange; legs black to dark brown, hind tarsus white to reddish; tarsal claws with 3 teeth; hind wing with cells $\mathrm{Cu}$ and $\mathrm{R} 1+\mathrm{Rs}$ contiguous (as in Figs 81, 110) rufitarsis (CRESSON) 
12. Hind coxa with cross striations or punctured (Figs 95, 100, 104); forewing with cells 1M and 1Rs separated by vein Rs+M (Fig. 97); mesonotum punctate (Figs 101, 105) or with transverse carinae (Fig. 90, 96); pronotum without anteriorly projecting tooth .......... 13 Hind coxa smooth, shining; forewing with cells $1 \mathrm{M}$ and $1 \mathrm{Rs}$ contiguous, without vein Rs+M (Figs 110, 119); mesonotum punctate, without transverse carinae (Figs 109, 114, $118)$; pronotum with or without anteriorly projecting tooth .................................. 16

13. Mesonotum punctate (Fig. 101); forewing with three more or less pale spots; femora and coxae black; hind wing with cells $\mathrm{Cu}$ and $\mathrm{R} 1+\mathrm{Rs}$ contiguous (as in Figs 81, 110) triclora, n. sp.

Mesonotum with transverse carinae, without punctures (Fig. 96); forewing infuscate on anterior half, paler to hyaline on posterior half (Figs 91, 97); femora and/or coxae partly orange; hind wing with cells $\mathrm{Cu}$ and $\mathrm{R} 1+\mathrm{Rs}$ separated by short vein $\mathrm{M}$ (as in Figs 97, 104) 14

14. Frons smooth, shining (Fig. 102) nigricoxae, n. sp. Frons somewhat punctate, dull (Figs 87, 93) 15

15. Frons with distinct closely set punctures, shining (Fig. 93); mesosoma black with propodeum and mesoscutum orange; coxae black anteala, n. sp. Frons finely reticulate, dull (Fig. 87); mesosoma orange to red brown; coxae orange torridus (BRADLEY)

16. Forewing with posterior half dark, anterior portion clearer to hyaline; pronotum with blunt anteriorly projecting tooth; orange with hind femur black postala, n. sp. Forewing darkened with central paler to hyaline spot basal to stigma (Figs 111, 119); pronotum with or without tooth; color various

17. Anterior margin of pronotum without projecting tooth (Fig. 108); hind femur black ..... unimacula, n. sp.

Anterior margin of pronotum with one projecting tooth (Fig. 117); hind femur orange stangei, n. sp.

18. Forewing hyaline, without spots (mesosoma black)

Forewing with black spot under stigma and at apex, or only at apex

19. Pronotum yellow; legs yellow; pronotum with anteriorly projecting tooth (Fig. 122); forewing with cells1M and 1Rs contiguous, without vein Rs+M (as in Fig. 119); hind wing with veins distinct, cells $\mathrm{Cu}$ and $\mathrm{R} 1+\mathrm{Rs}$ separated by short vein $\mathrm{M}$ (as in Figs 97, 104) tenuis, n. sp.

Mesosoma black; coxae black; pronotum without anteriorly projecting tooth (Fig. 126); forewing with cells $1 \mathrm{M}$ and $1 \mathrm{Rs}$ separated by a short Rs+M vein (as in Fig. 157); hind wing with veins faint to absent (as in Fig. 157) decolorus, n. sp.

20. Forewing with black spot at apex only 21

Forewing with black spot under stigma and at apex

21. Entirely black except for white spot at base of metasoma and band on ovipositor sheath; ovipositor length 1.7X forewing length annulatus KIEFFER 
Entirely orange or head and mesosoma orange; ovipositor length subequal to forewing length (female of $P$. singulus unknown)

22. Body, including metasoma black; anterior margin of pronotum without anteriorly projecting tooth; pronotum largely smooth and shining at center (Fig. 130) ...... singulus, n. sp. Metasoma orange like rest of body; anterior margin of pronotum with anteriorly projecting tooth; pronotum sculptured, dull (Fig. 134) candidus, n. sp.

23. Entirely orange, or head and mesosoma orange, metasoma may be blackish at apex or on venter 24

Head and mesosoma black, metasoma may be partly red to orange 28

24. Pronotum without anteriorly projecting tooth; mesoscutal middle lobe with transverse carinae or reticulate (Figs 169, 178); hind wing with veins distinct, cells $\mathrm{Cu}$ and $\mathrm{R} 1+\mathrm{Rs}$ separated by short vein M (as in Figs 97, 104)

- $\quad$ Pronotum with one anteriorly projecting tooth; mesoscutal middle lobe with transverse carinae (Fig. 167); hind wing with veins fain to absent (as in Fig. 157) 26

25. Head smooth, shining, almost impunctate (Figs 158, 159); propleuron shining; hind coxa smooth and shining . parkeri, n. sp. Head with vertex and frons with large punctures (Figs 169, 170); propleuron punctate; hind coxa dull with transverse carinae totoferrugineus, n. sp.

26. Mesosoma orange anterior to transscutal articulation, black posterior to transscutal articulation mexiuni, n. sp. Mesosoma orange, sometimes partly black on propleuron, sterna, and propodeum .... 27

27. Coxae and hind femur black tamaulipas, n. sp. Coxae and hind femur orange hespenheidei, n. sp.

28. Head shining, from above long behind eyes (Figs 153, 154); occipital carina small, less than a fifth diameter of an ocellus; black with contrasting bright orange legs

ruficruris, n. sp.

Head shining or dull, with large or small punctures, from above short behind eyes (Figs 136, $137,140,141,144,145)$; occipital carina small or large and flangelike, more than half diameter of an ocellus; legs partly black

29. Mesoscutal middle lobe reticulate (Fig. 143); forewing with cells $1 \mathrm{M}$ and 1 Rs contiguous, without vein Rs+M (as in Fig. 119) townesi, n. sp. Mesoscutal middle lobe with transverse carinae (Figs 139, 147); forewing with cells $1 \mathrm{M}$ and 1 Rs separated by vein Rs+M (as in Fig. 157) 30

30. Vertex and frons with large, widely spaced punctures, separated by distance of more $2 \mathrm{X}$ or more puncture diameters (Figs 136, 137); mesoscutal lateral lobes mostly reticulate (Fig. 138) omnimoniger, n. sp.

Vertex with fine punctures; frons with closely set punctures, separated by ridges equal to or less than puncture diameters (Fig. 144); mesoscutal lateral lobes with some transverse carinae (Fig. 147) arizonicus (Townes) 


\section{Aulacus maculosus Sмiтн, new species}

(Figs 1-4)

\section{Diagnosis:}

Head and mesosoma orange; legs black with tarsi white; forewing with apex and cell 2Cu black; head shining with large punctures; mesoscutum with strong transverse carinae; hind coxa smooth, shining.

\section{Female:}

Length, $9.5 \mathrm{~mm}$; forewing length, $9.0 \mathrm{~mm}$; ovipositor length $9.5 \mathrm{~mm}$. Color: Head orange; mesosoma orange with spot on mesosternum, metapleuron, and propodeum black, mesopleuron darkened; legs black with tarsi white. Ovipositor sheath with white band near apex. Wings hyaline with apex and cell $2 \mathrm{Cu}$ of forewing black (Fig. 4), veins and stigma black. Head: Antennal length 2.4X head width. Inner margins of eyes subparallel, upper and lower interocular distances subequal; lower interocular distance slightly less, $0.9 \mathrm{X}$, eye height (Fig. 1). Malar space $0.2 \mathrm{X}$ eye height. From above, narrowing behind eyes; distance behind eyes about 0.6X eye length (Fig. 2). Shining, punctures far apart on vertex and frons, separated by flat, shining interspaces greater

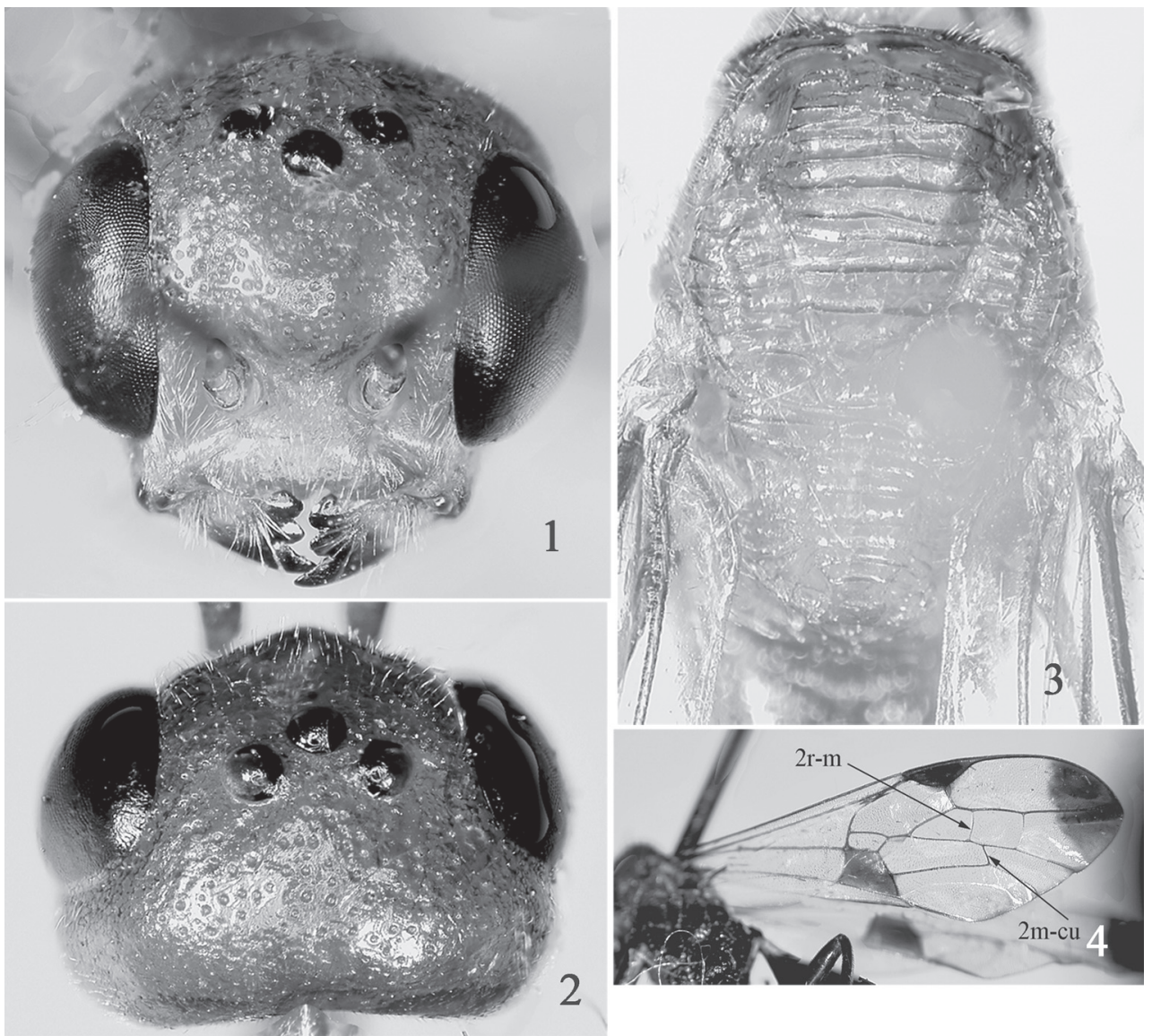

Figs 1-4: Aulacus maculosus. 1 Head, front. 2 Head, dorsal. 3 Mesosoma, dorsal. 4 Forewing. 
than puncture diameters. Gena without punctures except for indistinct row adjacent to outer orbits. Mesosoma: Propleuron smooth and shiny, with few fine punctures. Mesoscutum with coarse transverse carinae, about 10-12 on mesoscutal middle lobe; notauli meeting separately on transscutal articulation (Fig. 3); axillae smooth; mesoscutellum with coarse transverse carinae; axillula with fine diagonal carinae (Fig. 3). Pronotum with diagonal scrobiculate band, anteroventrally shining, posterodorsally shining with few large punctures in dorsoposterior corner; mesopleuron mostly scrobiculate dorsoposteriorly, with some large punctures anteroventrally; metapleuron mostly with large closely set punctures; propodeum with large, closely set punctures; sharp carina circles dorsal and lateral margins of metasomal insertion. Forewing with $\mathrm{Rs}+\mathrm{M}$ between cells $1 \mathrm{M}$ and 1 Rs long. Hind basitarsus about $1.2 \mathrm{X}$ length of remaining tarsal segments combined. Hind coxa smooth, shining, about 2.0X longer than broad, with diagonal ovipositor guide at center. Metasoma: Smooth, shining, with fine white pubescence from posterior third of segment 3 to apex, pubescence on segments 5 to apex densest. Ovipositor 1.2X forewing length.

Male: Length, $11.0 \mathrm{~mm}$; forewing length, $10.0 \mathrm{~mm}$. Color and structure similar to female.

Types:

Holotype: female, labeled "Est. Las Pailas, P.N. Rincon de la Vieja, Prov. Guana, Costa Rica, 800 m, 17-23 Jul 1993, K. Taylor, LN 306300_388600 \#2238” and bar code label "Costa Rica INBIO CRI001 133241.” (INBio) (“Guana” = Guanacaste). Paratypes: COSTA RICA: Est. Pitilla, 700 m, 9 km S Sta. Cecilia, P.N. Guanacaste, Prov. Guan., 18 abr a 9 may 1993, C. Moraga, L-N-330200, 380200 and bar code label "Costa Rica INBIO CRI001 357439 (1 o", INBio); Guan., 3 km SE R. Naranjo, 1-15 May 1992, F. D. Parker (1 ㅇ, USU); same data except 24-31 Mar 1992 (1 ơ, USU).

Etymology: From the Latin, maculosus, meaning spotted, referring to the black forewing cell $2 \mathrm{Cu}$.

\section{Remarks:}

The female and male are identical in color and structure except that the males are slightly larger than the females. The distinctive wing maculation is unique to this species.

\section{Aulacus ochreus SMITH}

(Figs 5-10)

Aulacus ochreus Sмітн 2005: 224, Figs 13-18.

\section{Diagnosis:}

Yellow orange with brownish marks; forewing with apex black; head shining with large, separated punctures, strongly narrowing behind eyes; mesonotum shining with large separated punctures, without carinae; hind coxa smooth and shining.

\section{Female:}

Length, $6.0 \mathrm{~mm}$; forewing length, $4.0 \mathrm{~mm}$; ovipositor length, $9.0 \mathrm{~mm}$. Color: Entirely yellowish with darker more brownish areas on antenna, apical halves of metasomal segments, tibiae, and dorsum of mesosoma. Wings hyaline with apex of forewing black (Fig. 8); veins and stigma black. Head: Antennal length nearly 3.0X head width. Eyes in front view slightly converging below, lower intraocular distance subequal to eye height; malar space $0.2 \mathrm{X}$ eye height (Fig. 5). 

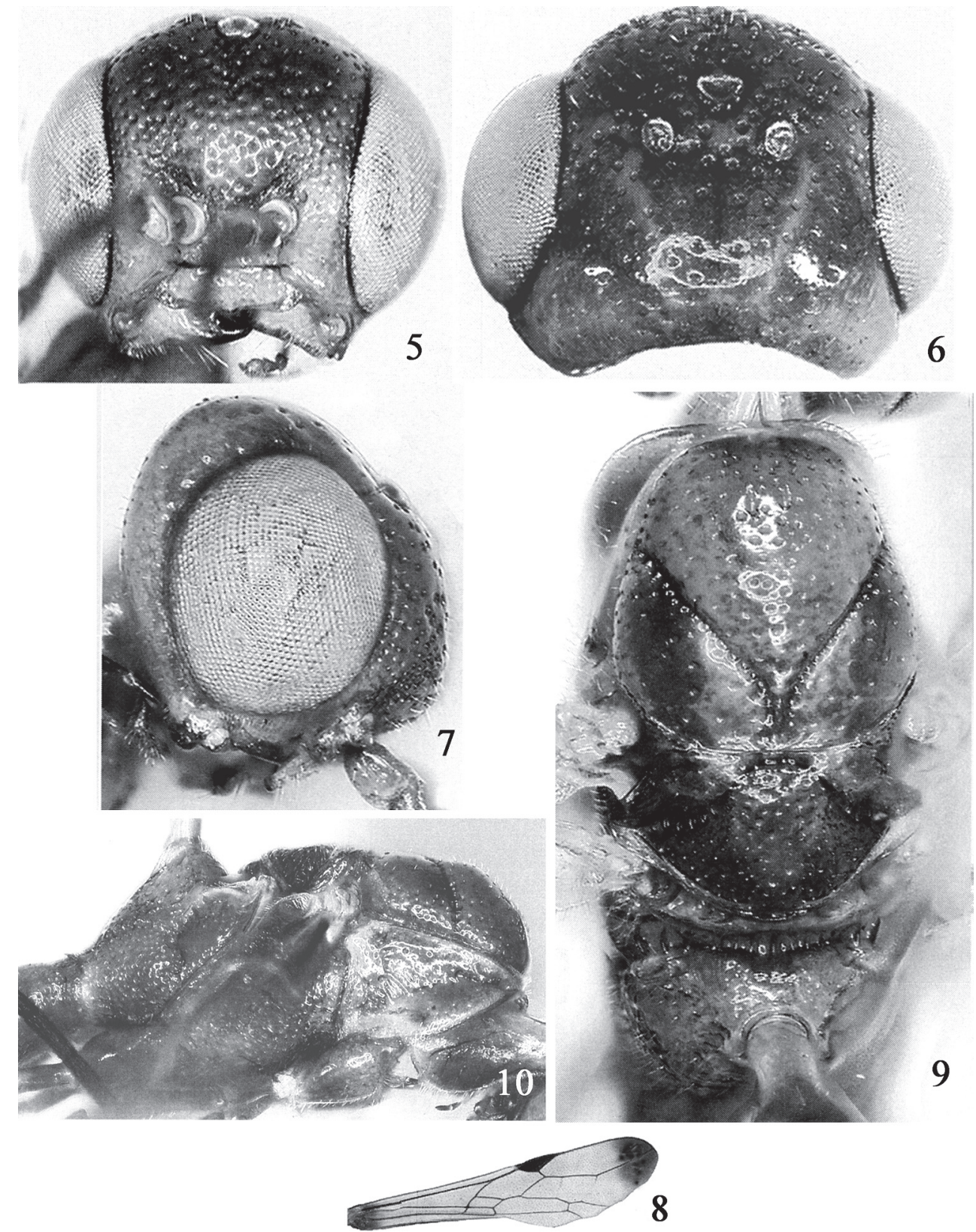

Figs 5-10: Aulacus ochreus. 5 Head, dorsal. 6 Head, front. 7 Head, lateral. 8 Forewing. 9 Mesosoma, dorsal. 10 Mesosoma, lateral.

Eyes large, close to posterior margin of head in lateral view (Fig. 7). Head in dorsal view, short and strongly narrowing behind eyes; length behind eyes about $0.3 \mathrm{X}$ eye length (Fig. 6). Shining, punctate, almost glabrous with short setae arising from punctures; vertex and gena with widely scattered punctures, separated by flat shining interspaces several times diameter of a puncture; 
punctures denser on lower half of frons, separated by ridges or flat, shining interspaces mostly less than diameter of a puncture (Figs 5-7). Mesosoma: Shining, smooth, glabrous, mostly punctate with short setae arising from punctures. Propleuron shining, small punctures posteriorly. Mesoscutum rounded anteriorly, with punctures separated by flat, shining interspaces equal to or about $2 \mathrm{X}$ puncture diameter on mesoscutal middle lobe, less dense and separated by several times puncture diameter on lateral lobes, dense and separated by about diameter of a puncture on mesoscutellum; axilla almost impunctate; notauli distinct and meeting posteriorly before reaching transscutal articulation (Fig. 9). Pronotum with lower half almost impunctate, upper half with scattered punctures and strigate at center; mesepisternum, metapleuron, and propodeum evenly closely punctate with punctures separated by shining interspaces (Fig. 10). Hind coxa shining, without sculpture; short, about as long as broad, with indistinct ovipositor guide near apex. Hind basitarsus 1.3X longer than remaining tarsal segments combined. Forewing with veins $2 \mathrm{r}-\mathrm{m}$ and 3r-m faint. Metasoma: Shining, impunctate; pubescence sparse on segments 6 to apex. Ovipositor about 2.2X length of forewing.

Male: Unknown.

Holotype: Female, labeled “Colombia, Magdalena PNN Tayroma Giaraca, 1120 'N, 72 2'W, 5 m, Malaise, 2/22/01 - 3/5/01, R. Henriquez, leg, M.1350” (HUM).

Specimens examined: Two female paratypes in addition to holotype. COLOMBIA: Magdalena PNN Tayroma Neguanje, 11 20"N, 72 2'W, 10 m, Malaise, 3/21/91 - 4/5/91, R. Henriquez, leg, M. 1482 (HUM). COSTA RICA: S. Rosa Park, Guan., 12 May 78, D. H. Janzen, Dry Hill (AEI).

\section{Remarks:}

This species and $A$. elongatus are the only Aulacus species with large punctures on the head and mesosoma; there is no reticulate or carinate sculpture. The two may be separated in the preceding key.

\section{Aulacus fascius SMITH, new species}

(Figs 11-13)

\section{Diagnosis:}

Orange; antenna and ovipositor sheath each black with white central band; legs brown, tarsi white; forewing black at apex; head shining with shallow separated punctures; mesoscutum with prominent transverse carinae; hind coxa with some punctures and fine cross striations.

\section{Female:}

Length, $8.2 \mathrm{~mm}$; forewing length $7.0 \mathrm{~mm}$; ovipositor length $6.8 \mathrm{~mm}$. Color: Entirely orange. Antenna and ovipositor sheath both with white band. Forewing hyaline with apical black spot, veins and stigma black. Head: Antennal length 2.6X head width. Inner margins of eyes subparallel, lower interocular distance equal eye height (Fig. 11); malar space 0.3X eye height. In dorsal view, head narrowing behind eyes, about $0.6 \mathrm{X}$ eye length (Fig. 12). Shining, with fine white pubescence; gena and vertex punctate, punctures separated by flat shining interspaces about 2X puncture diameters (Fig. 12); frons with similar punctures, but punctures smaller (Fig. 11). Mesosoma: Propleuron smooth, shining, impunctate, few small punctures on venter. Mesoscutal middle lobe with widely spaced transverse carinae; mesoscutal lateral lobes, axillae, and lateral 
portions of mesoscutellum reticulate; center of mesoscutellum with transversely directed sculpture (Fig. 13); notauli meeting transscutal articulation separately (Fig. 13). Pronotum shining, anteroventral third smooth, posterodorsal two-thirds reticulate; mesopleuron with upper third of mesepisternum and mesepimeron smooth, shining, lower two-thirds mesepisternum reticulate, mesosternum reticulate, lower two-thirds mesepimeron finely reticulate; metapleuron upper half smooth, shining, lower half reticulate; propodeum reticulate. Hind coxa shining, with punctures, $2 \mathrm{X}$ longer than broad. Hind basitarsus subequal to remaining tarsal segments combined. Metasoma: Smooth, shining, segments 4 to apex with white pubescence. Ovipositor length 1.1X forewing length.

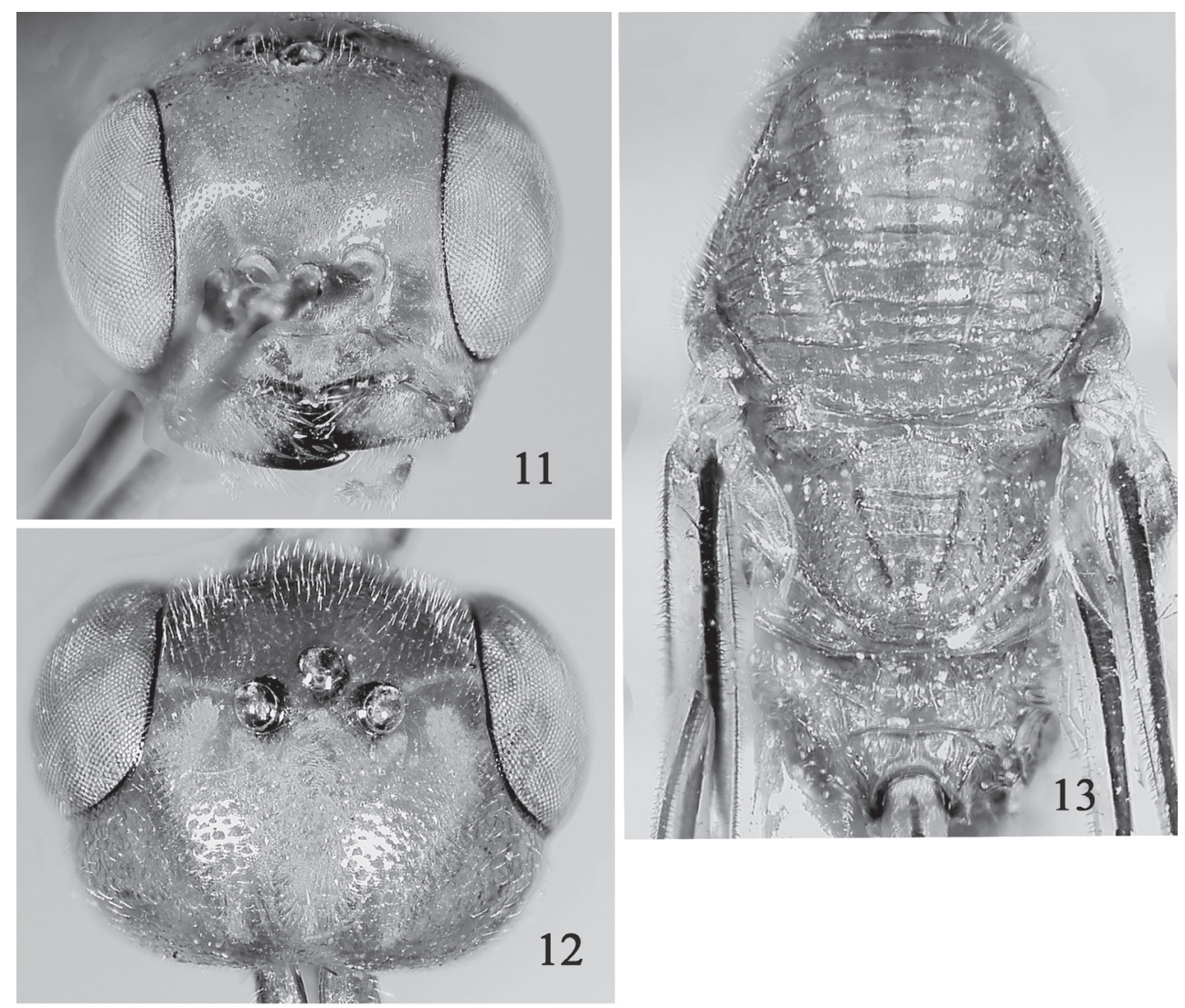

Figs 11-13. Aulacus fascius. 11 Head, front. 12 Head, dorsal. 13 Mesosoma, dorsal.

Male: Unknown.

Holotype: Female, labeled “Mexico: Veracruz, Est. Biol. de Los Tuxtlas, $18^{\circ} 35^{\prime} \mathrm{N}, 95^{\circ} 05^{\prime} \mathrm{W}$, 2-V-1991, H. A. Hespenheide (USNM).

Etymology: From the Latin fascia, meaning banded, referring the white-banded antenna.

\section{Remarks:}

This is the only known species of Aulacus in this region to have both the antenna and ovipositor sheath with a central white band. 
Beitr. Ent. 58 (2008) 2

\section{Aulacus veracruz SMITH, new species}

(Figs 14-17)

\section{Diagnosis:}

Orange with propodeum and antenna black; forewing apex black; head shining with shallow punctures; mesonotum finely punctate with transverse carinae.
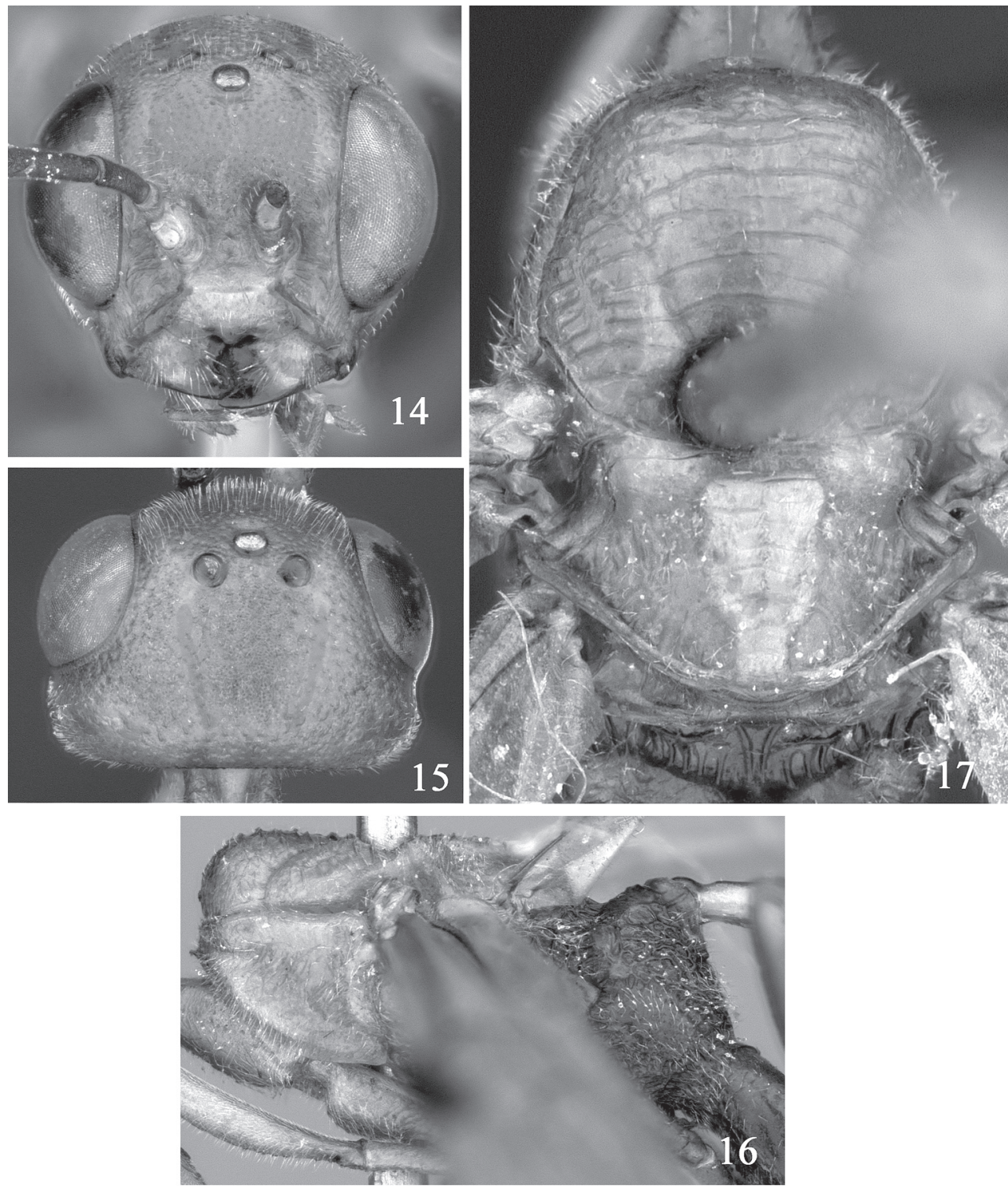

Figs 14-17: Aulacus veracruz. 14 Head, front. 15 Head, dorsal. 16 Mesosoma, lateral. 17 Mesosoma, dorsal. 


\section{Female:}

Length, $14.0 \mathrm{~mm}$; forewing length, $10.2 \mathrm{~mm}$; ovipositor length $14.0 \mathrm{~mm}$. Color: Orange with antennal flagellum brownish and mesosternum and propodeum black; metasoma with first segment except base and segments 4 to apex brownish. Mid- and hind coxae and hind legs brownish, hind tarsus white. Ovipositor sheath missing, black at base. Wings hyaline, veins and stigma black; forewing with black spot at apex. Head: Antennal length (12 segments present) 2.5X head width. Inner margins of eyes subparallel, lower interocular distance subequal to eye height; malar space $0.3 \mathrm{X}$ eye height (Fig. 14). Head from above straight behind eyes for short distance, then narrowing, distance behind eyes $0.7 \mathrm{X}$ eye length (Fig. 15). Vertex and frons with widely scattered punctures, separated by flat shining interspaces two or more times puncture diameters; punctures less dense on gena (Figs 14, 15). Mesosoma: Propleuron shining, without sculpture. Mesoscutum with transverse carinae; notauli meeting posteriorly at about the transscutal articulation (Fig. 15); axilla smooth; mesoscutellum with transverse carinae at center, more reticulate at side; pronotum smooth, shining with diagonal band of carinae; mesopleuron with mesepisternum finely punctate on upper third, coarsely reticulate on lower two-thirds, mesepimeron smooth and shining anteriorly, with carinae posteriorly, mesosternum reticulate; metapleuron with large smooth, shining spot on upper third, reticulate on lower two-thirds; propodeum shining, few transverse carinae dorsally, reticulate laterally and on venter (Figs 16, 17). Hind coxa smooth and shining, 2X longer than broad. Hind basitarsus 1.1X longer than length of remaining tarsal segments combined. Metasoma: Smooth, shining, with fine white pubescence on segments 4 to apex. Ovipositor length 1.4X forewing length.

Male: Unknown.

Holotype: Female, labeled "Mexico: Veracruz, 10 June 1965, G. N. Ross," "G. N. Ross Colln., MGCL Accession \#2006-20” (FSCA).

Etymology: Based on the State of Veracruz, Mexico; a noun in apposition.

\section{Remarks:}

The large size $(14 \mathrm{~mm})$, orange coloration and smooth, unsculptured hind coxae should distinguish this species. The size is rather large for an Aulacus species.

\section{Aulacus costaricensis $\mathrm{SMITH}$, new species}

(Figs 18-21)

\section{Diagnosis:}

Entirely black, only tarsi mostly whitish; forewing apex black. Head shining, no discernable punctures; mesoscutum shining, with coarse transverse carinae which are stronger posteriorly, but few punctures. Hind coxa smooth, shining.

\section{Female:}

Length, $11.0 \mathrm{~mm}$; forewing length, $9.0 \mathrm{~mm}$; ovipositor length $13.0 \mathrm{~mm}$. Color: Black. Tarsi mostly whitish. Wings hyaline, veins and stigma black; apex of forewing black. Ovipositor sheath with white band. Head: Antennal length 3.3X head width. Lower interocular distance subequal to eye height; malar space $0.3 \mathrm{X}$ eye height (Fig. 18). In dorsal view, narrowing behind eyes, about 0.6X eye length (Fig. 19). Head smooth and shining with fine white pubescence, pubescence densest in lower inner orbits and malar area; gena and vertex practically impunctate; 


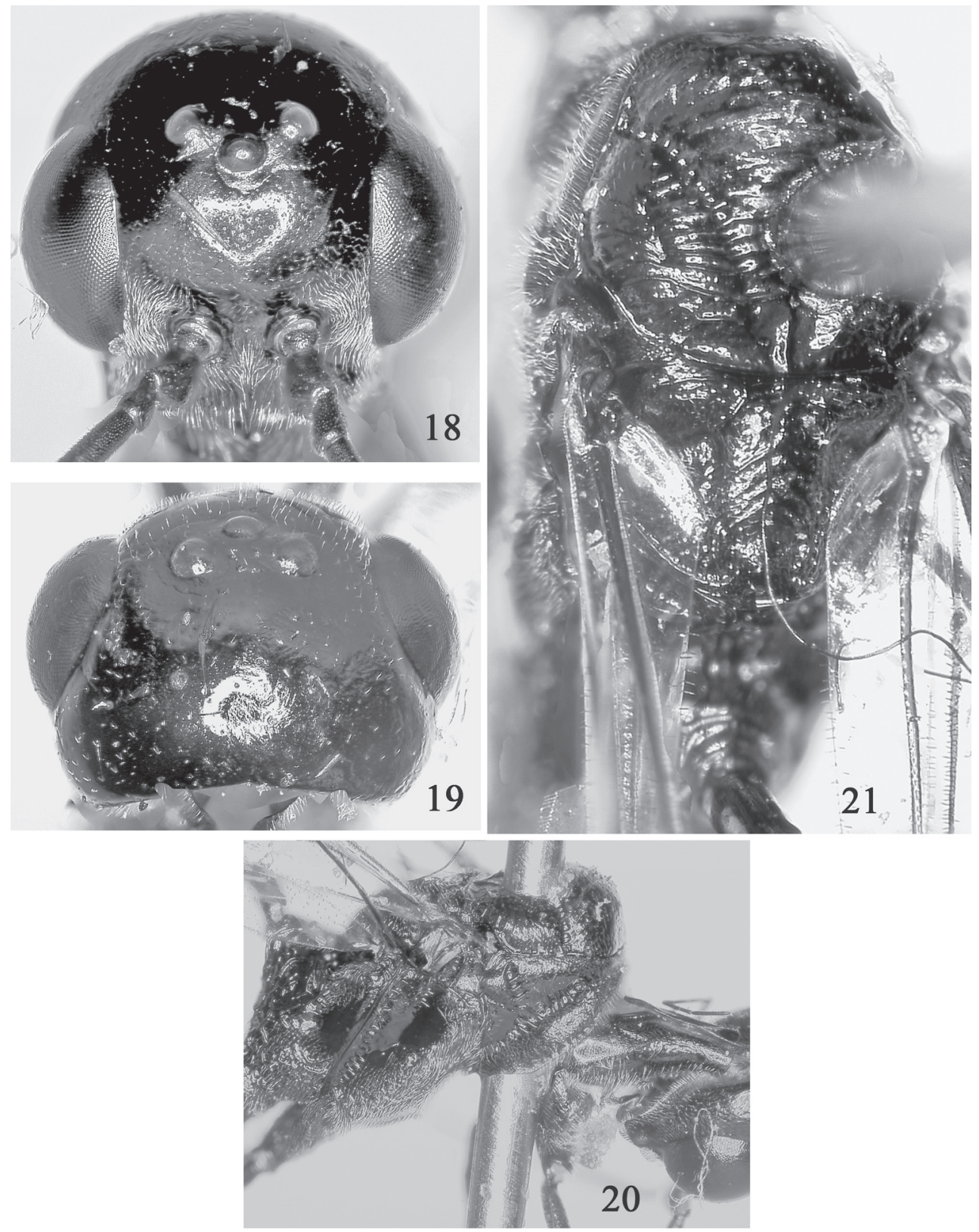

Figs 18-21: Aulacus costaricensis. $18 \mathrm{Head}$, front. 19 Head, dorsal. 20 Mesosoma, lateral. 21 Mesosoma, dorsal.

frons punctate, punctures almost contiguous (Figs 18, 19). Mesosoma: Propleuron smooth, shining, almost impunctate. Mesoscutal middle lobe with few punctures and transverse carinae; mesoscutal lateral lobes shining, inner margins with transverse carinae; notauli meeting posteriorly anterior to transscutal articulation (Fig. 21); axillae punctate; mesoscutellum punctate with few transverse carinae at center; pronotum finely punctate with anterior margin, 
diagonal line, and line perpendicular to diagonal line reticulate; mesopleuron, metapleuron, and propodeum mostly reticulate with posterior margin of mesopleuron narrowly scrobiculate (Figs 20,21). Hind coxa smooth and shining, 2.1X longer than broad; diagonal ovipositor groove at center on inner surface. Hind basitarsus 1.1X length of remaining tarsal segments combined. Metasoma: Smooth, shining, with fine white pubescence on segments 6 to apex. Ovipositor length $1.4 \mathrm{X}$ forewing length.

Male: Length, $12.5 \mathrm{~mm}$; forewing length, $10.5 \mathrm{~mm}$. Color and structure similar to female.

Types: Holotype: Female, labeled "Fca. Cafrosa, 1300 m, Est. Las Mellizas, P. Intgernac. La Amistad, Prov. Punt., Costa Rica, M. Ramirez, Jun 1991, L-S-316100, 596100" and "Costa Rica INBIO CRI000 604300” (INBio) (Fca." = Finca). Paratype: COSTA RICA: Puntarenas: Monteverde, 18-24 July 1990, coll. G. C. Snelling (1 o*, LACM).

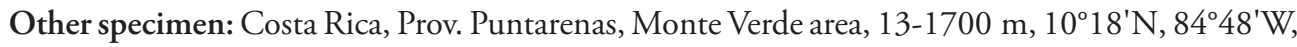
4-9.vi-1983, F. T. Hovore (1 , CHAH).

Etymology: Named for Costa Rica, the country of collection.

\section{Remarks:}

The holotype and paratype have most of the hind tarsus white. The other specimen has the hind tarsus black, and I prefer not to include it in the type series although all other features are identical to the types.

\section{Aulacus beredia SMITH, new species}

(Figs 22-25)

\section{Diagnosis:}

Head and mesosoma orange, propleuron black; head shining without sculpture; tarsi white.

Female: Unknown.

\section{Male:}

Length, $6.0 \mathrm{~mm}$; forewing length $5.0 \mathrm{~mm}$. Color: Head and mesosoma orange with blackish spot behind ocelli; propleuron, coxae, hind legs except white hind tarsus; and metasomal tergites blackish. Forewing hyaline with apical margin black; stigma and veins dark orange to brown. Head: Antennal length 3.3X head width. Lower interocular distance subequal to eye height; malar space about $0.3 \mathrm{X}$ eye height (Fig. 22). From above head long and gradually narrowing behind eyes, head behind eyes subequal to eye length (Fig. 23). Vertex and frons shining, without sculpture (Figs 22, 23). Mesosoma: Propleuron smooth, shining. Mesoscutum reticulate with wavy transversely directed sculpture; notauli meeting separately on transscutal articulation (Fig. 25); axilla and mesoscutellum reticulate. Pronotum smooth shining except several arced carinae at center; mesopleuron with mesepisternum smooth and shining above, very coarse reticulations at center, mesosternum finely reticulate, mesepimeron with widely spaced cross carinae; metapleuron smooth and shining above, below with large, coarse reticulations; propodeum coarsely reticulate (Figs 24, 25). Hind coxa smooth and shining, 2.1X longer than broad. Hind basitarsus 1.1X length of remaining tarsal segments combined. Metasoma: Smooth, shining, without pubescence. 


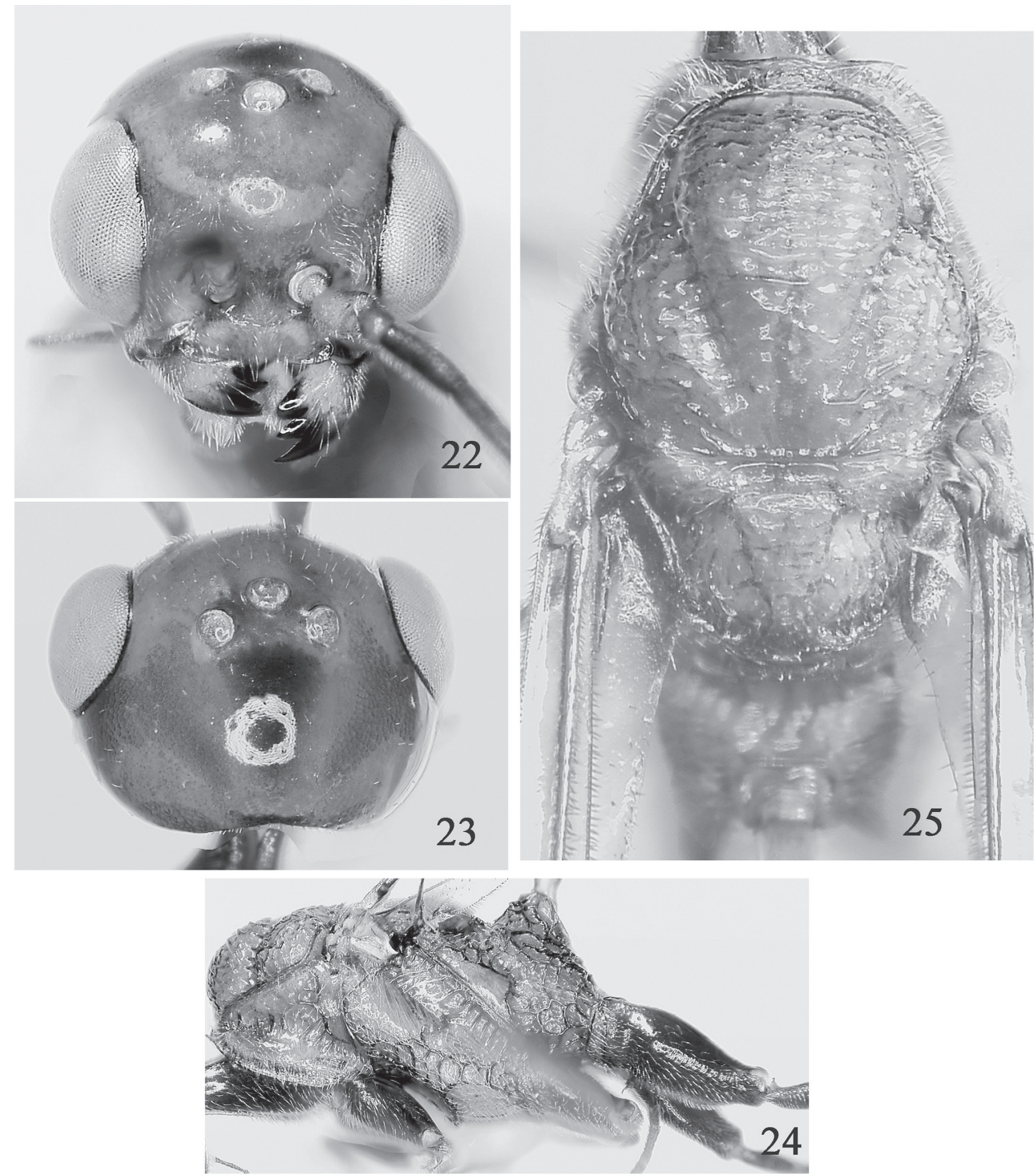

Figs 22-25: Aulacus heredia. 22 Head, front. 23 Head, dorsal. 24 Mesosoma, lateral. 25 Mesosoma, dorsal.

Holotype: Male, “Costa Rica, Prov. Heredia, 11 km ESE La Lirgen, 1021 'N, 84 03'W, 250-350 m, 3/M/16/096, 18.iv.2004, INBio-OET-transect” (USNM).

Etymology: Named for Heredia, the province in Costa Rica where this species was collected; a noun in apposition.

\section{Remarks:}

This is a small, orange, smooth and shining species and is therefore not likely to be the male of one of the described females in this family. 


\section{Aulacus elongatus SMITH, new species}

(Figs 26-29)

\section{Diagnosis:}

Head red; mesosoma black; forewing apex black. Hind strongly shining, extremely lengthened behind eyes. Mesosoma shining with only large, widely separated punctures; hind coxa smooth, shining.

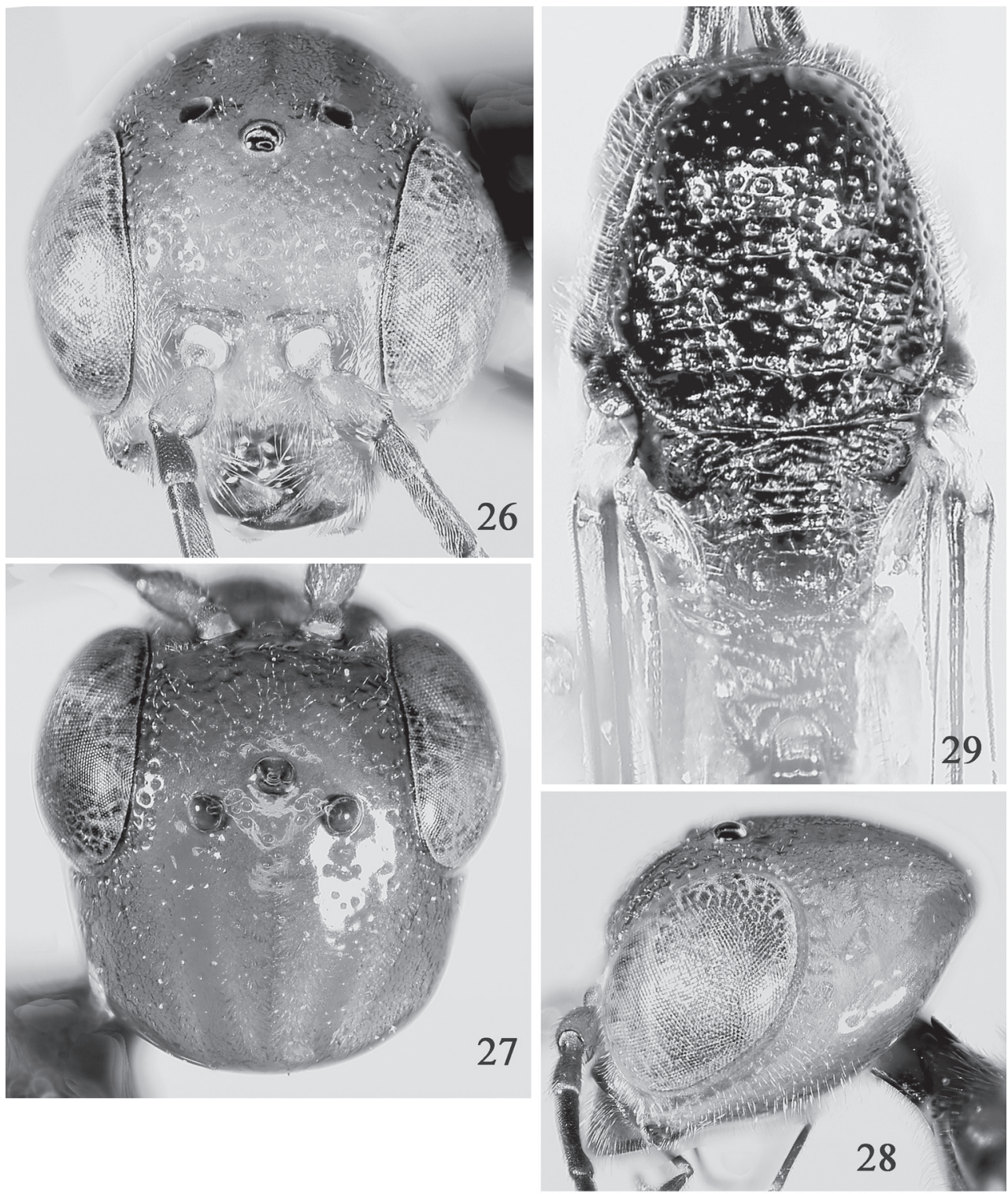

Figs 26-29: Aulacus elongatus. 26 Head, front. 27 Head, dorsal. 28 Head, lateral. 29 Mesosoma, dorsal. 


\section{Female:}

Length, holotype $11.5 \mathrm{~mm}$, paratype $7.5 \mathrm{~mm}$; forewing length, holotype $8.5 \mathrm{~mm}$, paratype $5.5 \mathrm{~mm}$; ovipositor length holotype $9.0 \mathrm{~mm}$, paratype $6.0 \mathrm{~mm}$. Color: Antenna black, scape orange. Head orange, apex of mandible black. Mesosoma black. Legs with coxae and trochanters black; fore- and mid femora with basal half blackish, apical half orange, hind femur black; foreand midtibiae orange brown, hind tibia with basal fifth white, apical four-fifths black; tarsi whitish. Metasoma black, first segment dark brown on sides. Ovipositor sheath black with white band. Wings hyaline, veins and stigma black; forewing with black spot at apex. Head: Antennal length 2.5X head width. Lower interocular distance $0.8 \mathrm{X}$ eye height, inner margins of eyes slightly converging below; malar space $0.2 \mathrm{X}$ eye height (Fig. 26). From above, straight and long behind eyes, length of head behind eyes in dorsal view almost subequal to slightly longer than eye length (Fig. 27); in lateral view, eye far removed from posterior margin of head (Fig. 28). Vertex and gena shining, with large, widely scattered punctures, interspaces several times diameter of punctures; frons shining with punctures denser than on vertex, separated by interspaces about or slightly more than puncture diameters (Figs 26-28). Mesosoma: Propleuron smooth, shining, impunctate. Mesoscutum and axilla shining with large punctures separated by shining interspaces more than puncture diameters; notauli indistinct, but meeting separately on transscutal articulation (Fig. 29); mesoscutellum with 5 or 6 transverse carinae, with small punctures between carinae (Fig. 29); pronotum shiny, smooth with few punctures, with narrow scrobiculate diagonal band; mesopleuron with upper anterior corner of mesepisternum shining, fine punctures on most of rest of mesepisternum except lower mesepisternum coarsely reticulate, mesepimeron smooth, shining, with narrow scrobiculate band on posterior margin; metapleuron shining, smooth on upper half, finely reticulate on lower half; propodeum reticulate. Mesepisternum more densely pubescent than rest of pleura. Hind coxa smooth and shining, about 2.0X longer than broad. Hind basitarsus 1.2X length of remaining tarsal segments combined. Metasoma: Segments 5 or 6 to apex with fine white pubescence. Ovipositor sheath about 1.1X forewing length.

Male: Unknown.

Types: Holotype: Female labeled "Panama: Canal Zone, Barro Colorado Is., 9 10'N, 79 50'W," "30-V-1977, H. A. Hespenheide," "Sloanea TF, SM4-5." (LACM). Paratype: COSTA RICA: S. Rosa Park, Guan., 13 Jun 77, D. H. Janzen, Dry Hill (1 + , AEI).

Etymology: The name refers to the unusually long head of this species.

\section{Remarks:}

Aulacus elongatus and $A$. ochreus are the only known two species with large punctures on both the head and mesosoma. In $A$. elongatus, the head is unusually long behind the eyes (Figs 27, 28), whereas in $A$. ochreus, the head is very short behind the eyes (Figs 5, 7). Also A. elongatus is a red and black species in contrast to the entirely orange $A$. ochreus.

\section{Aulacus leon SMITH, new species}

(Figs 30-33)

\section{Diagnosis:}

Black, dorsum of mesosoma orange; apex of forewing black. Head shining with scattered fine punctures. Mesoscutum with coarse transverse carinae. Hind coxa short, with cross striations laterally. 

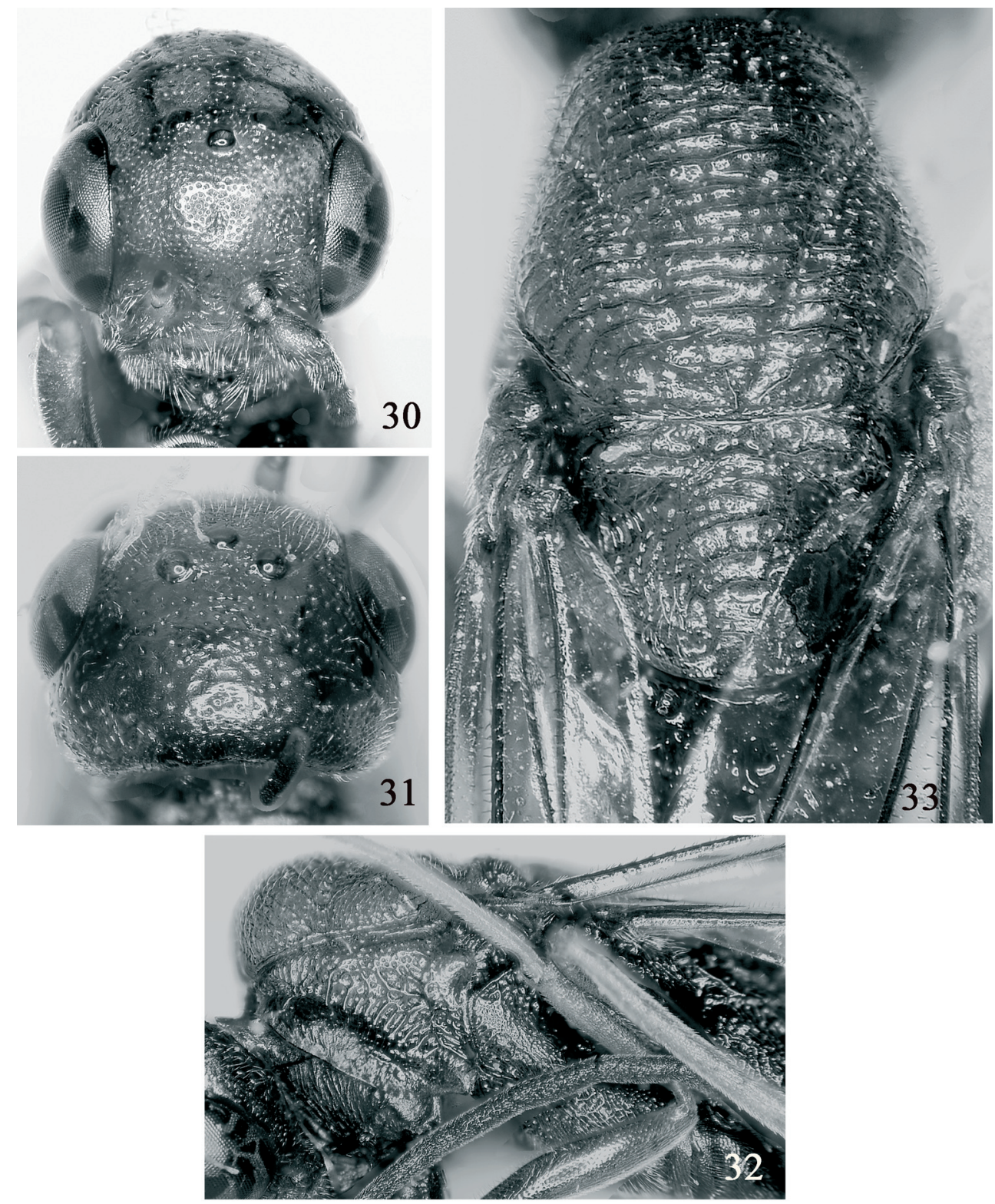

Figs 30-33: Aulacus leon. 30 Head, front. 31 Head, dorsal. 32 Mesosoma, lateral. 33 Mesosoma dorsal.

\section{Female:}

Length, $6.5 \mathrm{~mm}$; forewing length $5.5 \mathrm{~mm}$; ovipositor length, $5.5 \mathrm{~mm}$. Color: Antenna black with scape and pedicel orange. Head and mesonotum orange, rest of mesosoma black; fore- and midleg coxae, trochanters, and femora black, tibiae and tarsi white; hind leg black with basal quarter of tibia and all tarsus white. Metasoma black with white band on second segment. Ovipositor sheath with white band. Wings hyaline, veins and stigma black; forewing with faint black spot under stigma and spot at apex black. Head: Antennal length 2.5X head width. Lower interocular 
distance subequal to eye height; malar space $0.25 \mathrm{X}$ eye height (Fig. 30). From above, head straight behind eyes then roundly narrowing, head behind eyes about $0.7 \mathrm{X}$ eye length (Fig. 31). Shining with fine white pubescence; gena and vertex with large punctures, interspaces mostly 2 or more times puncture diameters; frons evenly punctate with flat shining interspaces mostly about equal to puncture diameters (Figs 30, 31). Mesosoma: Propleuron shining, punctate. Mesonotum with rather evenly reticulate sculpture, that on mesoscutum somewhat transverse; notauli meet posteriorly at point of transscutal articulation (Fig. 33). Pronotum coarsely reticulate posteriorly, anteriorly reticulations finer; mesopleuron, metapleuron, and propodeum reticulate, with area of fine punctures on upper central part of mesopleuron (Figs 32, 33). Hind basitarsus 1.2X longer than length of remaining tarsal segments combined. Hind coxa shining above, finely punctate to striate and duller laterally, about 2.0X longer than broad. Metasoma: Segments 2 or 3 to apex with fine white pubescence and fine punctures. Ovipositor length subequal to forewing length.

Male: Unknown.

Types: Holotype: Female, labeled “Chipinque Mesa, 5400', nr. Monterrey, N.L., Mex., VII.8. 1963, H. \& A. Howden” (CNC). Paratype: Mexico: Tamaulipas, Gomez Farias: 900 m, Alta Cima, T. Malaise, 15-22.V.1999, Col. Sonia Hernandez A. (1 ㅇ, USNM).

Etymology: The name is from Nueva León, a noun in apposition.

\section{Remarks:}

This species and $A$. dispilis are similar. In $A$. leon, the ovipositor length is subequal to the forewing length, the ovipositor sheath has a white band, and the propodeum is black. In $A$. dispilis, the ovipositor length is longer than the forewing length, the ovipositor sheath is black, and the mesosoma is orange with black, if present, confined to the lower portion of the pleura.

\section{Aulacus whartoni SмIтH, new species}

(Figs 34-38)

\section{Diagnosis:}

Head and mesosoma black; legs orange, metasoma orange; wings entirely hyaline. Head shining, without genal carina. Mesonotum with coarse transverse carinae. Hind coxa smooth, shining. Tarsal claws with one inner tooth near base, longer and broader than outer tooth. Ovipositor length slightly shorter than forewing length.

\section{Female:}

Length, $9.2 \mathrm{~mm}$; forewing length, $7.0 \mathrm{~mm}$; ovipositor length $6.5 \mathrm{~mm}$. Color: Black; scape, pedicel, clypeus, malar space, and metasoma orange; base of metasoma black. Legs orange with coxae and trochanters black and extreme bases of hind femur more or less black. Wings entirely hyaline, lacking black spots, veins and stigma black. Head: Antennal length $4.4 \mathrm{X}$ head width. Lower interocular distance about $1.2 \mathrm{X}$ eye height, malar space about $0.4 \mathrm{X}$ eye height (Fig. 34). Head from above short and narrowing behind eyes (Fig. 35). Shining, very fine punctures on frons, with fine white pubescences densest on lower half of frons to clypeus and malar area (Figs 34, 35). Mesosoma: Mesoscutal middle lobe with about 10 transverse carinae, lateral lobe with short carinae on inner margin. smooth, finely punctate laterally; notauli meet transscutal articulation slightly separately (Fig. 37); axilla reticulate; mesoscutellum with 5-6 transverse carinae at center, reticulate laterally; pronotum finely reticulate, smooth shining area on posterior 

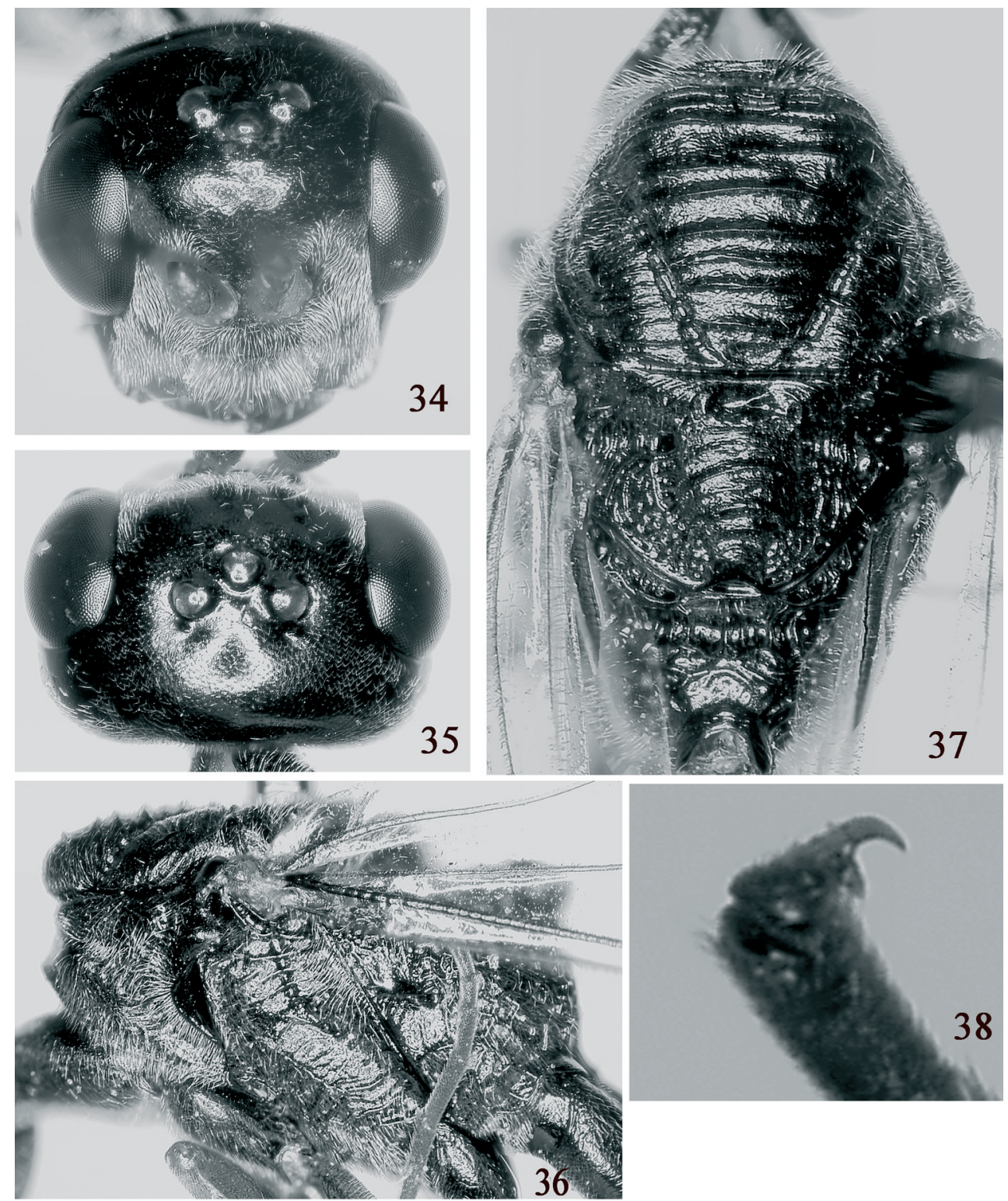

Figs 34-38: Aulacus whartoni. 34 Head, front. 35 Head, dorsal. 36 Mesosoma, lateral. 37 Mesosoma, dorsal. 38 Tarsal claw.

margin; mesepisternum anteriorly reticulate, posteriorly with carinae; mesepimeron finely striate; metapleuron finely reticulate on dorsal half, coarsely reticulate on ventral half; propodeum reticulate (Figs 36, 37). Hind coxa smooth and shining, with very fine transverse carinae laterally, about 2.0X longer than broad. Hind basitarsus 1.1X longer than length of remaining tarsal segments combined. Tarsal claw with large tooth at base, almost appearing as a large, acute basal lobe (Fig. 38). Metasoma: Shining; apical 2 or 3 segments with fine white pubescence. Ovipositor length about $0.9 \mathrm{X}$ forewing length. 
Male: Unknown.

Holotype: Female, labeled "Mexico: Oaxaca, 10 mi. SE Totolapam, VII-20-1987, 4000 ft., R. Wharton" (TAMU).

Etymology: Named for Dr. Robert A. Wharton, Texas A\&M University, College Station, who collected this species.

\section{Remarks:}

The long inner tooth of the tarsal claws is unusual for Aulacus, but all other characters place A. whartoni in this genus. The color is also unique with the head (except clypeus and malar space) and mesosoma black and metasoma mostly orange. This also is the only species of Aulacus treated here that has the ovipositor slightly shorter than the forewing length.

\section{Aulacus aneurus WALKLEY}

(Figs 39-41

Aulacus aneurus WalkLey 1952: 185.-Muesebeck 1958: 88.-CARLSON 1979: 1114.-SMith 2001: 269.

\section{Diagnosis:}

Entirely black. Head dull with fine transverse microsculpture. Mesonotum with fine transverse carinae. Hind coxa with cross striations. Forewing without second recurrent vein.

\section{Female:}

Length, $6.0 \mathrm{~mm}$; forewing length, $4.5 \mathrm{~mm}$; ovipositor length $5.5 \mathrm{~mm}$. Color: Black; metasoma and legs beyond coxae more brownish. Wings clear hyaline, without black spots, veins and stigma black. Head: Antennal length 4.0X head width. Lower interocular distance 1.1X eye height; malar space $0.3 \mathrm{X}$ eye height (Fig. 39). From above, head short and narrowing behind eyes (Fig. 40). Entire head dulled with very fine, wavy microsculpture (Figs 39, 40). Mesosoma: Propleuron shining, faintly reticulate to striate ventrally and anteriorly. Mesonotum with fine transverse striae, striae more diagonal on axillae and lateral parts of mesoscutellum; notauli meet transscutal articulation separately (Fig. 41); pronotum shining, mostly finely striate; mesopleuron shining, finely striate dorsally, with large carinae on ventral half, mesosternum reticulate; metapleuron shining on dorsal half, reticulate on ventral half; propodeum reticulate. Hind coxa with fine transverse carinae, $2.0 \mathrm{X}$ longer than broad, with indistinct diagonal ovipositor guide on basal quarter of inner surface. Hind basitarsus subequal in length to remaining tarsal segments combined. Metasoma: Shining, almost glabrous. Ovipositor length 1.2X forewing length.

Male: Length, $5.5 \mathrm{~mm}$; forewing length, $4.5 \mathrm{~mm}$. Color and structure similar to female.

Holotype: Female, "caged tree infested Dendroctonus, Lincoln N. F., Cloudcroft, N. Mex, \#52-1432, C. Hay, Hopk US 34218-M-3” (USNM).

Other specimens examined: USA: NEW MEXICO: Two male paratypes with same data as holotype (USNM); Lincoln N.F., 7/2/62, Hopk. US 37240-F, Pinus ponderosa, J. F. Chansler, Collector ( 4 ㅇ + , USNM).

Host: According to label data, specimens emerged from caged trees infested with Dendroctonus sp., and another specimen labeled, Pinus ponderosa. Notes from the Hopkins' cards suggest that some 

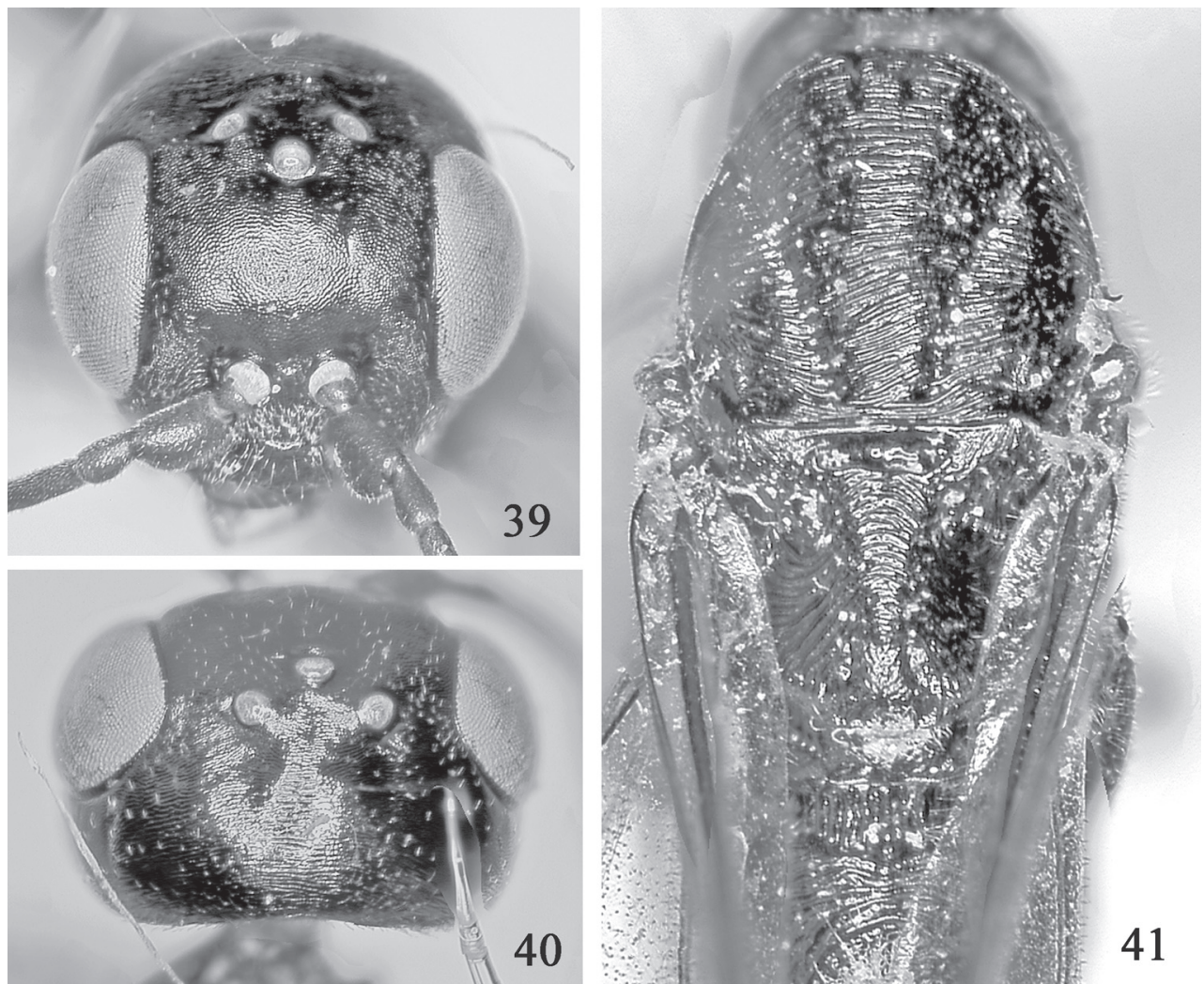

Figs 39-41: Aulacus aneurus. 39 Head, front. 40 Head, dorsal. 41 Mesosoma, dorsal.

specimens emerged from trees infested with Dendroctonus adjunctus Blanford (Scolytidae), and that all were associated with Dendroctonus. Carlson (1979) believed that D. adjunctus was the likely host.

\section{Remarks:}

This small black species lacks reticulate or carinate sculpture; all sculpture is the fine, dull microsculpture of the head and mesosoma. Lengths of specimens examined are all similar.

\section{Aulacus dispilis Townes}

(Figs 42-44)

Aulacus dispilis Townes 1950: 114.-Townes 1951: 659.-WALKLey 1967: 285.-Carlson 1979: 1114.SмITH 2001: 270.

\section{Diagnosis:}

Orange with metasoma and legs darker, more brownish; base of hind tibia white. Head with deep, scattered punctures. Mesonotum with coarse transverse carinae. Hind coxa shining, with few fine punctures. 

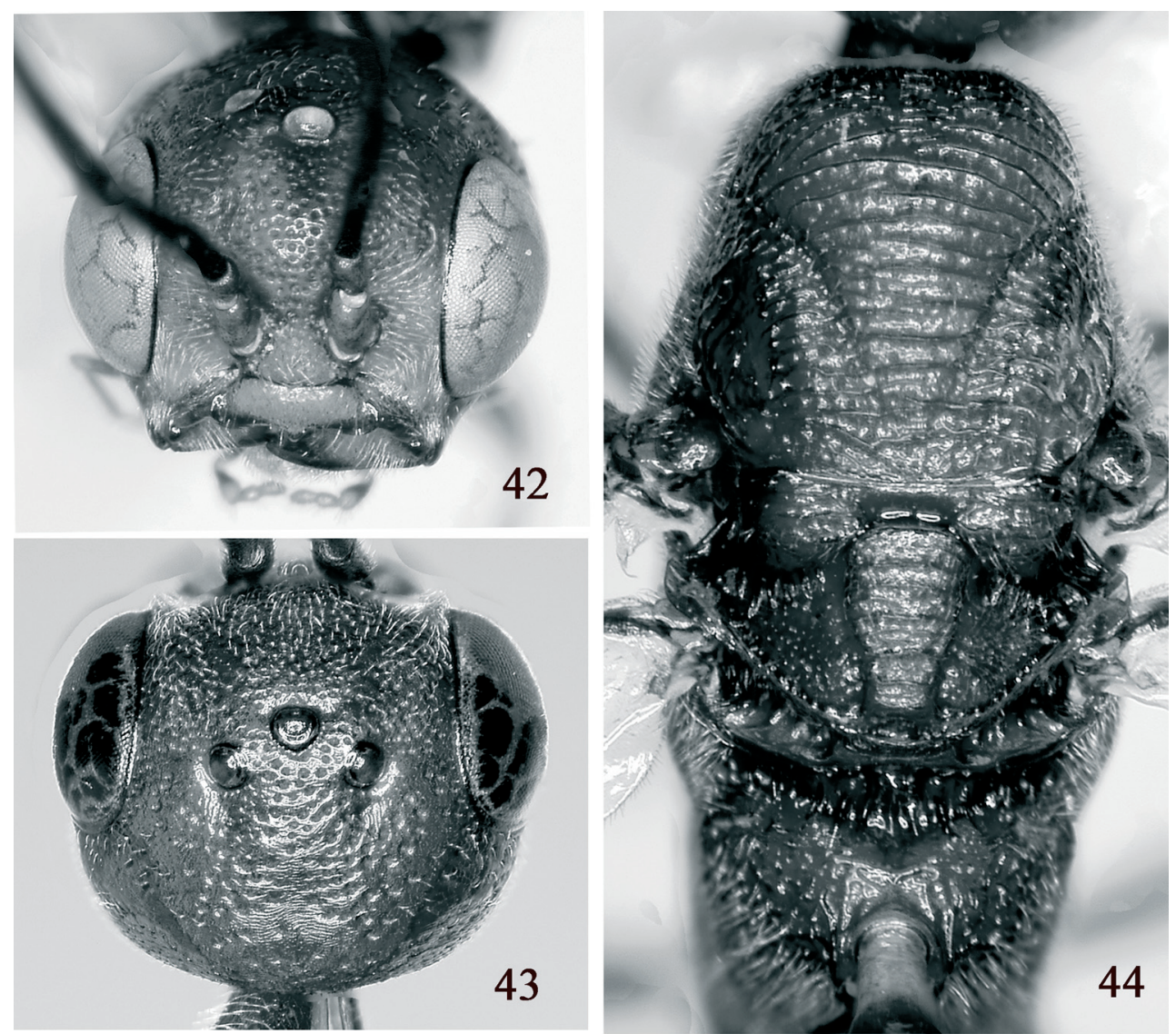

Figs 42-44: Aulacus dispilis. $42 \mathrm{Head}$, front. $43 \mathrm{Head}$, dorsal. 44 Mesosoma, dorsal.

\section{Female:}

Length, $7.5 \mathrm{~mm}$; forewing length, $5.5 \mathrm{~mm}$; ovipositor length, $6.0 \mathrm{~mm}$. Color: Antenna black with scape and pedicel orange; head and mesosoma orange, blackish on venter of propleuron, mesosternum, and ventral propodeum; fore- and midlegs orange with coxae black; hind leg black with basal fifth of tibia white and tarsus orange. Metasoma brown with white band on second segment. Ovipositor sheath with white band. Wings hyaline, forewing with apical black spot, veins and stigma black. Color of both sexes similar. Head: Antennal length $2.5 \mathrm{X}$ longer than head width. Lower interocular distance 1.1X eye height; malar space $0.3 \mathrm{X}$ eye height (Fig. 42). Head from above short and sharply narrowing behind eye (Fig. 43). Vertex and frons with widely scattered punctures separated by flat shining interspaces mostly equal to or less than puncture diameters (Figs 42, 43). Mesosoma: Propleuron shining, finely punctate. Mesoscutal middle lobe with transverse carinae, lateral lobes with transverse carinae mixed with reticulations; notauli meet transscutal articulation at about same point (Fig. 44); axillae reticulate; mesoscutellum with about 5 transverse carinae mixed with reticulations, laterally reticulate (Fig. 44); pronotum reticulate; mesopleuron reticulate with band of carinae on posterior margin; metapleuron shining and smooth on dorsal half, reticulate on ventral half; propodeum reticulate. Hind coxa shining finely punctured, especially on sides and at apex and with indistinct transverse striae near apex, 1.7X longer than broad, ovipositor guide indistinct. Hind basitarsus subequal in length to length of 
remaining tarsal segments combined. Metasoma: Shining, with fine white pubescence on segment 3 to apex. Ovipositor length about 1.2X forewing length.

Male: Length, $6.5 \mathrm{~mm}$; forewing length, $4.8 \mathrm{~mm}$. Color and structure similar to female.

Holotype: Female, from "Brownsville, Texas, March 20, 1908, Jones and Pratt" (USNM). Described from one female.

Other specimens examined: TEXAS: Brownsville, bred, Celtis mississip., H. S. Barber, Collector, Insectary No. 6, '04 (1 +, USNM); Hidalgo County, Bentsen-Rio Grande Valley St. Pk., 16.31-III.77, C. C. Porter, coll., Malaise trap (1 ․, USNM), same except 16-31-III-76 (1 o,

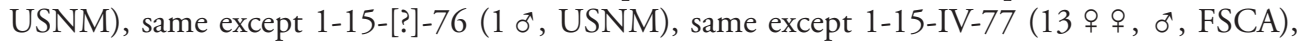
same except 16-30-IV-77 (11 우 우, o, FSCA), same except 16-31-III-77 (3 우 우, ơ, FSCA), same except 19-III-82 (1 ๆ , FSCA); Ca. Mission, Bentsen Rio Grande Valley State Park, 17-III-76 (1 ๆ, FSCA); McAllen, 2 April '75, C. Porter (1 + , FSCA); Hidalgo Co., Santa Ana Wildlife Refuge, collector G. H. Nelson, reared from Pithecellobium flexicaule (Beuth.), wood coll'd 27.VI-1968, emerged 21.VIII.1969 (1 + , FSCA).

Host: Emerged from Celtis laevigata Willd. (WalkLey 1967). From label data, bred from Celtis mississippiensis Bosc, C. laevigata (Cannabaceae) and Pithecellobium flexicaule (Benth.) J. M. Coult. (Fabaceae).

\section{Remarks:}

See remarks under $A$. leon.

\section{Pristaulacus argutus SMITH, new species}

(Figs 45-48)

\section{Diagnosis:}

Black; antenna black; hind leg black, fore- and midlegs orange; ovipositor sheath with a white band; antenna black. Pronotum with one anteriorly projecting tooth. Hind coxa with punctures and some cross striations.

\section{Female:}

Length, $9.5 \mathrm{~mm}$; forewing length, $7.0 \mathrm{~mm}$; ovipositor length, $7.5 \mathrm{~mm}$. Color: Black; ovipositor sheath with white band; fore- and mid femora, tibiae, and tarsi orange. Wings hyaline, veins and stigma black; forewing with black spot under stigma and black at apex. Head: Antennal length 2.7X head width. Lower interocular distance $0.9 \mathrm{X}$ eye height; malar space $0.3 \mathrm{X}$ eye height (Fig. 45). Head from above straight to slightly narrowing behind eyes, length behind eyes about half of eye length (Fig. 46). Occipital carina moderate, about 0.3X diameter of an ocellus. Vertex and gena smooth, shining; frons with moderate-sized punctures, separated by flat interspaces about equal to puncture diameters; fine white pubescence, densest on lower frons, malar area, interantennal area, and clypeus (Figs 45, 46). Mesosoma: Mesoscutum with two acute anterolateral projections Propleuron shining with few fine punctures. Pronotum with one anteriorly projecting tooth. Mesoscutum reticulate anteriorly, two transverse scrobiculate rows posteriorly; axillae and sides of mesoscutellum reticulate, center of mesoscutellum with several transverse carinae; pronotum reticulate posteriorly, more punctate anteriorly; mesopleuron, metapleuron, and propodeum reticulate (Figs 47, 48). Hind coxa with punctures and few transverse carinae, about 2.3X longer than broad. Tarsal claws with 3 teeth and small basal lobe. Hind basitarsus subequal in length to 

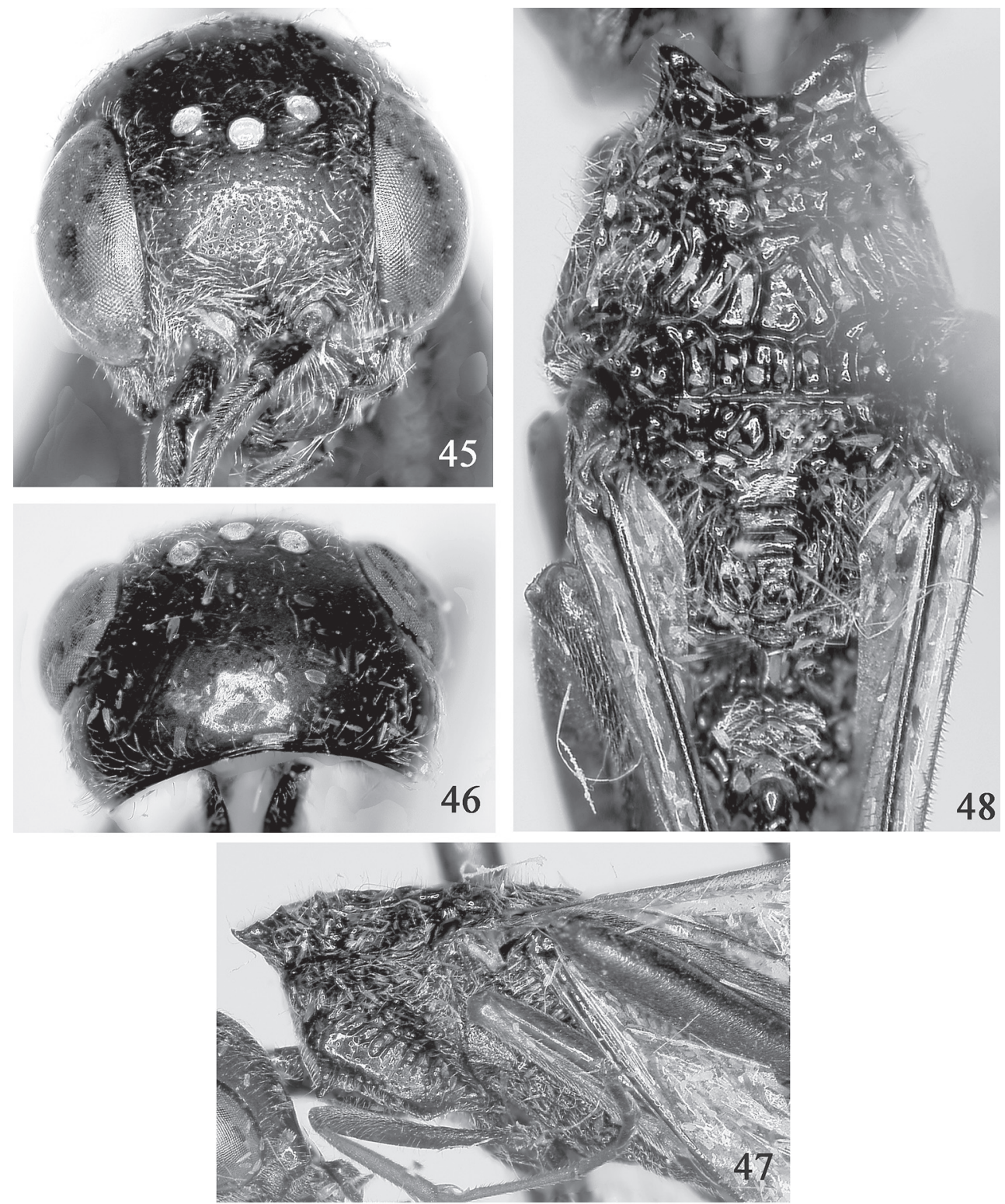

Figs 45-48: Pristaulacus argutus. 45 Head, front. 46 Head, dorsal. 47 Mesosoma, lateral. 48 Mesosoma, dorsal.

length of remaining tarsal segments combined. Forewing with cells $1 \mathrm{M}$ and 1 Rs separated by long vein Rs+M. Hind wing venation absent (as in Fig. 157). Metasoma: Segments 3 to apex with fine white pubescence and fine punctures. Ovipositor length 1.1X forewing length.

Male: Unknown.

Holotype: Female, labeled "Mexico: Tamaulipas, Gomez Farias: 300 m, Los Cedros, Malaise, 31.vii.-7.viii 1999, Col. Sonia Hernandez A.” (USNM). 
Etymology: From the Latin argutus, referring to the acute anterolateral angles of the mesonotum.

\section{Remarks:}

This species is very similar to P. ambiguus (SCHLETTERER) from southern Brazil; both are black, but the latter species has entirely black legs. Pristaulacus argutus, P. tria, P. maculata, and P. ruficollis treated here, and P. ambiguous, P. ruficeps (Westwood), P. brasiliensis (KiefFer), P. punctatus Smith, P. haemorrhoidalis (Westwood), P. femurrubrum Smith, and a number of other species from South America belong in a group that has the anterolateral angles of the mesoscutum acute (as in Figs 48, 52, 57, 62), one anteriorly projecting tooth on the pronotum, and the tarsal claws with three teeth and a basal lobe. Tamaulipas, Mexico, is the northernmost record for species of this group; the southernmost species occur in northern Argentina.

\section{Pristaulacus tria SMITH, new species}

(Figs 49-52)

\section{Diagnosis:}

Entirely black; ovipositor sheath black. Pronotum with three anteriorly projecting teeth. Hind coxa shining.

\section{Female:}

Length, $11.5 \mathrm{~mm}$; forewing length $10.0 \mathrm{~mm}$; ovipositor length $12.5 \mathrm{~mm}$. Color: Black; foretibia and tarsus brownish. Wings hyaline except apex of forewing black; veins and stigma black. Head: Antennal length 2.5X head width. Lower interocular distance subequal to eye height; malar space $0.3 \mathrm{X}$ eye height (Fig. 49). Occipital carina distinct, flangelike, half or more diameter of an ocellus. From above, head long behind eyes, only gradually narrowing, head behind eyes subequal to eye length (Fig. 50). Gena and vertex smooth and shining, almost impunctate; frons with large scattered punctures, farther apart than several times puncture diameters; with fine white pubescence, densest and longest on malar area, interantennal area, and clypeus (Figs 49, 50). Mesosoma: Mesoscutum with two acute anterolateral teeth. Mesoscutum with large, indistinct reticulations, with indistinct transverse scrobiculate area posteriorly; axilla and lateral areas of mesoscutellum reticulate, center of mesoscutellum with several transverse carinae; propleuron smooth, shiny; pronotum with three anteriorly projecting teeth, a row of diagonal carinae posteriorly, and mostly shining anteriorly; mesopleuron coarsely reticulate; metapleuron reticulate with narrow scrobiculate band posteriorly; propodeum reticulate (Figs 51, 52). Hind coxa smooth, shining, 2.5X longer than broad; diagonal ovipositor groove near apex on inner surface. Tarsal claws with 3 teeth and small basal lobe. Hind basitarsus 1.6X longer than length of remaining tarsal segments combined. Forewing with cells $1 \mathrm{M}$ and $1 \mathrm{Rs}$ separated by long vein Rs+M. Hind wing with veins absent (as in Fig. 157). Metasoma: Segment 5 with fine white pubescence, segments 6 to apex densely pubescent. Ovipositor length about $1.3 \mathrm{X}$ forewing length.

Male: Unknown.

Holotype: Female, labeled "Costa Rica: CATIE, 3 km SE Turrialba, 600 m, Cartago Prov., V-16-85, J. Chemsak” (UCB).

Etymology: From the Latin tria, meaning three, referring to the three anteriorly projecting teeth of the pronotum. 

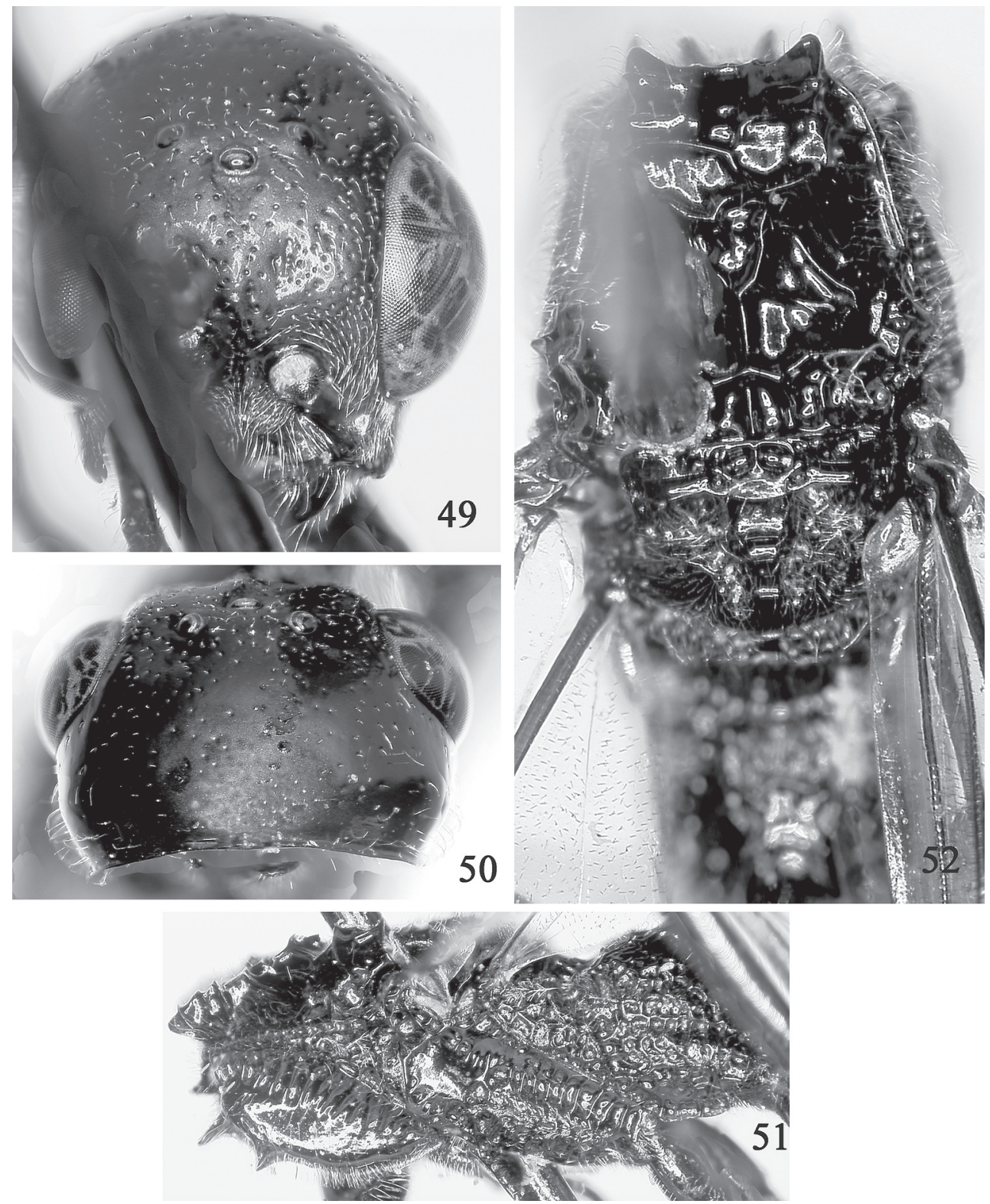

Figs 49-52: Pristaulacus tria. $49 \mathrm{Head}$, front (partially obscured by pin). $50 \mathrm{Head}$, dorsal. 51 Mesosoma lateral. 52 Mesosoma, dorsal.

\section{Remarks:}

Two species from South America have three anteriorly projecting teeth on the pronotum, P. decemdentatus Kieffer from Brazil and P. tridentatus SMith from Colombia. Pristaulacus decemdentatus has a red head, mostly reddish legs, and a central white band on the ovipositor sheath. Pristaulacus tridentatus has the metasoma red. 


\section{Pristaulacus maculatus (SCHLETTERER)}

(Figs 53-58)

Aulacus maculatus Schletterer 1889: 497, 531, t. 22, f. 144.-Dalla Torre 1902: 1061.-Kieffer 1902: 11.

Pristaulacus maculatus: KiefFer 1903: 455.-KiefFer 1904: 10.-Sмith 2001: 288.-Sмith 2005: 238, Figs $45-50$.

Odontaulacus maculatus: KiefFer 1912: 365, 369.-Hedicke 1939: 22.

\section{Diagnosis:}

Head red; mesosoma mostly black; wing with dark spot under stigma. Pronotum with one anteriorly projecting tooth. Head shining with few small punctures on frons. Hind coxa punctate.

\section{Female:}

Length, $8.0 \mathrm{~mm}$; ovipositor length, $6.0 \mathrm{~mm}$; forewing length $6.0 \mathrm{~mm}$. Color: Antenna black, scape cark reddish. Head red with apex of mandible and palpi black. Mesosoma black with pronotum mostly reddish except anterior portion at center and upper surface of propleuron reddish. Metasoma black with venter of first segment reddish brown; ovipositor sheath black with central white band. Legs reddish brown with coxae, trochanters, extreme bases of femora, and hind tibia and hind tarsus black. Wings hyaline, extreme apex of forewing with black spot and with small, faint infuscate spot below stigma (Fig. 56); veins and stigma black. Head: Antennal length about 2.7X head width. Eyes in front view subparallel, lower interocular distance about $0.3 \mathrm{X}$ eye height; malar space a little less than $0.3 \mathrm{X}$ eye height (Fig. 53). In dorsal view, head broad and slightly narrowing behind eyes; length behind eyes about $0.7 \mathrm{X}$ eye length (Fig. 55). Occipital carina very narrow, less than $0.3 \mathrm{X}$ diameter of an ocellus. Vertex and gena glabrous, smooth, shining, without punctures; vertex without pubescence and very sparse pubescence on gena; frons shining with small punctures separated by flat interspaces one to several times diameter of punctures; pubescence dense on frons, malar area, and clypeus (Figs 53-55). Mesosoma: Propleuron shining, punctate rugose. Anterior margin of pronotum with one anteroventrally projecting tooth. Coarsely sculptured, pubescence rather sparse, densest on mesoscutal lateral lobes, scutellum, and mesepisternum. Mesonotum with short, acute, outwardly protruding anterolateral projections; mesoscutal middle lobe aerolate, with 3 or 4 irregular transverse carinae forming 4 large punctures at each side lobe; axillula more finely reticulate punctate. Pronotum with oblique scrobiculate area, anteroventrally finely reticulate punctate, dorsoposteriorly coarsely reticulate; mesepisternum finely reticulate punctate; mesepimeron scrobiculate; metapleuron and propodeum coarsely reticulate; propodeum dorsally with large punctures than laterally (Figs 57, 58). Upper surface of hind coxa densely punctate, with transverse carinae on apical half; about 1.7X longer than broad; inner surface with ovipositor guide near apex. Hind basitarsus slightly longer than length of remaining tarsal segments combined. Tarsal claws with 3 teeth and small basal lobe. Forewing with cells $1 \mathrm{M}$ and 1 Rs separated by long vein Rs+M (Fig. 56). Hind wing veins absent (as in Fig. 157). Metasoma: Shining, impunctate; pubescence densest on distal halves of segments 4 to apex. Ovipositor length about equal to forewing length.

Male: Unknown.

Specimens examined: Records from Brazil, Colombia, Guyana, and Peru are given by Smith (2005). COSTA RICA: Prov. Heredia, F. La Selva, $3 \mathrm{~km} \mathrm{S.} \mathrm{Pto.} \mathrm{Viejo,} 10^{\circ} 26^{\prime} \mathrm{N}, 84^{\circ} 01^{\prime} \mathrm{W}$, 6-IV-1964, H. A. Hespenheide, on fallen branch of Pentaclethra macroloba (1 9 , CHAH); same except 3-IV-94 (1 +, CHAH); same except 8-VII-1992 (1 , CHAH); Guan., 14 km. S. Canas, 

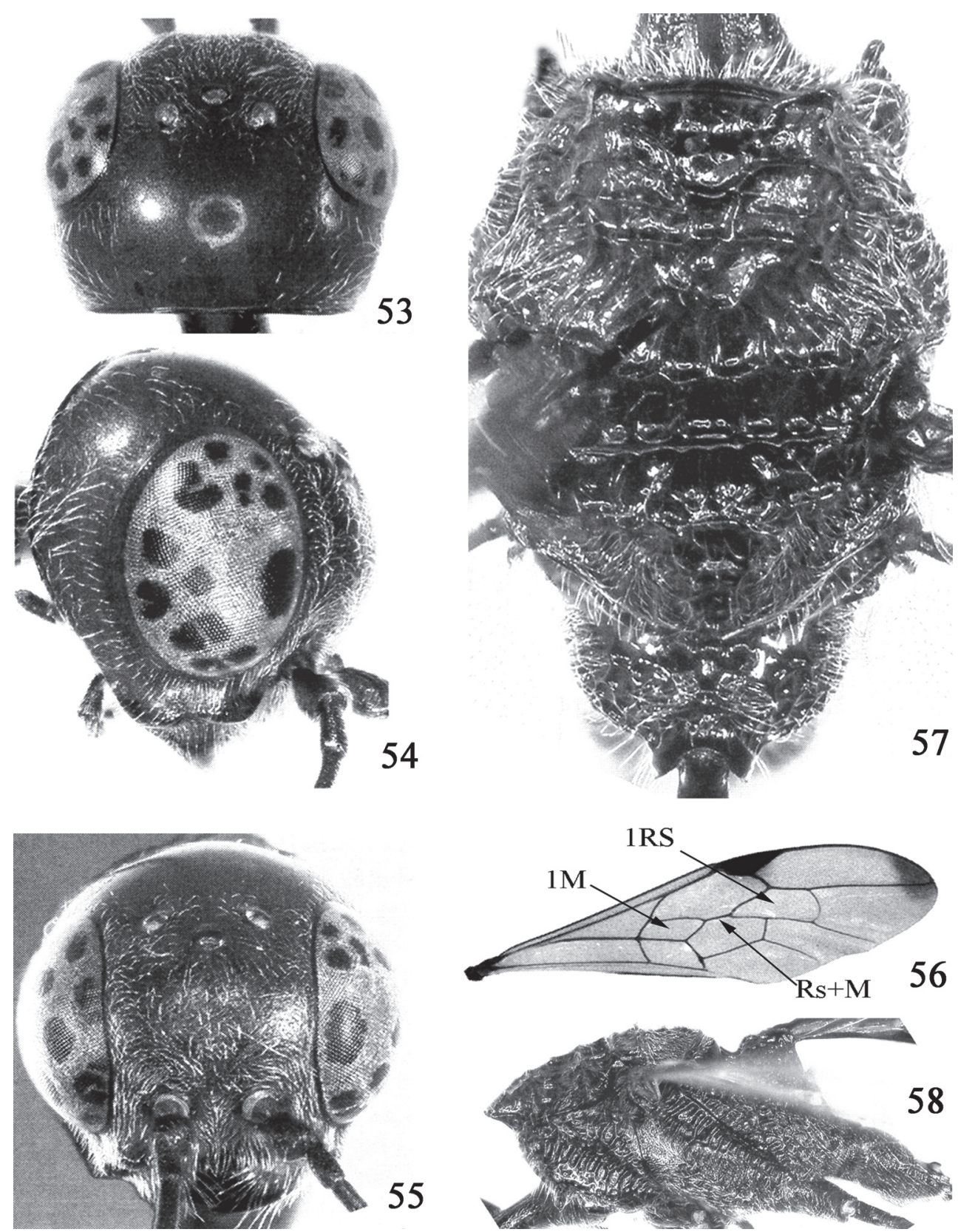

Figs 53-58: Pristaulacus maculatus. 53 Head, dorsal. 54 Head, front. 55 Head, lateral. 56 Forewing. 57 Mesosoma, dorsal. 58 Mesosoma, lateral.

1-11 Feb. 1990, F. D. Parker (2 우, USU); same except 11-31 Jan. 1990 (1 ․, USU); Punta Arenas Prov., Piedras Blancas, 23, 26-VII-1981, H. V. Weems, Jr., G. B. Edwards, rain forest (1 , FSCA); Palmar, CR49F (1 +, USNM); Limon Prov., 2 mi S. Cahuita, 24-25-XII-1988, A. S. Menke, rain forest (1 ㅇ, USNM); Guanacaste, $500 \mathrm{~m}, 9^{\circ} 52.096^{\prime} \mathrm{N}, 85^{\circ} 056^{\prime} \mathrm{W}$, Reserva 
Privada, 2-4-IV-2005, Malaise, B. Brown et al. (1 ㅇ, USNM). NICARAGUA: Rio San Juan Pr., Refugio Bartolo, $10 \mathrm{~km}$ ESE El. Castillo, $10^{\circ}$ 58/59N, 84² 20/21W, 22-IV-1999, H. A. Hespenheide (9 우, 애AH). PANAMA: Canal Zone, Barro Colorado, VIII-1924, N. Banks (1 +, MCZ); Canal Zone, 0.5 mi. S Palo Seco, 854'N, 79³4'W, 8-VI-1973, H. A. Hespenheide (2 ㅇ ㅇ, CHAH); Panama Prov., Pan American Hwy., 30 km E of Canita, 15-29 June 1992, Jean \& Keve Ribardo (2 ㅇ ㅇ, CAS); Provincia de Chiriqui, Pan-Am Hwy., Rio Tabasara, 133 m, 23-I-1987, Edward S. Ross (1 +, CAS); Las Sabanas, nr. Panama City, 3-24-1924, 2-2918, ex Trachysomus thomsoni (1 + , USNM); Orange trunk, Parita, emerged 9-20-'22, J. Zetek, Coll., Zetek No. 1787 (1 우 USNM).

Types: The holotype female (ZMUC) is labeled "Brasilien (Amazonenstrom)" "Coary Amazonas" [handwritten, uncertain of spelling], "[?] Schletterer [?]" [handwritten, first and third words illegible], "Coll. Wustnel." "Aulacus maculatus Schletterer," "Type” [red], "Zool. Museum DK Copenhagen."

Hosts: Specimens from Costa Rica were collected on a fallen branch of Pentaclethra macroloba (Willd.) Kuntze (Fabaceae). A specimen from Panama is labeled "ex Trachysomus thomsoni," which probably refers to Trachysomus thomsoni Aurivillius (Cerambycidae).

\section{Remarks:}

This is a widespread species occurring from Brazil and Peru north to Nicaragua.

\section{Pristaulacus ruficollis (CAMERON)}

(Figs 59-62)

Aulacus ruficollis Cameron 1887: 423, pl. 18, Fig. 10.-Schletterer 1889: 521.-Dalla Torre 1902: 1062.-Kieffer 1902: 10.-Kieffer 1912: 371, 373.-Hedicke 1939: 18.

Pristaulacus ruficollis: KiefFer 1903: 455 (? Pristaulacus).-SMiтH 2001: 295.

\section{Diagnosis:}

Head black; mesosoma red anterior to transscutal articulation; forewing with only black apical spot. Pronotum with one anteriorly projecting tooth. Head with frons shining, only few small punctures. Hind coxa punctate.

\section{Female:}

Length, $10.0 \mathrm{~mm}$; forewing length, $7.5 \mathrm{~mm}$; ovipositor length, $8.0 \mathrm{~mm}$. Color: Antenna black, scape may be dark orange. Head black; clypeus, mandible except apex, malar area all or in part dark orange. Mesosoma black with mesoscutum and most or all of pronotum red; narrow anterior margin and lower half of pronotum may be blackish; upper surface of Propleuron and spot on mesepimeron may be dark orange. Legs mostly black; fore- and midtibia and tarsus orange to dark brown. Metasoma black. Ovipositor sheath black with white band near apex. Wings hyaline, veins and stigma black; forewing with black spot under stigma and black spot at apex. Head: Antennal length 2.5X head width. Lower interocular distance subequal to eye height; malar space $0.3 \mathrm{X}$ eye height (Fig. 59). From above head behind eyes gradually narrowing, head $0.8 \mathrm{X}$ eye length (Fig. 60). Vertex and gena smooth and shining; frons densely punctate, most punctures at center separate by short ridges shorter or equal to puncture diameters; with fine white pubescence, densest and longest on lower frons, malar area, and clypeus (Figs 59, 60). Mesosoma: Mesoscutum with acute anterolateral teeth, each slightly projecting outward toward apex; mesoscutum 


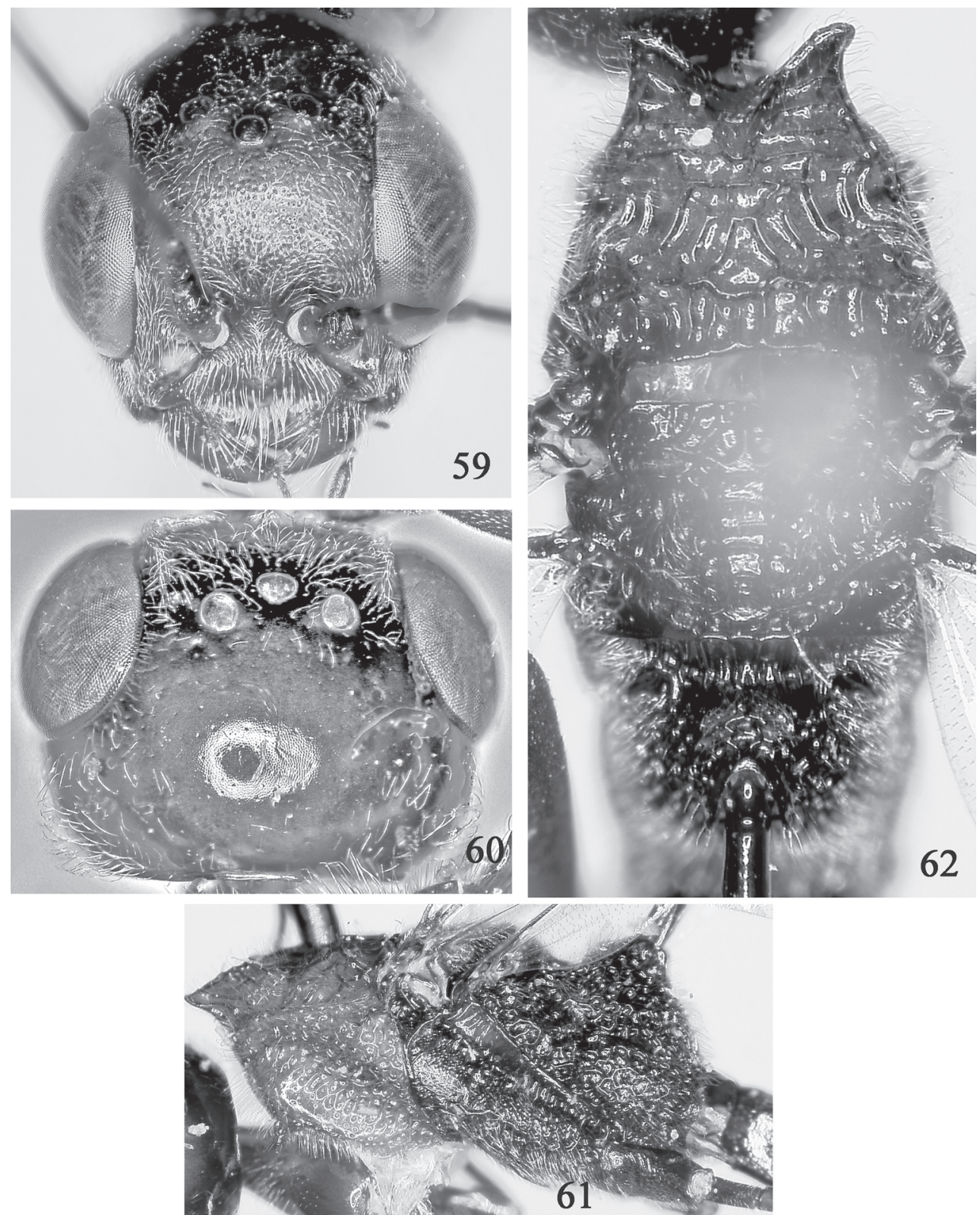

Figs 59-62: Pristaulacus ruficollis. 59 Head, front. $60 \mathrm{Head}$, dorsal. $61 \mathrm{Mesosoma,} \mathrm{lateral.} 62$ Mesosoma, dorsal.

reticulate anteriorly, posteriorly with two transverse scrobiculate rows; axilla and lateral portions of mesoscutellum reticulate, mesoscutellum with several transverse carinae at center. Propleuron smooth, shining, with few fine punctures; pronotum with one anteriorly projecting tooth, mostly reticulate, more punctate anteriorly; mesopleuron reticulate, narrowly scrobiculate posteriorly, mesepimeron with small finely punctate area, metapleuron and propodeum reticulate (Figs 61, 
62). Hind coxa shining, 2.0X longer than broad, with punctures; shallow ovipositor groove near apex on inner surface. Tarsal claws with 3 teeth and small basal lobe. Hind basitarsus subequal in length to remaining tarsal segments combined. Forewing with cells $1 \mathrm{M}$ and 1 Rs separated by long crossvein Rs+M. Hind wing veins absent (as in Fig. 157). Metasoma: Shiny; fine white pubescence on gastric segment 4 to apex. Ovipositor length about 1.1X forewing length.

Male: Unknown.

Type: A female from "Guatemala, Torola 1000 feet (Champion). The specimen is at the BMNH, labeled "type" [round label], "B.M. TYPE HYM. 3.a.92", "Aulacus ruficollis Cam., type, BCA ii $423 \mathrm{~d}$ " [handwritten], "Torola, $1000 \mathrm{ft}$, Champion”, "B.C.A. Hymen.I.Aulacus ruficollis Cam." The number of specimens was not given by Cameron (1887); thus, it is not known if he had more than one specimen. I designate this specimen the lectotype to ensure stability of the name.

Specimens examined: HONDURAS: Catacamus, Olancho, 30-IX-1980, R. W. Jones (1 $q$, TAMU). MEXICO: 24 mi. N. Matias Romero, Oax., VI-24-1969, Bright \& Campbell (1 , CNC).

\section{Remarks:}

Pristaulacus ruficollis is very similar in size and structure to $P$. maculatus. In P. ruficollis, the mesosoma is red only anterior to the transscutal articulation, the ovipositor is slightly longer than the forewing length, and there is never a dusky or dark spot below the stigma of the forewing.

\section{Pristaulacus auricomus SMITH, new species}

(Figs 63-66)

\section{Diagnosis:}

Head and body with golden pubescence, with black and yellow pattern. Wings with anterior half dark brown, posterior half paler to hyaline. Head shining. Mesonotum with transverse carinae. Hind coxa shining with cross striations at posterior.

\section{Female:}

Length, $16.0 \mathrm{~mm}$; forewing length, $12.0 \mathrm{~mm}$; ovipositor length, $14.0 \mathrm{~mm}$. Color: Covered with golden pubescence. Antenna black with segments 1-3 yellow; anterior margin of clypeus brown. Mesosoma black with following yellow: lateral areas on mesoscutal middle lobe, lateral spot on each lateral lobe; axilla; anterior third of pronotum; spot on upper metapleuron; diagonal streak above hind coxa; semicircle on propodeum around metasomal insertion. Fore- and midlegs yellow with coxae and trochanters black; hind leg black with second trochanteral segment and extreme base of tibia brown and stripe on inner surface of hind tibia and hind tarsus yellow except blackish apical one or two segments. Metasoma black; first segment yellow ventrally. Ovipositor sheath yellow brown, apex black. Head: Antennal length 2.0X head width. Lower interocular distance $1.2 \mathrm{X}$ eye height; malar space $0.3 \mathrm{X}$ eye height (Fig. 63). Head behind eyes from above long, straight, head behind eyes $1.3 \mathrm{X}$ eye length (Fig. 66). Occipital carina narrow, about a fifth or less diameter of an ocellus. Gena, vertex, and frons somewhat dull, finely punctate; dense, long golden pubescence, densest and longest on anterior vertex through frons to malar area and clypeus (Figs 63, 66). Mesosoma: Covered with rather dense, golden pubescence, half length or less than that on front of head. Anterior mesoscutum rounded; mesoscutum reticulate, with faint transverse sculpture on middle lobe and middle lobe separated from lateral lobe by narrow 


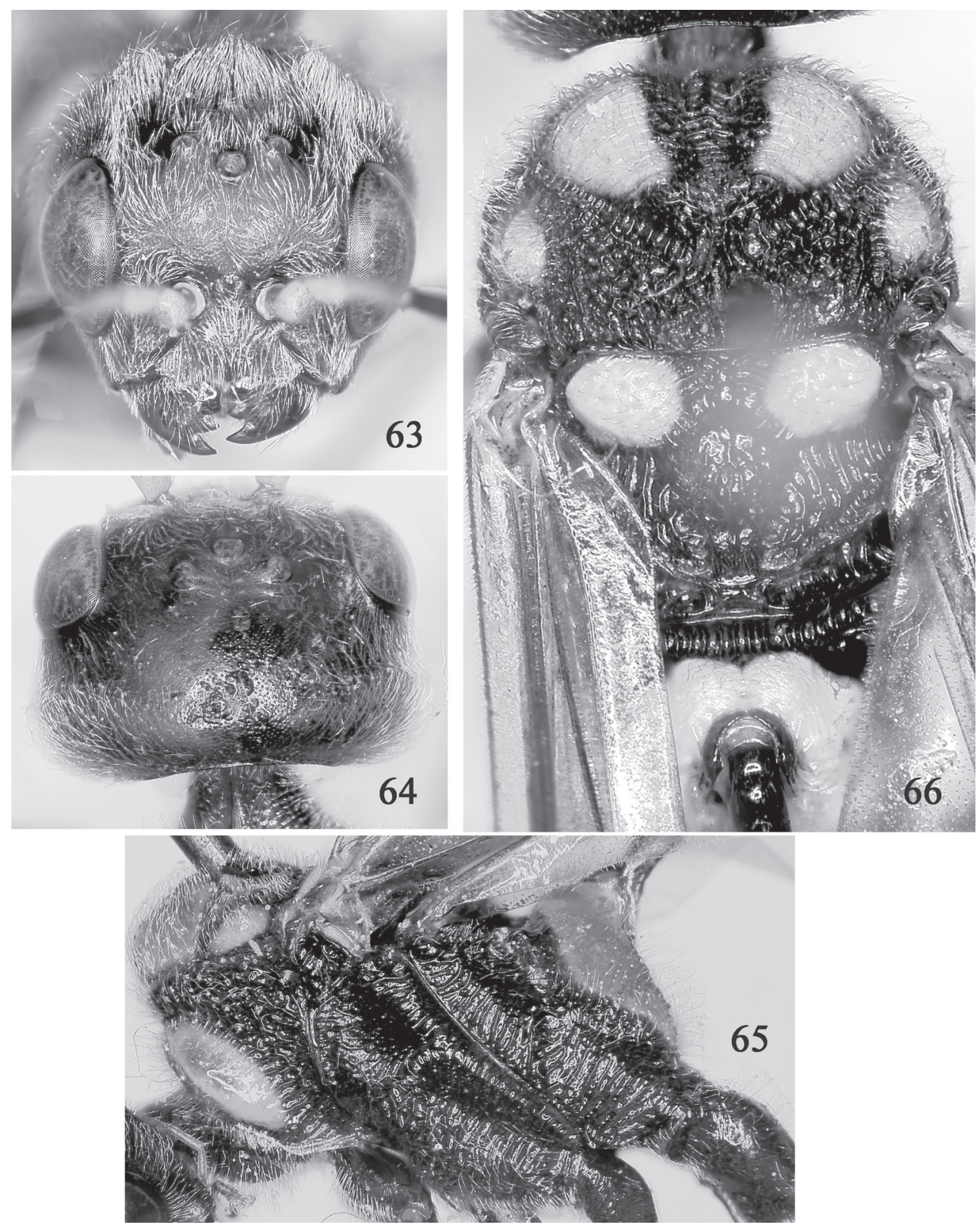

Figs 63-66: Pristaulacus auricomus. 63 Head, front. 64 Head, dorsal. 65 Mesosoma, lateral. 66 Mesosoma, dorsal.

scrobiculate area. Propleuron shining, finely punctate; pronotum without anteriorly projecting tooth, reticulate posteriorly with smooth, shining area anteriorly; mesopleuron reticulate with faint carinae on lower half, smoother area toward posterior margin, and very narrow scrobiculate area posteriorly; metapleuron mostly with diagonal carinae; propodeum shining, median groove on dorsum, transverse carinae below metasomal insertion, laterally with diagonal carina dorsally 
and transverse carinae ventrally (Figs 65, 66). Hind coxa stout, less than $2 \mathrm{X}$ longer than broad, shining with few transverse carinae on apical half; nearly perpendicular ovipositor groove near apex on inner surface. Tarsal claws with 6 teeth, basal most tooth very small. Hind basitarsus 1.2X length of remaining tarsal segments combined. Forewing with cells $1 \mathrm{M}$ and 1 Rs separated by long vein $\mathrm{Rs}+\mathrm{M}$. Hind wing with veins distinct, cells $\mathrm{Cu}$ and $\mathrm{R} 1+\mathrm{Rs}$ contiguous (as in Fig. 110). Metasoma: Smooth, shining, with fine white pubescence on segments 2 to apex. Ovipositor length 1.2X forewing length.

Male: Length, $14.5 \mathrm{~mm}$; forewing length, $10.0 \mathrm{~mm}$. Color and structure similar to female.

Types: Holotype: Female, labeled "Mazatlan, 9 mi. N. Sin., MEX., VII-25-28-72, J. \& M. A. Chemsak, A. \& M. Michelbacher” (UCB). Paratypes: HONDURAS: Tegucigalpa, VI.18-18, F. J. Dyar, Col., No. 40456, 41432 (1 ơ, USNM). MEXICO: Same data as holotype (15 i q , UCB); Yautepec, Mor., VII-31-1963, F. D. Parker, L. A. Stange, Collectors (1 o, UCD), same except VII-13 1963 (1 ㅇ, UCD); Sinaloa, 7 mi. N. Guamachil, VIII-18-66, Linsleys, Chemsak, At light, J. Powell, collector (1 क, UCB); Est. Bio. Chamela, Jalisco, VII-20/27-1984, J. A. Chemsak, J. T. Doyen, at lights (1 \%, UCB); $1.1 \mathrm{mi}$ W El Quelite, Sinaloa, VII-18-1974, M. L. Siri, Colr. (1 ơ, UCD); Sinaloa, 15 mi. N. Mazatlan, Aug. 7, 1973, E. Giesbert, Coll. (1 $q$, LACM); Mazatlan, Sin., Aug. 16, 1964, at sea level, J. F. McAlpine (1 ơ CNC). UNITED STATES: Arizona, Cochise Co., s. fk. cave ck. cyn. [probably south fork, Cave Creek Canyon], VIII-8 1974, Eichlin et al. (1 + , CDA).

Etymology: From the Latin auricomus, meaning with golden hairs, referring to the long, dense, golden pubescence of the head and mesosoma.

\section{Remarks:}

The long, golden hairs of the head and mesosoma, the infuscate anterior half of the forewing, and the black mesosoma with yellow maculae as shown in Figs 65 and 66, are distinctive for this large species.

\section{Pristaulacus virga SMIтH, new species}

(Figs 67-71)

\section{Diagnosis:}

Head, mesosoma, and legs orange. Forewing black with hyaline band at center basal to stigma and hyaline band near apex apical to stigma. Ovipositor with a white band. Head smooth and shining. Mesoscutum with 8-9 coarse transverse carinae. Hind coxa smooth and shining. Pronotum without anteriorly projecting tooth.

\section{Female:}

Length, $9.0 \mathrm{~mm}$; forewing length $7.0 \mathrm{~mm}$; ovipositor length $7.0 \mathrm{~mm}$. Color: Antenna with scape and pedicel orange, flagellomeres 1-4 black (missing beyond 4). Head and body orange; apex of mandible and infuscate to black band at apex of first metasomal tergite. Ovipositor brownish with white band near apex. Forewing (Fig. 71) with base, broad band below stigma, and apex black, hyaline areas between base and band below stigma and between band below stigma and apical dark stripe; stigma mostly yellow, infuscate toward base. Hind wing (Fig. 71) black at base, center, and apex with hyaline areas in between. Veins mostly black with those in hyaline areas more yellowish. Head: [Both antennae of holotype broken beyond $6^{\text {th }}$ segment.] Lower interocular 

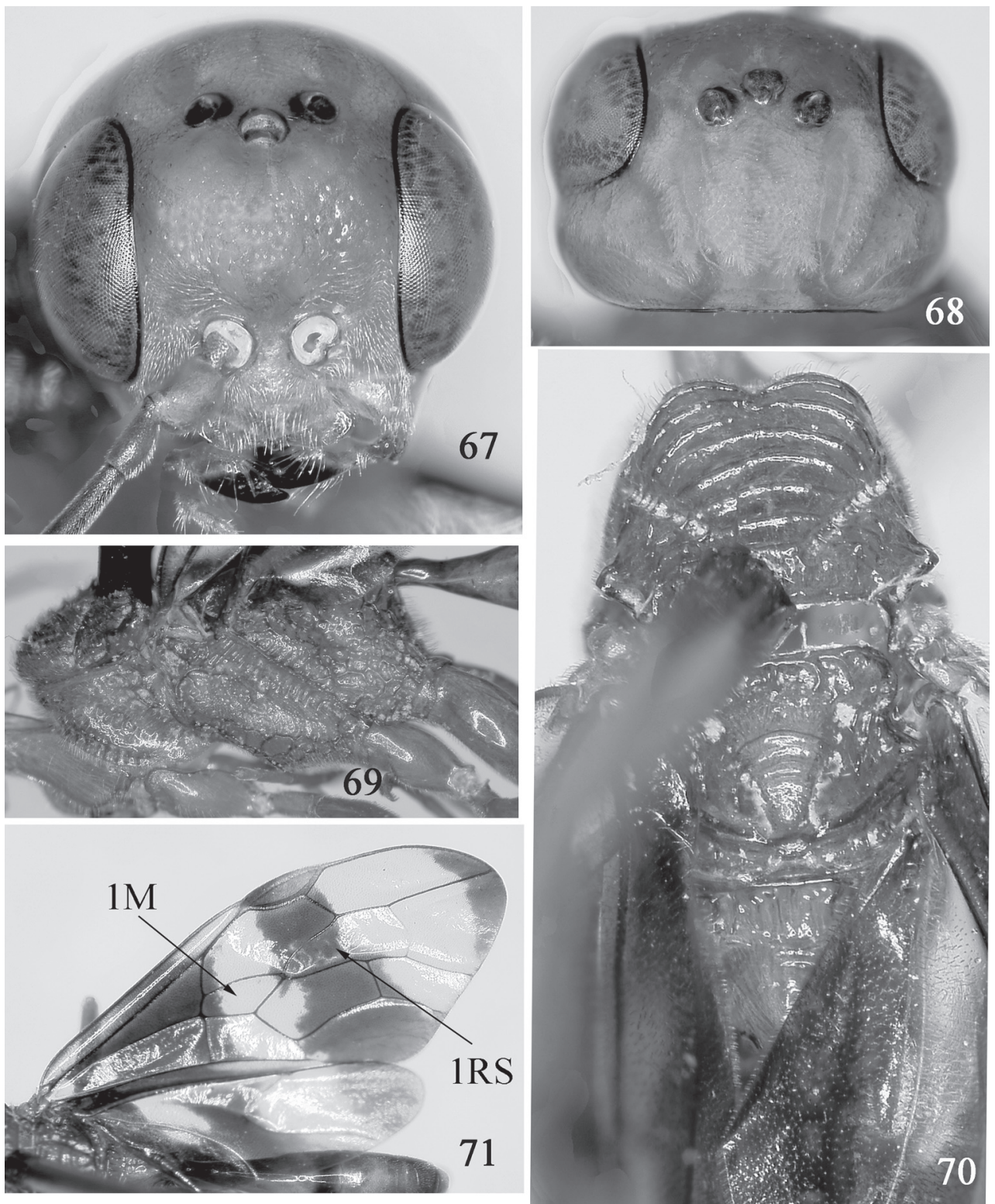

Figs 67-71: Pristaulacus virga. 67 Head, front. 68 Head, dorsal. 69 Mesosoma, lateral. 70 Mesosoma, dorsal. 71 Wings.

distance subequal to eye height; malar space $0.4 \mathrm{X}$ eye height (Fig. 67). Head behind eyes straight then sharply narrowing, head length $0.8 \mathrm{X}$ eye length (Fig. 68). Occipital carina very narrow, hardly discernable, less than a fifth diameter on an ocellus. Shining, almost impunctate. With fine white pubescence, densest on interantennal area, lower inner orbits, malar area, and clypeus (Figs 67, 68). Mesosoma: Pronotum without anteriorly projecting tooth. Propleuron smooth and shining. Mesoscutum with transverse carinae, 8-10 carinae on middle lobe; axilla reticulate, mesoscutellum with 3 or 4 arc-shaped transverse carinae, more reticulate laterally; pronotum with 
narrow scrobiculate band on anterior margin, center shining with diagonal band of fine carinae, reticulate dorsoposteriorly; mesepisternum finely punctate with coarse reticulations on lower third; mesepimeron shining with narrow scrobiculate band on posterior margin; metapleuron finely reticulate on dorsal half, coarsely reticulate on ventral half; propodeum reticulate (Figs 69, 70). Hind coxa smooth and shining, $2.5 \mathrm{X}$ longer than broad, with diagonal ovipositor guide near apex on inner surface. Tarsal claws with 5 teeth. Hind basitarsus $1.2 \mathrm{X}$ longer than length of remaining tarsal segments combined. Forewing with cells $1 \mathrm{M}$ and $1 \mathrm{Rs}$ contiguous, without vein $\mathrm{Rs}+\mathrm{M}$ (Fig. 71). Hind wing veins distinct, cells $\mathrm{Cu}$ and $\mathrm{R} 1+\mathrm{Rs}$ contiguous (as in Fig. 110). Metasoma: Shining, with fine white pubescence on tergite 2 to apex. Ovipositor length subequal to forewing length.

Male: Unknown.

Holotype: Female labeled "Mexico: Jalisco, Chamela Biol. Stn., 12 July 1989, R. Brooks, C. Michener, A. Roig Alsina, \#024” (UKAN).

Etymology: From the Latin virga, meaning stripe, referring to the striped- or banded-color pattern of the wings.

\section{Remarks:}

This is one of three species with black-banded forewings. It is separated from the other two, $P$. punctum and $P$. decorus, by the entirely orange color, lack of an anteriorly projecting tooth on the pronotum, and the transverse carinae of the mesoscutum.

\section{Pristaulacus punctum SMIтH, new species}

(Figs 72-76)

\section{Diagnosis:}

Antenna and ovipositor black; mesosoma black. Forewing black with hyaline band at center basal to stigma and hyaline band near apex apical to stigma. Head long, extended, behind eyes, shining. Mesosoma shining with closely-set punctures, without carinae. Hind coxa smooth and shining. Pronotum with two anteriorly projecting teeth, dorsal one small.

\section{Female:}

Length, $10.5 \mathrm{~mm}$; forewing length $8.0 \mathrm{~mm}$; ovipositor length, $5.5 \mathrm{~mm}$. Color: Antenna black; scape orange. Head orange with area from anterior half or more of vertex through frons to clypeus black; apex of mandible black. Legs orange; coxae, mid- and hind femora, and hind tibia dark brown to black; tarsi yellowish. Mesosoma black. Metasoma black with orange spot at base of first tergum; ovipositor black. Forewing with base, broad band below stigma widening toward posterior margin, and apex black; two bands between black areas hyaline to slightly yellowish (Fig. 76). Hind wing black at base, hyaline toward apex. Forewing stigma black, more amber on apical half; veins black, those in hyaline areas more yellowish. Head: Antennal length 2.7X head width. Lower interocular distance 1.1X eye height; malar space $0.4 \mathrm{X}$ eye height (Fig. 72). Head from above long behind eyes, straight then gradually narrowing, 1.1X eye length (Fig. 73). Occipital carina very narrow, less than a fifth diameter of an ocellus. Head smooth and shining, very fine punctures on frons, with fine white pubescence, densest on frons to clypeus and malar area (Figs 72, 73). Mesosoma: Pronotum with two anteriorly projecting teeth near dorsum. Propleuron smooth and shining. Mesosoma entirely, evenly reticulate; pronotum shining anteroventrally, with diagonal 

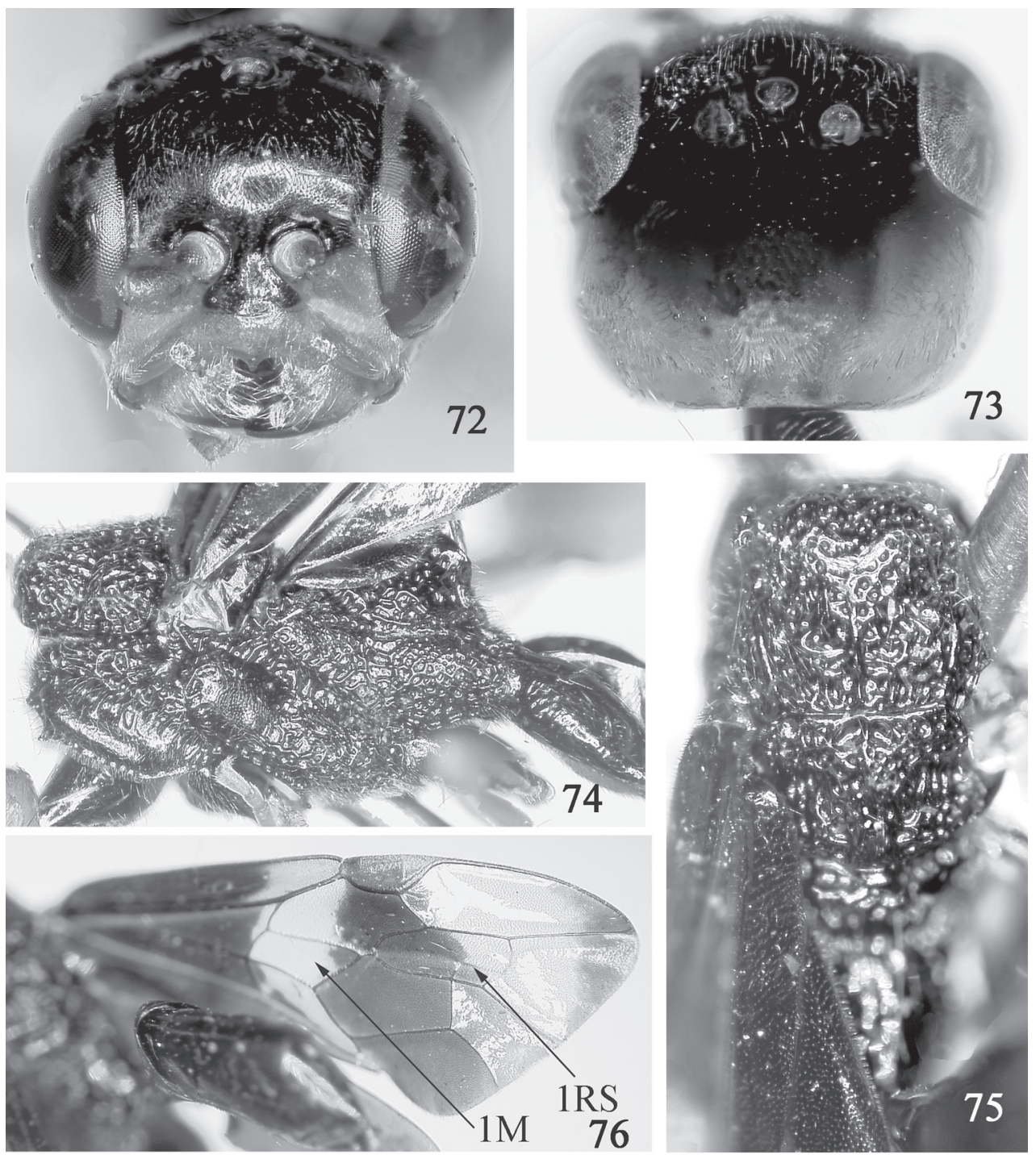

Figs 72-76: Pristaulacus punctum. $72 \mathrm{Head}$, front. $73 \mathrm{Head}$, dorsal. 74 Mesosoma, lateral. 75 Mesosoma, dorsal. 76 Wings.

scrobiculate band at center, finely reticulate dorsoposteriorly; mesepisternum shining and finely punctate on upper half, more reticulate on lower half; mesepimeron shining with scrobiculate band on posterior margin; metapleuron finely punctate on upper half, coarsely reticulate on ventral half; propodeum reticulate, smooth and shining above adjacent to metasomal insertion (Figs 74, $75)$. Hind coxa smooth, shining, $2.2 \mathrm{X}$ longer than broad; shallow ovipositor groove at apex in inner surface. Hind basitarsus 1.1X length of remaining tarsal segments combined. Forewing with cells $1 \mathrm{M}$ and 1 Rs contiguous or separated by very short vein Rs+M; costal cell broad, about 1.2X broader than stigma (Fig. 76). Tarsal claws with 6 teeth. Hind wing with veins distinct, cells $\mathrm{Cu}$ and $\mathrm{R} 1+\mathrm{Rs}$ contiguous (as in Fig. 110). Metasoma: Shining; fine white pubescence and fine punctures on segment 2 to apex. Ovipositor length about $0.7 \mathrm{X}$ forewing length. 
Male: Unknown.

Types: Holotype: Female, labeled "Los Almendros, P.N. Guanacaste, Prov., Costa Rica, 11-30 Jun 1993, E. Lopez, LN 334800_369800, \#2267,” “Costa Rica INBIO, CRI1001 126456” (INBio). Paratype: COSTA RICA: S. J. Escazu, 21-26 My 1989, F. D. Parker (1 , USU).

Etymology: From the Latin punctum, referring to the punctured or pitted mesoscutum.

\section{Remarks:}

This species is close to $P$. decorus, and both run to the same couplet in the key. They are similar in structure, but differ by the more extensive black color in P. punctum. Also, P. punctum is known only from Costa Rica and $P$. decorus only from Mexico. I have not seen specimens in between, and it is possible they represent extremes of the same species.

\section{Pristaulacus decorus SMith, new species}

(Figs 77-82)

\section{Diagnosis:}

Head black with head black between eyes; mesosoma black with pronotum orange. Forewing black with hyaline band at center basal to stigma and hyaline band near apex apical to stigma. Head long behind eyes, shining. Mesosoma with anterolateral lobes of mesonotum roundly produced; mesonotum shining, with large closely set punctures. Hind coxa smooth, shining. Pronotum with 2 anteriorly projecting teeth, dorsal on e small.

\section{Female:}

Length, $13.0 \mathrm{~mm}$; forewing length $10.0 \mathrm{~mm}$; ovipositor length, $6.0 \mathrm{~mm}$. Color: Antenna black; scape and pedicel orange. Head orange with large black area from just behind ocelli through frons to about level of antenna.; apex of mandible black. Mesosoma black with propleuron and pronotum orange. Legs orange with hind femur and tibia dark brown; tarsi yellowish. Metasoma orange; ovipositor sheath black. Forewing with base, broad band below stigma, and apex black; stigma brownish (Fig. 81). Hind wing hyaline at base, becoming black toward apex. Veins black, those in hyaline parts yellowish to brown. Head: Antennal length 2.7X head width. Lower interocular distance subequal to eye height; malar space about $0.3 \mathrm{X}$ eye height (Fig. 77). Head from above long behind eyes, straight, length of head 1.2X eye length (Fig. 78). Occipital carina very narrow, less than a fifth diameter of an ocellus. Smooth and shining, few fine punctures on frons; pubescence densest on fronts to clypeus and malar area, sparse elsewhere (Figs 77, 78). Mesosoma: Pronotum with two anteriorly projecting teeth near dorsum. Propleuron smooth and shining. Mesonotum shining with large punctures, distance between most punctures more than a puncture diameter (Fig. 80); pronotum with broad smooth and shining diagonal band, coarsely reticulate above and below band; mesopleuron with dorsoanterior finely punctate area, rest coarsely reticulate; metapleuron and propodeum coarsely reticulate (Fig. 79). Hind coxa smooth and shining, few indistinct carinae laterally, 2.0X longer than broad; ovipositor groove on inner surface indistinct. Hind basitarsus subequal to length of remaining tarsal segments combined. Tarsal claw with 6 teeth and indistinct basal lobe; lower tooth small and near basal lobe (Fig. 82). Forewing with cells $1 \mathrm{M}$ and $1 \mathrm{Rs}$ contiguous, without vein Rs+M; costal cell broad, 1.2 times broader than stigma (Fig. 81). Hind wing with veins distinct, cells $\mathrm{Cu}$ and $\mathrm{R} 1+\mathrm{Rs}$ contiguous (Fig. 81). Metasoma: Shining; fine white pubescence and fine punctures on segments 2 to apex. Ovipositor length about 0.6X forewing length. 

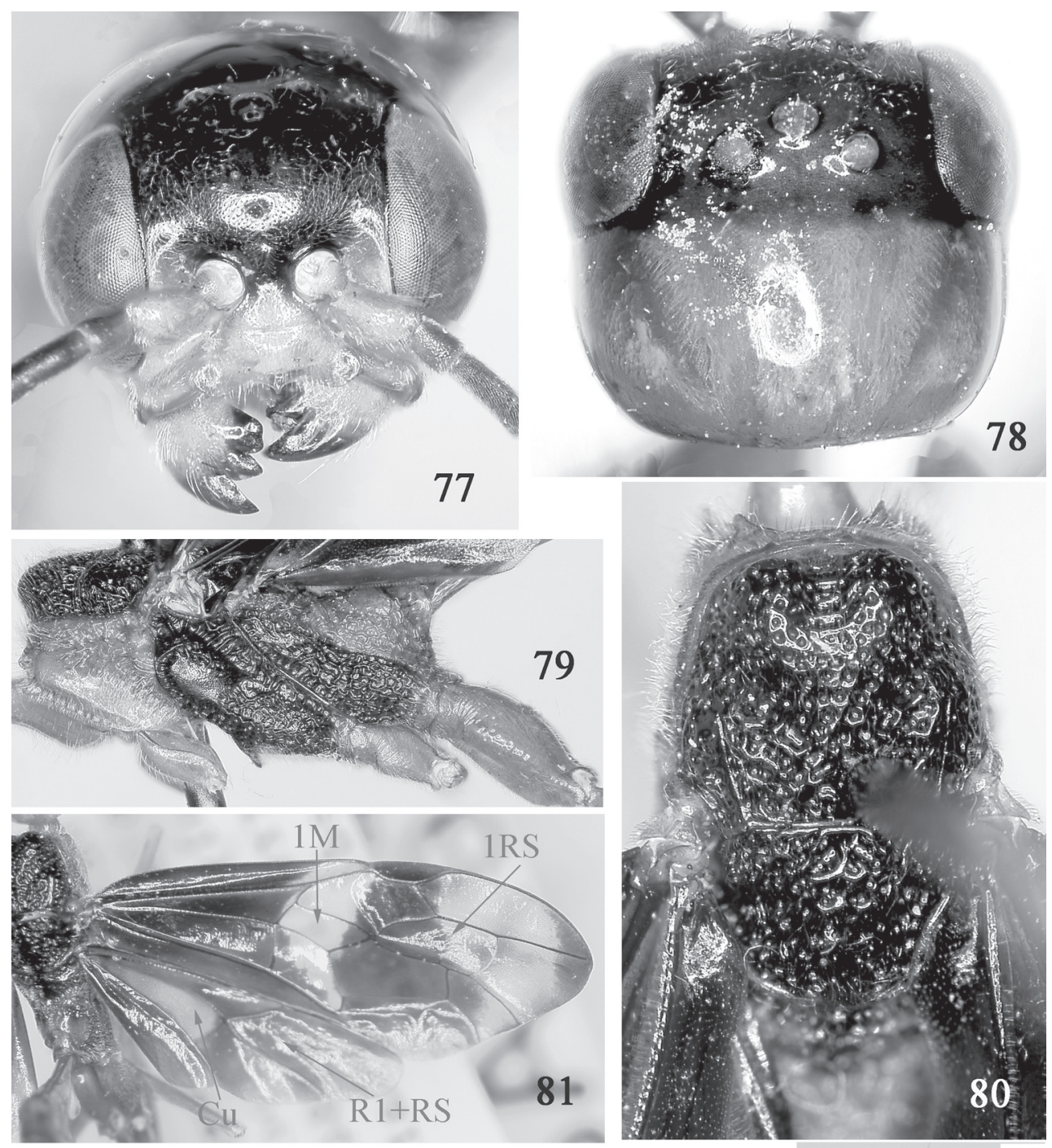

Figs 77-82: Pristaulacus decorus. 77 Head, front. 78 Head, dorsal. 79 Mesosoma, lateral. 80 Mesosoma, dorsal. 81 Wings. 82 Tarsal claws.

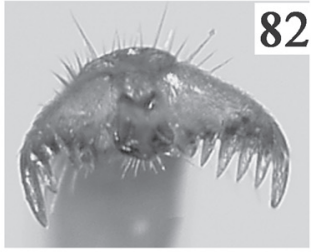

Male: Length, $13.0 \mathrm{~mm}$; forewing length, $13.0 \mathrm{~mm}$. Color and structure similar to female except: Black on head ends above antennal insertions; propleuron may be black; metasoma may be black at base or almost entirely black.

Types: Holotype: Female, labeled "13 mi. S. Cuernavaca, Mor., Mex., VII-8-1962, D. H. Janzen, Collector" (UCB). Paratypes: MEXICO: GUERRERO: Mexcala, Jun 3, 1946, J. \& D. Pallister $\left(1 o^{\star}, A M N H\right) ; 6$ mi. e. Xochipala, July 18, 1984, Carroll, Schaffner, Friedlander (1 ․ TAMU); 
Mexcala, VI-29-51, H. E. Evans, Collector (1 ㅇ, AEI). JALISCO: Chamela Biol. Stn., 11 July 1989, R. Brooks, C. Michener, A. Roig Alsina, \#015 (1 + , UKAN); 11 mi. n. Autlan, July 6, 1984, Carroll, Schaffner, Friedlander (1 + , TAMU); Chamela Res. Sta., 20 July 1986, M. Sanchez - M.T. ( 1 \% , USU), same data except 24 July 1986 (1 + , USU); Est. Biol. UNAM, Chamela, 5 km. SE Chamela, 13/14 July 1981, E. M. Fisher, collector (1 ㅇ, 1 o ${ }^{\star}$, CDA). MICHOACÁN: 36.7 km NE. Areaga, 16 July 1989, R. Borks, A. Roig, \#052, ex Vitex pyramidta (1 ${ }^{\star}$, UKAN), same data except \#053, ex. Oxalis comiculata albicans (1 $0^{\star}$, UKAN). MORELOS: Same data as holotype (2 $0^{\star} 0^{\star}$, 1 metasoma missing, UCB); 6 mi. S. Temixco, VII-16-1963, F. D. Parker, L. A. Stange, Collectors (2 ㅇ ㅇ, $10^{\star}$, UCD). NAYARIT: Arroyo Santiago, nr. Jesus Maria, VII-5-55, B. Malkin, Collector (1 ơ , UCB). OAXACA: Totolapan, 2 mi NW, 3300 ft., VII-6-1953, Univ. Kans. Mex. Expedition (1 9 head missing, UKAN); $26 \mathrm{~km}$. NE. Tapanatepec, 29 June 1981, E. M. Fisher, collector (1 + , CDA); 10 km E. De Tehuantepec, 25-V-53, Ana Maria de Buen., collector (1 ơ, AEI); nr. Totolapan, Aug. 5, 1965, Flint \& Ortiz (1 +, USNM). SINALOA: Mazatlan, 5 mi. N., VII-27-72, J. \& M. A. Chemsak, A. \& M. Michelbacher (1 +, 1 o, UCB); 5 mi. N. Mazatlan, VIII-1-1973, J. Chemsak \& E. G. Linsley (1 +, UCB); Mazatlan, 5 mi. N., VII-27-64, Scoparia dulcis, J. A. Chemsak, Collector (1 + , UCB); 8 mi. south Elota, VII-2-63, F. D. Parker, L. A. Stange, Collectors (1 ㅇ, UCD); Concordia, VII-4-1963, F. D. Parker, L. A. Stange, Collectors (1 ㅇ, UCD); 5 mi. N. of Mazatlan, VII-19-1972, Collector, C. H. Nelson (1 + , FSCA); Mazatlan, 10 km. S., July

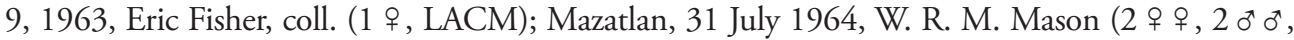
CNC). VERACRUZ: Cotaxtla Exp. Sta., Cotaxtla, VI-28-1962, D. H. Janzen, Collection (1 , $\left.10^{\star}, \mathrm{UCB}\right)$, same data except VII-1-1962 (1,$+ 10^{\star}$, UCB), same data except VII-5-1962 (1 , UCB); Anton Lizardo, 23 June 1961, L. B. Carney, \#26 (3 ㅇ ㅇ , $40^{\star} 0^{\star}$, UKAN); 1 mi. W. Anton Lizardo, 5 ft., 23 June 1961, U. Kans. Mex. Exp. (1 ơ, UKAN).

Etymology: From the Latin decorus, meaning beautiful, for one of the most strikingly colored aulacids of this region.

Hosts: No rearing records are indicated on labels. Some adults were taken from the following plants, apparently by sweeping: Vitex sp. (Lamiaceae); Oxalis corniculata L. (Oxalidaceae), and Scoparia dulcis L. (Plantaginaceae).

\section{Remarks:}

See remarks under P. punctum. This species has been collected rather frequently in Mexico.

\section{Pristaulacus aquilus SMITH, new species}

(Figs 83-86)

\section{Diagnosis:}

Orange with ocellar area and meso- and metapleura black; legs all orange. Wings and veins uniformly black. Head shining above, frons dull, sculptured. Mesonotum with large closely set punctures, without carinae. Hind coxa shining, with cross striations. Pronotum without anteriorly projecting tooth.

Female: Unknown.

Male:

Length, $14.5 \mathrm{~mm}$; forewing length $11.5 \mathrm{~mm}$. Color: Antenna orange; pedicel, flagellomeres 1 and 2, and apical 3 blackish. Head orange; apex of mandible and interocellar area black. 


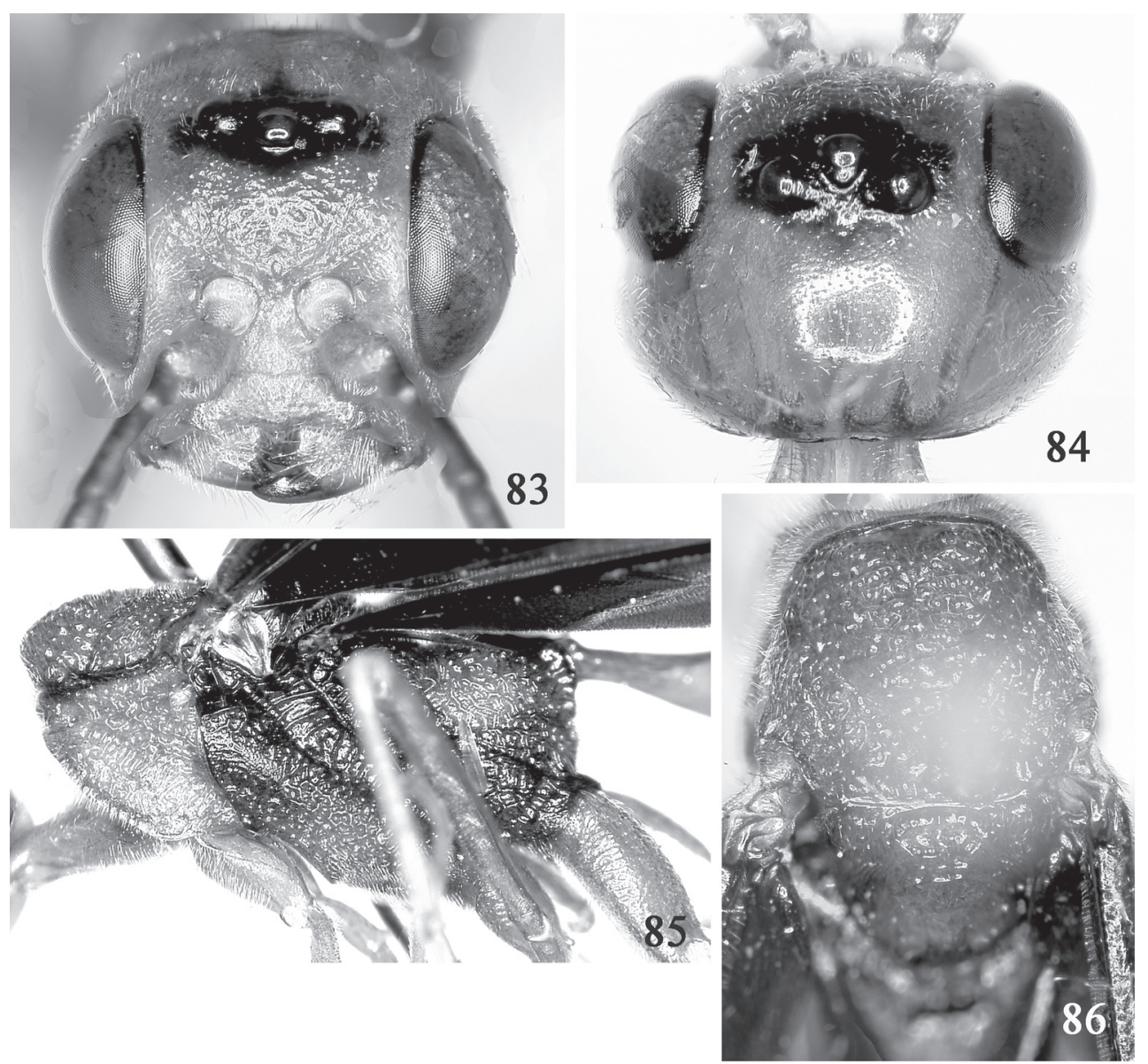

Figs 83-86: Pristaulacus aquilus. 83 Head, front. 84 Head, dorsal. 85 Mesosoma, lateral. 86 Mesosoma, dorsal.

Mesosoma orange with narrow posterior line on pronotum, upper mesepisternum, mesepimeron, metapleuron, spot on lower propodeum, and areas lateral to mesoscutellum black. Legs orange; tarsi more yellowish. Metasoma orange. Wings uniformly black; veins and stigma black. Head: Antennal length 2.6X head width. Lower interocular distance subequal to eye height; malar space $0.3 \mathrm{X}$ eye height (Fig. 83). Occipital carina very narrow, less than a fifth diameter of an ocellus. Mostly shining, covered with fine white pubescence; vertex and gena with fine punctures (Fig. 84); frons, interantennal area, and clypeus more reticulate to punctate and slightly duller than vertex with fine microsculpture (Fig. 83). Mesosoma: Pronotum without anteriorly projecting tooth. Mostly, uniformly coarsely reticulate (Figs 85, 86); propleuron smooth, shining; pronotum with somewhat scrobiculate diagonal band; posterior margin of mesopleuron scrobiculate. Hind coxa with coarse, transverse carinae; about 2.2X longer than broad. Tarsal claws with 6 teeth and small basal lobe, basal lobe appearing as a sixth tooth. Hind basitarsus $1.2 \mathrm{X}$ longer than length of remaining tarsal segments combined. Forewing with long vein $\mathrm{Rs}+\mathrm{M}$ separating cells $1 \mathrm{M}$ and $1 \mathrm{Rs}$ (as in Fig. 91). Hind wing with veins distinct, vein $\mathrm{M}$ separates cells $\mathrm{Cu}$ and $\mathrm{R} 1+\mathrm{Rs}$ (as in Fig. 104). Metasoma: Shining; fine white pubescence and fine punctures on segment 2 to apex. 
Holotype: Male labeled "Mexico, Jalisco, Chamela 26/30-IX-85, FD Parker, TL Griswold" (USU).

Etymology: From the Latin aquilus, meaning dark colored, referring to the entirely dark wings.

\section{Remarks:}

This large, shining, orange male cannot be associated with females I have seen, and it is the only species I know that has the forewing entirely black without hyaline areas.

\section{Pristaulacus torridus (BRADLEY)}

(Figs 87-92)

Tropaulacus torridus Bradley 1908: 125.-KiefFer 1912: 362.-Hedicke 1939: 17.

Aulacostethus torridus: Townes 1950: 92.-TownEs 1951: 659.

Pristaulacus torridus: CARLson 1979: 1114.-SMITH 2001: 299.

\section{Diagnosis:}

Frons finely punctate. Mesoscutum with transverse carinae. Pronotum without anteriorly projecting tooth. Hind coxa punctate, striate laterally. Wings dark on anterior half, paler on posterior half, without distinct spots.

\section{Female:}

Length, $10.0 \mathrm{~mm}$; forewing length, $9.0 \mathrm{~mm}$; ovipositor length, $8.0 \mathrm{~mm}$. Color: All orange with brownish areas on frons, lateral portions of mesoscutellum, meso- and metapleura, propodeum, and coxae; hind legs missing beyond coxae. Forewing with anterior half infuscate, posterior half subhyaline; hind wing subhyaline; veins brownish, stigma dark orange (Fig. 91). Head: Antennae missing. Lower interocular distance subequal to eye height; malar space about $0.2 \mathrm{X}$ eye height (Fig. 87). Occipital carina narrow, less than $0.2 \mathrm{X}$ diameter of an ocellus. From above, somewhat straight, then narrowing behind eyes, about $0.7 \mathrm{X}$ eye length (Fig. 88). Smooth and shining with fine white pubescence, pubescence densest on lower frons, lower inner orbits and malar area; gena and vertex impunctate; frons with few widely scattered punctures, farther apart than puncture diameters, somewhat microsculptured between punctures (Figs 87, 88). Mesosoma: Pronotum without anteriorly projecting tooth. Propleuron finely punctured. Mesoscutal middle lobe with transverse sculpturation; mesoscutal lateral lobes, axillae, and mesoscutellum more reticulate, with indication of transverse sculpturation at middle of mesoscutellum; pleura and propodeum mostly reticulate with finely punctate area on dorsal mesopleuron (Figs 89, 90, 92). Hind coxa punctured, more striate laterally, about 2.2X longer than broad (Fig. 92), with diagonal ovipositor groove near apex on inner surface. Tarsal claws with 5 teeth and indistinct basal lobe. Forewing with long vein Rs+M separating cells $1 \mathrm{M}$ and RS (Fig. 91). Hind wing with veins distinct, cells $\mathrm{Cu}$ and $\mathrm{R} 1+\mathrm{Rs}$ separated by vein $\mathrm{M}$ (as in Fig. 104). Metasoma: Smooth, shining, with fine white pubescence on segments 3 to apex. Ovipositor length about 0.9X forewing length.

Male: Unknown

Holotype: Described from “one female” labeled "Brownsville, Texas, June," “2268," "TYPE Tropaulacus torridus J. Chester Bradley [red].” (UKAN). 


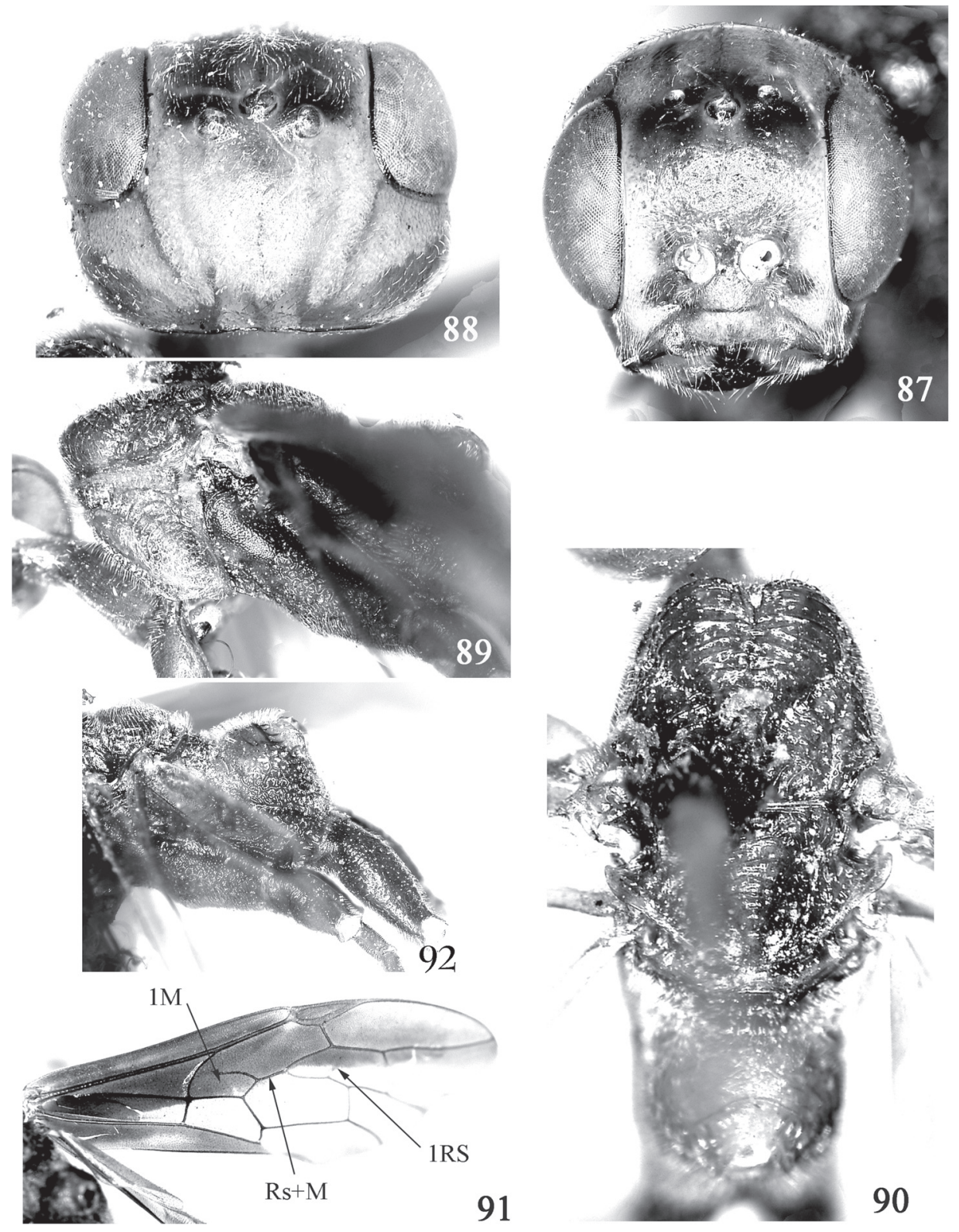

Figs 87-92: Pristaulacus torridus. $87 \mathrm{Head}$, front. $88 \mathrm{Head}$, dorsal. 89 Mesosoma, lateral. 90 Mesosoma, dorsal. 91 Wings. 92 Posterior portion of mesosoma and mid- and hind coxae.

\section{Remarks:}

The holotype seems faded, but this species can be separated by characters given in the key. The other species with the anterior half of the forewing black and the posterior half hyaline to yellowish hyaline are $P$. anteala and $P$. nigricoxae. The transverse carinae of the mesoscutum and duller punctate frons are shared by $P$. torridus and $P$. anteala, but $P$. torridus has the mesosoma almost entirely orange to red brown and a more punctate rather than reticulate frons. 


\section{Pristaulacus anteala SMITH, new species}

(Figs 93-97)

\section{Diagnosis:}

Head orange with frons between eyes black; antenna black. Mesosoma with mesoscutum and anterior portion of pronotum orange. Forewing with anterior half black, posterior half nearly clear hyaline. Head shining, frons finely punctate. Mesoscutum with transverse carinae. Hind coxa with punctures and cross striations. Pronotum without anteriorly projecting tooth.

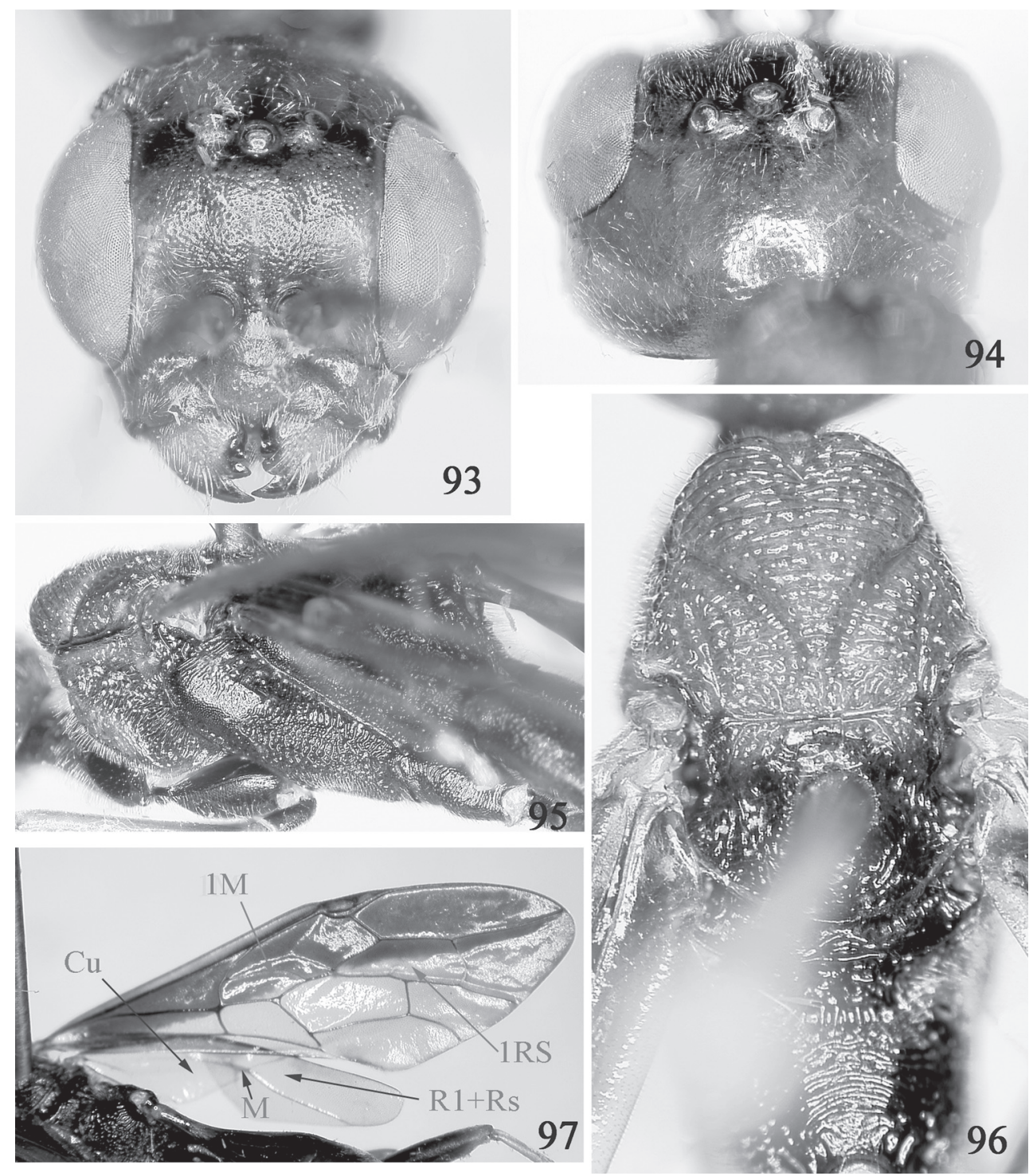

Figs 93-97: Pristaulacus anteala. 93 Head, front. $94 \mathrm{Head}$, dorsal. 95 Mesosoma, lateral. 96 Mesosoma, dorsal. 97 Wings. 


\section{Female:}

Length, $14.0 \mathrm{~mm}$; forewing length, $12.0 \mathrm{~mm}$; ovipositor length, $7.5 \mathrm{~mm}$. Color: Antenna black; scape orange. Head orange with large black area on frons, extending from hind ocelli to above antenna with extension through interantennal area to clypeus, with inner orbits narrowly orange; apex of mandible black. Mesosoma black; Propleuron orange ventrally; band on posterior margin of pronotum and laterally on anterior margin, and tegula orange. Legs with coxae and most of trochanters black; basal part of mid- and most of hind femora black except apex of hind femur; tibiae and tarsi yellow orange. Metasoma black with narrow posterior margins of segments and base of first segment orange. Ovipositor sheath yellowish with apex black. Forewing with anterior half black, posterior half hyaline (Fig. 97); costa, stigma, and vein $2 \mathrm{r}$ of forewing dark orange, remaining veins black; hind wing hyaline to slightly yellowish; veins and stigma brown. Head: Antennal length 2.2X head width. Lower interocular distance subequal to eye height; malar space $0.3 \mathrm{X}$ eye height (Fig. 93). Occipital carina very narrow, less than a fifth diameter of an ocellus. Shining, with fine white pubescence; vertex and gena with fine punctures (Fig. 94); frons more densely punctate than vertex with close punctures, interspaces ridgelike and much shorter than puncture diameters; interantennal area and clypeus finely punctate (Fig. 93). Mesosoma: Pronotum without anteriorly projecting tooth. Mesoscutal middle lobe with transverse carinae; mesoscutal lateral lobes, axillae, and mesoscutellum more reticulate (Fig. 96). Propleuron shining; pleura and propodeum finely reticulate, dosoanterior area of mesopleuron finely punctate (Fig. 95). Hind coxa densely punctured with distinct transverse carinae; about $2.1 \mathrm{X}$ longer than broad. Tarsal claws with 5 teeth and small basal lobe. Hind basitarsus $1.4 \mathrm{X}$ longer than length of remaining tarsal segments combined. Forewing with cells $1 \mathrm{M}$ and $1 \mathrm{Rs}$ contiguous not separated by vein $\mathrm{Rs}+\mathrm{M}$ (Fig. 97). Hind wing with veins distinct, cells $\mathrm{Cu}$ and $\mathrm{R} 1+\mathrm{Rs}$ separated by vein $\mathrm{M}$ (Fig. 97). Metasoma: Shining; fine white pubescence on segment 2 to apex. Ovipositor length about $0.7 \mathrm{X}$ forewing length.

Male: Unknown.

Holotype: Female, labeled "Estacion Santa Rosa, P.N. Santa Rosa, Prov. Guanacaste, Costa Rica, 300 m, Jun 1993, W. Hallwachs, D. H. Janzen, LN 31300_359800 \#2249," “Costa Rica, INBIO CRI001 935907” (INBio).

Etymology: From the Latin ante (anterior) and ala (wing), referring to the dark- colored anterior portion of the forewing.

\section{Remarks:}

See remarks under $P$. torridus.

\section{Pristaulacus triclora SMITH, new species}

(Figs 98-101)

\section{Diagnosis:}

Antenna orange. Mesosoma orange with pleura black; coxae and femora black. Forewing black with more or less three hyaline areas, at center of anterior margin basal to stigma, on anteroapical margin apical to stigma, and on posterior margin posterior to stigma. Head shining, frons punctate. Mesonotum with large closely set punctures. Hind coxa with punctures and cross striations. Pronotum without anteriorly projecting tooth. 


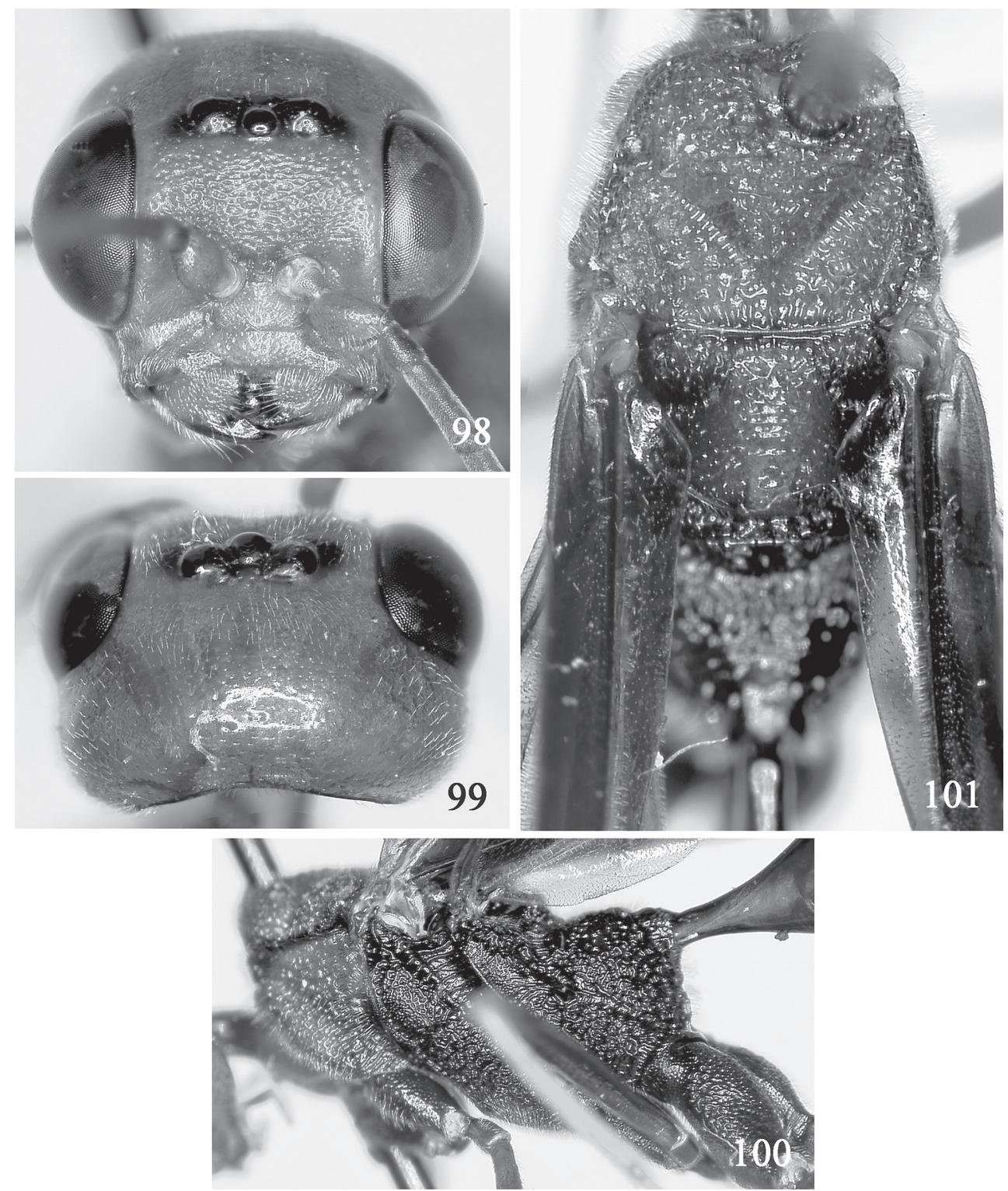

Figs 98-101: Pristaulacus triclora. 98 Head, front. 99 Head, dorsal. 100 Mesosoma, lateral. 101 Mesosoma, dorsal.

\section{Female:}

Length, $12.0 \mathrm{~mm}$; forewing length, $10.5 \mathrm{~mm}$; ovipositor length, $6.5 \mathrm{~mm}$. Color: Antenna orange; pedicel and first and apical flagellomeres brown. Head orange; interocellar area and apex of mandible black. Mesosoma black with propleuron, most of pronotum except anteroventral corner, mesoscutum, and mesoscutellum orange. Legs with coxae and trochanters black, forefemur brown, mid- and hind femora black; tibiae and tarsi yellow. Metasoma dark orange; black spot at base of first segment. Ovipositor sheath yellow with apex black. Forewing with black and hyaline pattern; 
black with oval area near anterior margin basal to stigma, anterior portion of radial cell, large area on apicoventral area, and extreme posterior margin hyaline; Costa, subcosta and marginal radial veins orange, remaining veins black in black areas, brownish in hyaline areas. Hind wing blackish with anterior half more hyaline, veins brownish in paler areas, black in black areas. Head: Antennal length 2.2X head width. Lower interocular distance $1.1 \mathrm{X}$ eye height, malar apace $0.3 \mathrm{X}$ eye height (Fig. 98). Occipital carina very narrow, less than a fifth diameter of an ocellus. Head from above rounded and narrowing behind eyes, distance behind eyes subequal to eye length. Shining with fine white pubescence. Vertex and gena with scattered fine punctures (Fig. 99); frons reticulate; interantennal area and clypeus punctate (Fig. 98). Mesosoma: Propleuron shining with few scattered punctures. Pronotum without anteriorly projecting tooth. Mesonotum reticulate; axillae and mesoscutellum with few large punctures, interspaces on mesoscutellum mostly wider than puncture diameters; few fine transverse carinae at center of mesoscutellum (Fig. 101); mesepimeron more finely reticulate than rest of mesosoma, posterior margin scrobiculate (Fig. 100). Hind coxa about $2 \mathrm{X}$ longer than broad, densely punctured with distinct transverse carinae; with diagonal ovipositor guide near apex on inner surface. Tarsal claws with 5 teeth and an acute basal lobe, basal lobe appearing as a sixth tooth. Tarsal claws apparently with 6 teeth, basal most tooth small, appearing as basal lobe. Hind basitarsus 1.3X longer than length of remaining tarsal segments combined. Forewing with long vein Rs+M separating cells $1 \mathrm{M}$ and $1 \mathrm{Rs}$ (as in Fig. 91). Hind wing with veins distinct, cells $\mathrm{Cu}$ and $\mathrm{R} 1+\mathrm{Rs}$ contiguous (as in Fig. 110). Metasoma: Segments 2 to apex with fine white pubescence and finely punctate. Ovipositor length $0.6 \mathrm{X}$ forewing length.

Male: Unknown.

Holotype: Female, labeled “Mexico: Oaxaca, 27 mi SW Salina Cruz, VII-14-1987, R. Wharton” (TAMU).

Etymology: From the Latin tri (three) and clora (clear), referring to the three yellowish to hyaline spots on the forewing.

\section{Remarks:}

The maculation of the forewing, shining head with the reticulate frons, and reticulate mesoscutum are distinctive for this species.

\section{Pristaulacus nigricoxae SMITH, new species}

(Figs 102-105)

\section{Diagnosis:}

Mesosoma with only mesonotum and pronotum orange. Legs with coxae black, rest orange. Forewing with anterior half black, posterior half paler, to hyaline. Head shining. Mesoscutum with transverse carinae. Hind coxae with punctures and cross striations. Pronotum without anteriorly projecting tooth.

\section{Female:}

Length, $10.0 \mathrm{~mm}$; forewing length $10.0 \mathrm{~mm}$; ovipositor length, $8.0 \mathrm{~mm}$. Color. Antenna orange, pedicel and flagellar segment 3 and 4 black (broken past 4). Head orange with black spot on each side of occipital foramen. Mesosoma black; upper and lower surfaces of propleuron, pronotum except black spot on lower third, and mesonotum except black anterior margin and lateral sides of mesoscutellum orange. Legs orange with coxae black and foretrochanter brownish, mid- and hind 

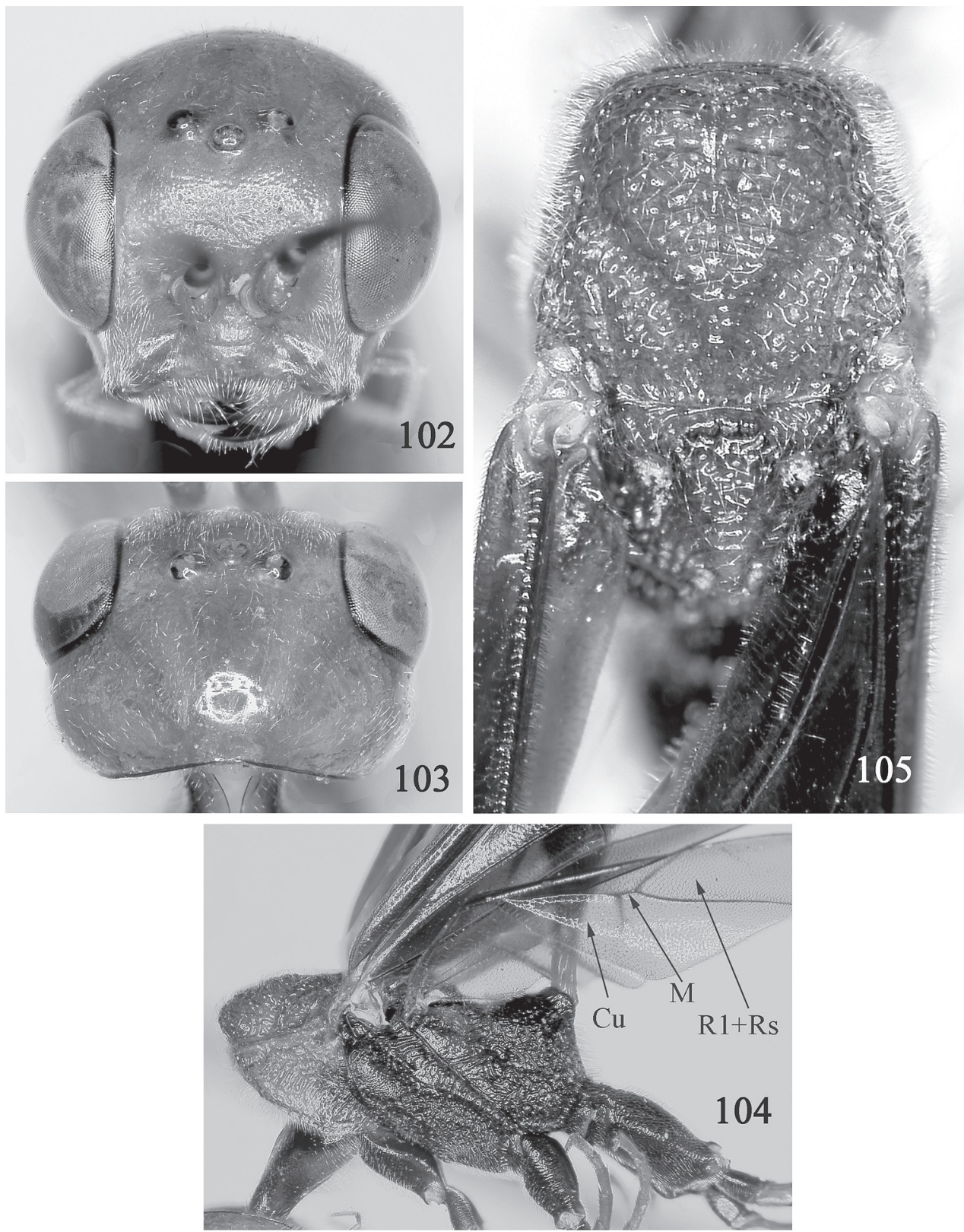

Figs 102-105: Pristaulacus nigricoxae. 102 Head, front. 103 Head, dorsal. 104 Mesosoma, lateral. 105 Mesosoma, dorsal.

trochanters black. Metasoma orange with apex of first segment and lateral areas of segments 3-5 blackish; ovipositor sheath orange with apex black. Forewing with anterior half black, posterior half hyaline to slightly yellowish, stigma dark orange with black at center, marginal radial vein and $2 \mathrm{r}$ orange, remaining veins black; hind wing almost uniformly blackish; veins and stigma black. Head: Lower interocular distance subequal to eye height; malar space about $0.3 \mathrm{X}$ eye height (Fig. 102). 
Head from above straight behind eyes then narrowing posteriorly, length of head about $0.7 \mathrm{X}$ eye length (Fig. 103). Occipital carina very narrow, less than a fifth diameter of an ocellus. Shining with fine white pubescence, pubescence denser on lower inner orbits and malar area. Vertex and gena practically impunctate (Fig. 103); frons very finely reticulate (Fig. 102). Mesosoma: Anterior margin of pronotum without anteriorly projecting tooth. Reticulate; propleuron shining, with few punctures laterally and dorsally; central diagonal band on pronotum and posterior margin of mesopleuron scrobiculate; mesepimeron with finer sculpture than rest of mesosoma (Figs 104, 105). Hind coxa about $2.1 \mathrm{X}$ longer than broad, densely punctured with distinct transverse carinae; diagonal ovipositor guide near apex on inner surface. Hind basitarsus $1.4 \mathrm{X}$ longer than length of remaining tarsal segments combined. Tarsal claws with 5 teeth plus small basal lobe, lower tooth smallest. Forewing with cells $1 \mathrm{M}$ and $2 \mathrm{RS}$ separated by long vein Rs+M (as in Fig. 91). Hind wing with cells $\mathrm{Cu}$ and $\mathrm{R} 1+\mathrm{Rs}$ separated by vein M (as in Fig. 104). Metasoma: Segments 2 to apex with fine white pubescence and with fine punctures. Ovipositor length $0.8 \mathrm{X}$ forewing length.

Male: Unknown.

Types: Holotype: Female, labeled "Mexico: Guerrero, 32 miles southeast Petatlan, July 10, 1985, Jones, Schaffner” (TAMU). Paratype: Est. Palo Verde, 10 m, Ref. Nac. Fauna Silv. R. L. Rodriguez, Prov. Guan., Costa Rica, U. Chavarria, May 1991, L-N-259000, 388400" “Costa Rica, INBIO CRI000 510783” (1 \&, INBio).

Etymology: From the Latin niger (black) and coxae, referring the black coxae, contrasting with the bright orange of the rest of the legs.

\section{Remarks:}

The paratype has the interocellar area blackish, most of the hind femur black, and more black on the metasoma with the apical half of the first segment and the entire second segment black. Also, the transverse carinae on the mesoscutum are more distinct. See remarks under $P$. torridus.

\section{Pristaulacus unimacula SMITH, new species}

(Figs 106-110)

\section{Diagnosis:}

All orange except hind femur black. Wings black with paler to hyaline spot at center of anterior margin just basal to stigma. Head shining. Mesonotum densely punctate, without transverse carinae. Hind coxa smooth, shining. Pronotum without anteriorly projecting tooth.

\section{Female:}

Length, $11.0 \mathrm{~mm}$; forewing length $9.0 \mathrm{~mm}$; ovipositor length $6.0 \mathrm{~mm}$. Color: Antenna with scape and pedicel orange, flagellar segments 2 and 3 black (broken beyond 4). Head orange. Mesosoma orange with posterior spot and narrow medial line on venter of propleuron, narrow anterior margin of pronotum, mesosternum, and extreme lower portion of metapleuron black. Legs with forecoxa black, mid- and hind coxae orange with black on inner surfaces; trochanters orange; femora black except extreme base and apex orange; fore- and midtibiae yellowish, hind tibia with basal half yellow, apical half black; tarsi yellow. Metasoma orange with lateral and ventral portions of segments 1-6 and medial spot on tergites 2-5 blackish; ovipositor sheath black with white streak on outer surface of basal half. Forewing almost completely black with hyaline to yellowish spot near anterior margin basal to stigma (Fig. 110); hind wing uniformly black; veins and stigma 


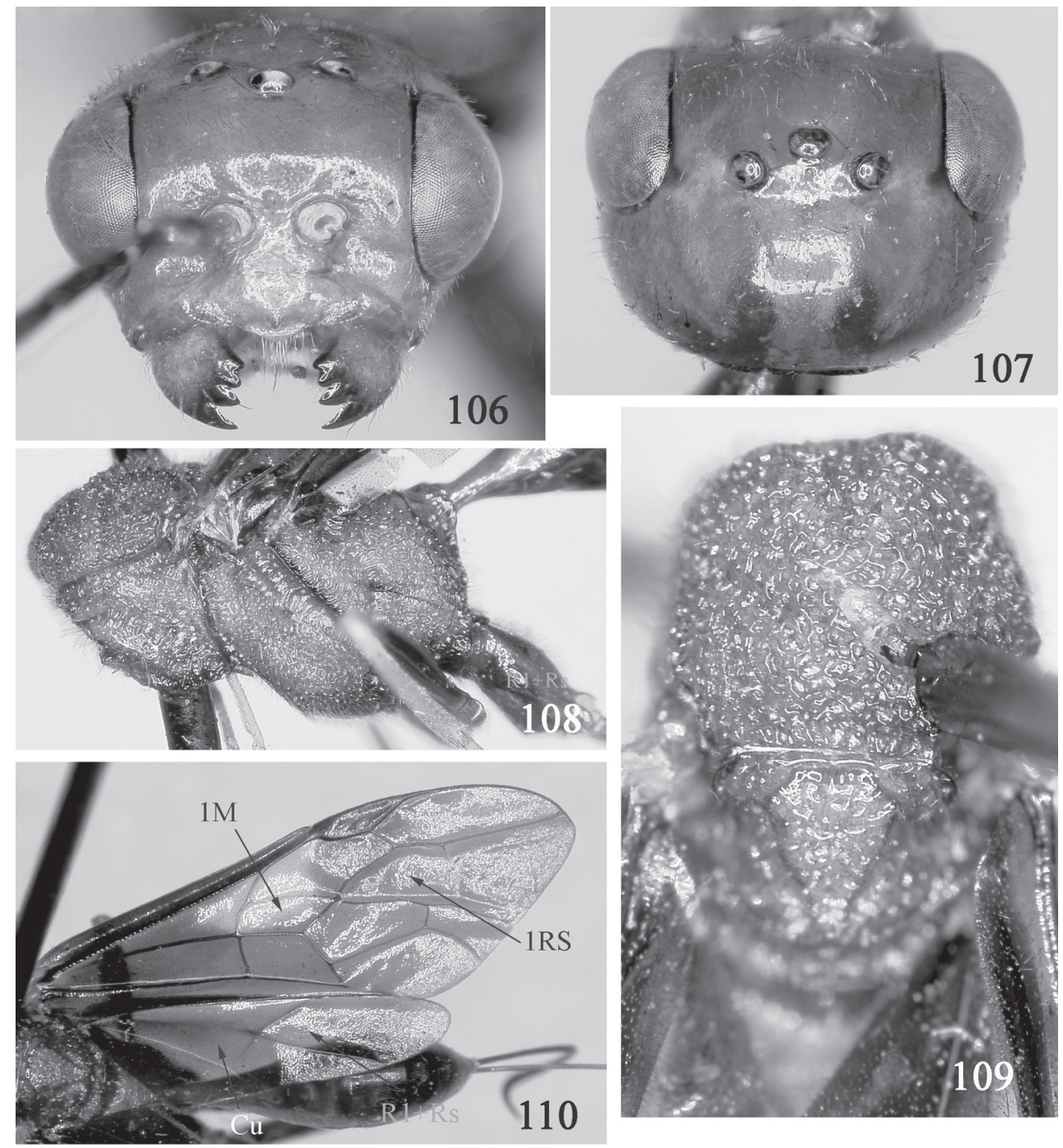

Figs 106-110: Pristaulacus unimacula. $106 \mathrm{Head}$, front. $107 \mathrm{Head}$, dorsal. 108 Mesosoma, lateral. 109 Mesosoma, dorsal. 110 Wings.

black. Head: Lower interocular distance $1.4 \mathrm{X}$ eye height, very slightly longer; malar space $0.25 \mathrm{X}$ eye height (Fig. 106). Occipital carina very narrow, less than a fifth diameter of an ocellus. Head from above long, roundly narrowing behind eyes, about subequal to eye length (Fig. 107). Shining, practically impunctate, with fine white pubescence (Figs 106, 107). Mesosoma: Pronotum without anteriorly projecting tooth. Propleuron shining, with few punctures laterally; rest of mesosoma shining, reticulate; hind margin of mesopleuron narrowly scrobiculate (Figs 108, 109). Hind coxa about $2 \mathrm{X}$ longer than broad; smooth and shining (Fig. 108). Tarsal claws with 5 teeth, lower tooth smallest. Hind basitarsus 1.1X length of remaining tarsal segments combined. Forewing with cells $1 \mathrm{M}$ and 1 Rs contiguous, without connecting vein Rs+M (Fig. 110). Hind wing with veins distinct, cells $\mathrm{Cu}$ and $\mathrm{R} 1+\mathrm{Rs}$ contiguous (Fig. 110). Metasoma: Segments 2 to apex with fine white pubescence and fine punctures. Ovipositor length about $0.7 \mathrm{X}$ forewing length. 
Male: Unknown.

Holotype: Female, labeled "Malpica, Mexico, Sinaloa, 29 June 1961, R. A. Scheibner" (MSU).

Etymology: From the Latin uni (one) and macula (spot), referring to the one hyaline spot on the forewing basal to the stigma.

\section{Remarks:}

The single hyaline spot at the anterocentral part of the forewing is not known in other Pristaulacus species.

\section{Pristaulacus postala SMITH, new species}

(Figs 111-114)

\section{Diagnosis:}

All orange except antennal flagellum and hind femur black. Forewing with posterior half black, anterior half paler, to hyaline. Head shining. Mesonotum densely punctate without transverse carinae. Hind coxa smooth, shining. Pronotum with one short, blunt anteriorly projecting tooth.

\section{Female:}

Length, $14.0 \mathrm{~mm}$; forewing length, $10.0 \mathrm{~mm}$; ovipositor length, $7.0 \mathrm{~mm}$. Color: Antenna with scape and pedicel orange, flagellar segment 3-5 black, 6 orange (broken beyond 6). Head, mesosoma, and metasoma orange with lateral portion of venter of segments 2-4 or 5 blackish. Legs orange; midfemur brownish; hind femur black except extreme apex orange; hind tibia brownish yellow, apex darkest; tarsi white with apical segment black. Ovipositor sheath black with white streak on outer surface of basal third. Forewing with anterior half hyaline to yellowish, posterior half black; hind wing black, somewhat paler on anterior half; stigma and anterior veins yellowish, veins black in black portion. Head: Lower interocular distance 1.1X eye height, very slightly longer; malar space about $0.3 \mathrm{X}$ eye height (Fig. 111). From above, head behind eyes roundly narrowing, length behind eyes about $0.9 \mathrm{X}$ eye length (Fig. 112). Occipital carina very small, less than a fifth diameter of an ocellus. Entirely shining and practically impunctate with white pubescence; frons, interantennal area, and clypeus with very few fine scattered punctures (Figs 111, 112). Mesosoma: Pronotum with one short, blunt anteriorly projecting tooth. Propleuron shining, smooth, with few fine punctures especially dorsally; rest of mesosoma shining, almost evenly reticulate with central diagonal band on pronotum and narrow posterior margin of mesopleuron somewhat scrobiculate (Figs 113, 114). Hind coxa about 2.0X longer than broad, smooth and shining. Tarsal claws with 5 teeth, lower tooth smallest. Hind basitarsus about 1.3X longer than length of remaining tarsal segments combined. Forewing with very short vein Rs+M separating cells $1 \mathrm{M}$ and $1 \mathrm{Rs}$ (as in Fig. 157). Hind wing with veins distinct, cells $\mathrm{Cu}$ and $\mathrm{R} 1+\mathrm{Rs}$ contiguous (as in Fig. 110). Metasoma: Segments 2 to apex with fine white pubescence and fine punctures. Ovipositor length about $0.7 \mathrm{X}$ forewing length.

Male: Unknown.

Holotype: Female, labeled "10 mi. north Holpechen Camp, Mex., IV-17-1962, L. A. Stange, Collector" (UCD).

Etymology: From the Latin post (rear) and ala (wing), referring to the black posterior part of the forewing. 

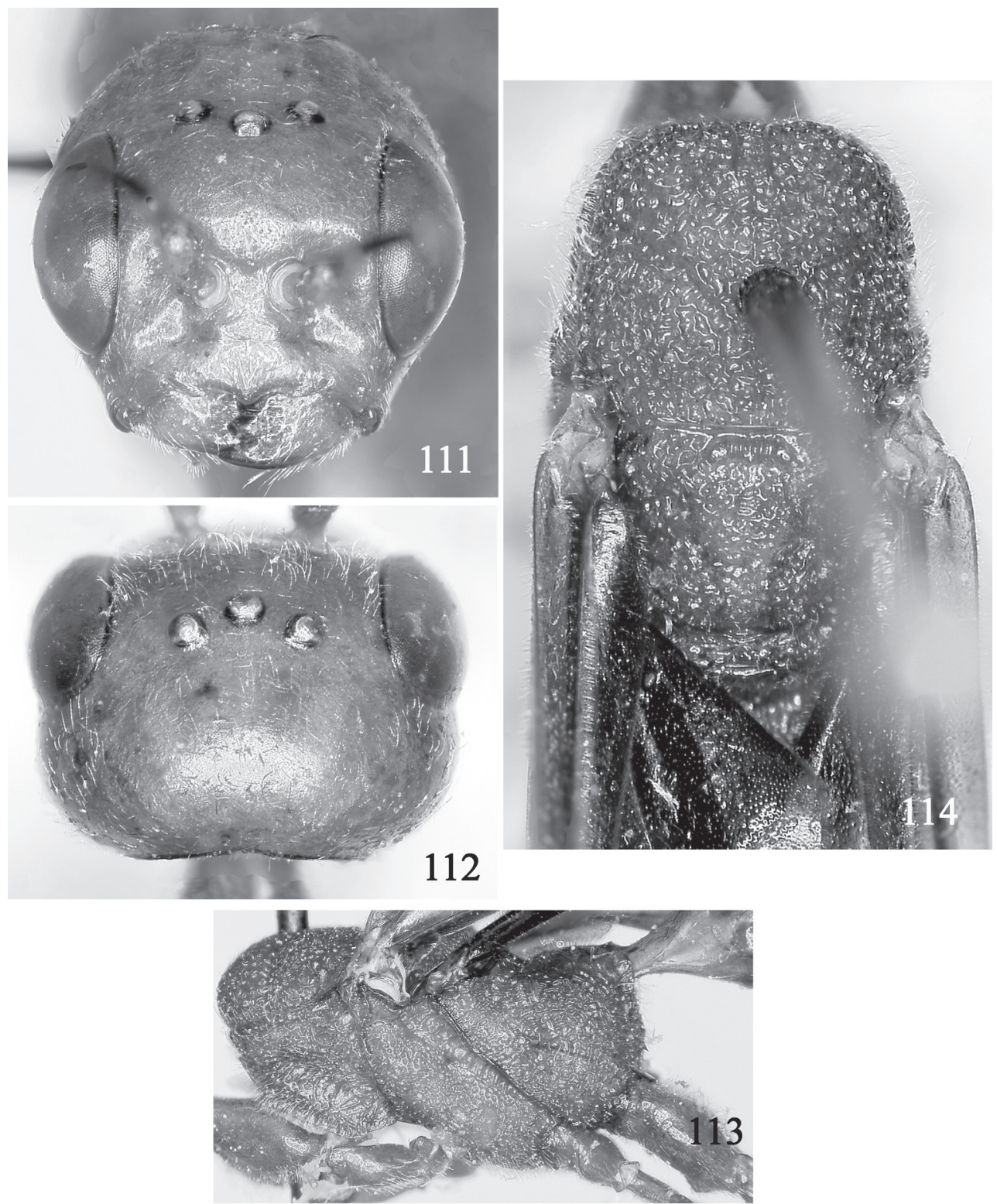

Figs 111-114: Pristaulacus postala. 111 Head, front. 112 Head, dorsal. 113 Mesosoma, lateral. 114 Mesosoma, dorsal.

\section{Remarks:}

This is the only species I have seen that has the posterior half of the forewing black and the anterior half hyaline to yellowish. 


\section{Pristaulacus stangei SMITH, new species}

(Figs 115-119)

\section{Diagnosis:}

All orange; antenna with white band. Forewing black with paler to hyaline spot at center of anterior margin just basal to stigma; costa and stigma orange. Head shining. Mesonotum densely punctate, without transverse carinae. Hind coxa smooth, shining, with very fine cross striations. Pronotum with a blunt anteriorly projecting tooth.
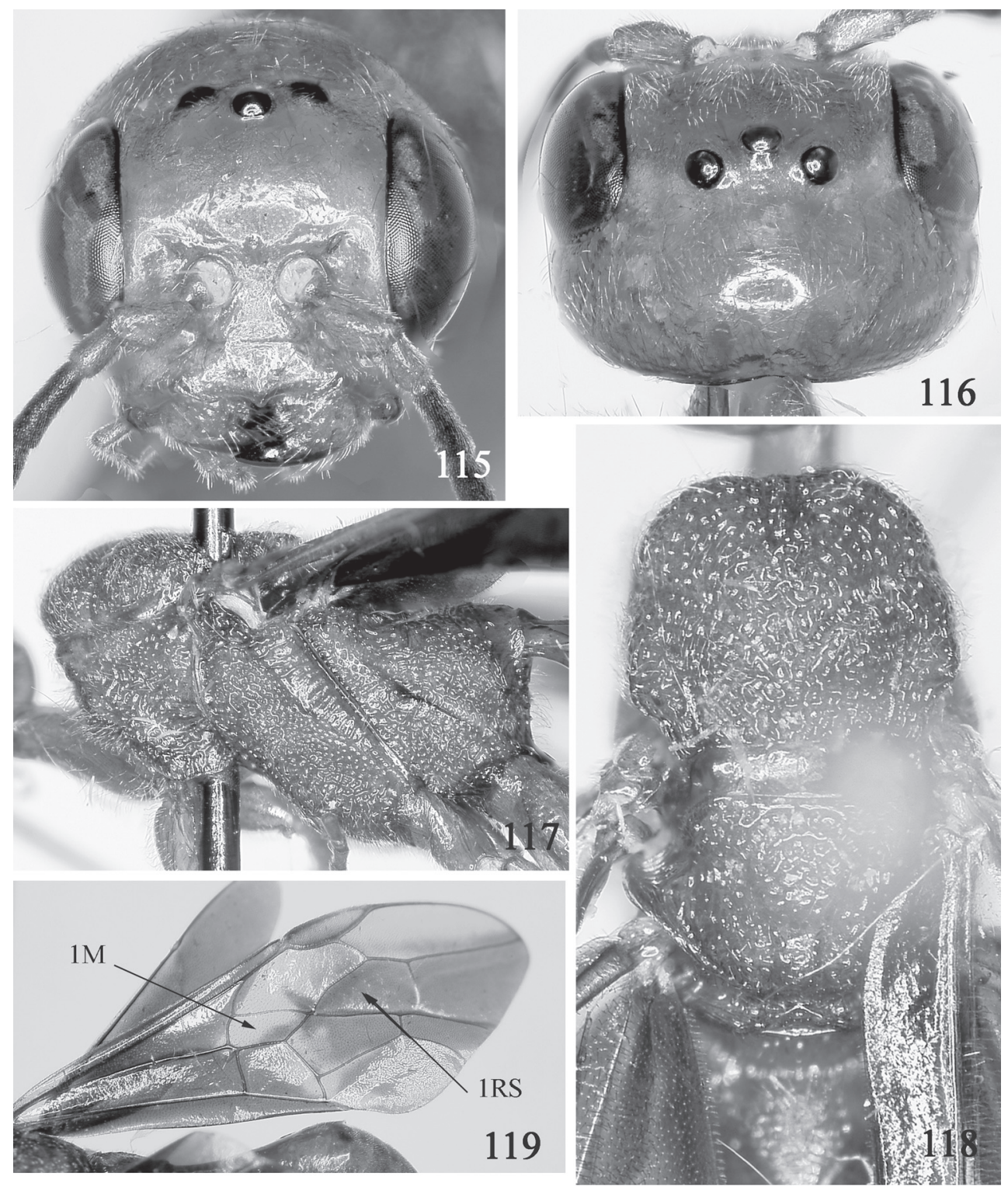

Figs 115-119: Pristaulacusstangei. $115 \mathrm{Head}$, front. $116 \mathrm{Head}$, dorsal. 117 Mesosoma, lateral. 118 Mesosoma, dorsal. 119 Wings. 


\section{Female:}

Length, $10.5 \mathrm{~mm}$; forewing length, $9.0 \mathrm{~mm}$; ovipositor length, $7.0 \mathrm{~mm}$. Color: Antenna with scape and pedicel orange; flagellar segment 3 and outer surface of 4 and 5 black, inner surface of 4 and 5 and all of 6-7 orange, segments 8 and 9 white, segments 10 to apex black. Head, body, and legs orange; tarsi yellowish; ovipositor sheath black with white streak on outer surface of basal half. Forewing black at base and black central spot on apical half with intervening hyaline to yellowish spots from radial cell to stigma and posteriorly to ventral apical area (Fig. 119). stigma and veins in hyaline to yellowish part orange to brownish, those in black areas black; hind wing uniformly black, veins black. Head: Antennal length 2.5X head width. Lower interocular distance subequal to eye height; malar space about $0.3 \mathrm{X}$ eye height (Fig. 115). Head from above broad behind eyes, then roundly narrowing, head length about $0.7 \mathrm{X}$ eye length (Fig. 116). Occipital carina very small, less than a fifth diameter of an ocellus. Shining with white pubescence, practically impunctate; few very fine widely scatter punctures on frons, slightly denser on supraclypeal area and clypeus (Figs 115, 116). Mesosoma: Anterior margin of pronotum with short, blunt anteriorly projecting tooth. Propleuron shining, with very fine scattered punctures. Rest of mesosoma shining, evenly reticulate, posterior margin of mesopleuron narrowly scrobiculate and upper part of pronotum and metapleuron more punctate (Figs 117, 118). Hind coxa smooth and shining, $2 \mathrm{X}$ longer than broad, with diagonal ovipositor guide near apex on inner surface. Hind basitarsus about 1.2X length of remaining tarsal segments combined. Tarsal claws with 5 teeth, lower tooth smallest. Forewing with cells $1 \mathrm{M}$ and $1 \mathrm{Rs}$ contiguous not separated by vein $\mathrm{Rs}+\mathrm{M}$ (Fig. 119). Hind wing with veins distinct, cells $\mathrm{Cu}$ and $\mathrm{R} 1+\mathrm{Rs}$ contiguous (as in Fig. 110). Metasoma: Segments 2 to apex with fine white pubescence and fine punctures. Ovipositor length $0.8 \mathrm{X}$ forewing length.

Male: Unknown.

Types: Holotype: Female, labeled "Honduras: Francisco, Morazan, 25 km. S. Talanga (Hacienda Hachado), 11-V-1993, L. Stange \& R. Miller" (FSCA). Paratype: \#15 - "Los Mayos, Sinaloa, Mex., VII-24-52, J. D. Lattin, Collector" (1 ㅇ, UCB).

Etymology: Named for Lionel Stange, Florida Department of Agriculture and Consumer Services, Florida State Collection of Arthropods, Gainesville, FL.

\section{Remarks:}

The paratype has the costal cell more infuscate than the yellowish costal cell of the holotype. I have not seen other species of Pristaulacus with the maculation as in Fig. 119.

\section{Pristaulacus tenuis SMITH, new species}

(Figs 120-123)

\section{Diagnosis:}

Head yellow with black spot on vertex; mesosoma black, pronotum yellow; metasoma and legs yellow. Wings hyaline without black spots. Head shining. Mesosoma with anterolateral corners of mesonotum lobed; mesoscutal middle lobe with transverse carinae. Hind coxa shining, smooth. Pronotum without anteriorly projecting tooth.

Female: Unknown. 

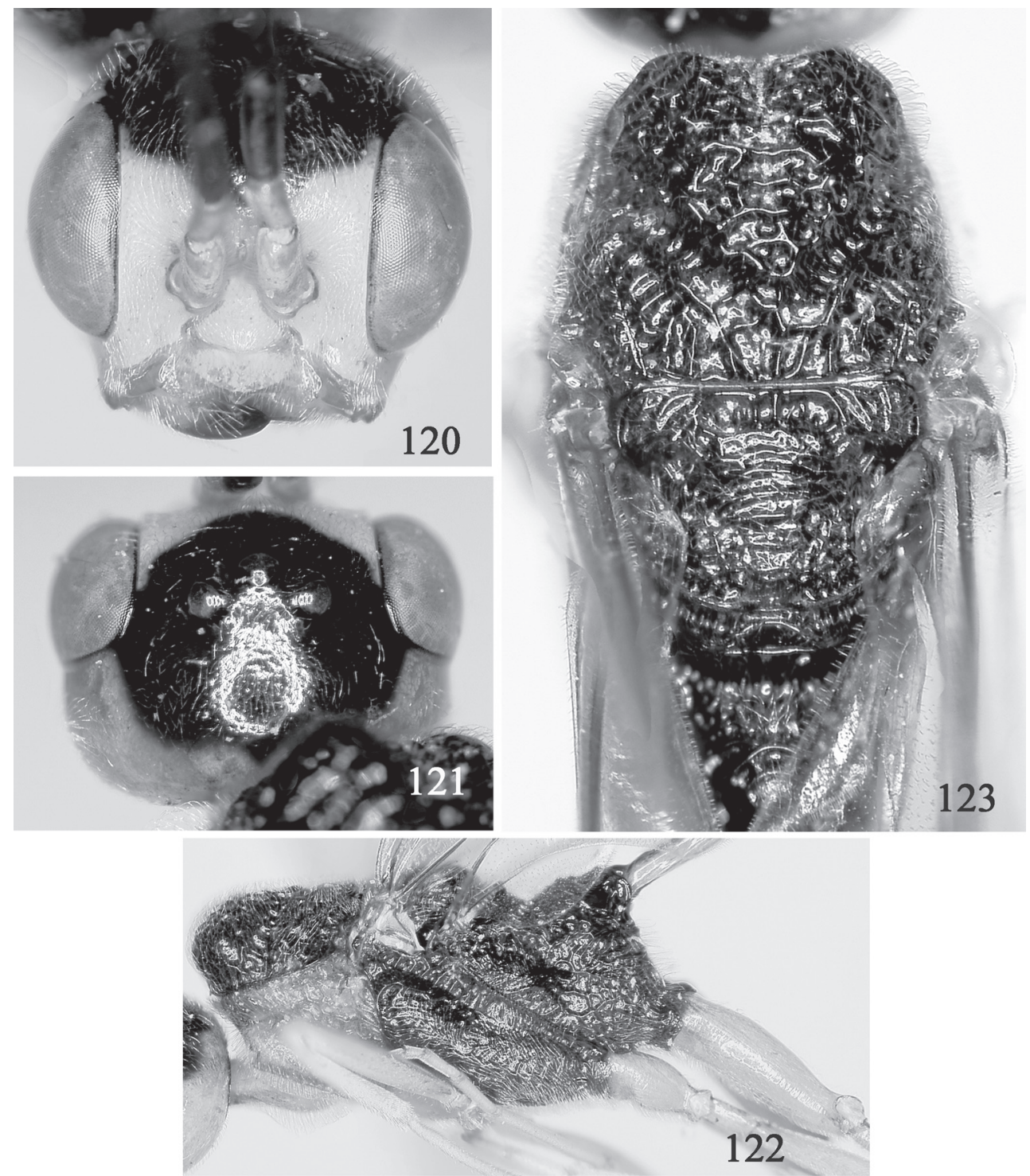

Figs 120-123: Pristaulacus tenuis. 120 Head, front. 121 Head, dorsal. 122 Mesosoma, lateral. 123 Mesosoma, dorsal.

\section{Male:}

Length, $12.0 \mathrm{~mm}$; forewing length, $8.0 \mathrm{~mm}$. Color: Antenna with scape and pedicel yellow, flagellar segments 3-5 black (segments beyond 5 missing). Head yellow with large black area on vertex and frons, black at center of vertex from near occipital carina touching upper inner margin of eyes, through ocelli to center of frons. Mesosoma black with propleuron and pronotum yellow orange. Legs yellow orange with black stripe on outer surface of hind tibia. Metasoma orange. Wings hyaline without black spots; veins and stigma brownish. Head: Lower interocular distance subequal to eye height; malar space about $0.25 \mathrm{X}$ eye height (Fig. 120). Head from above straight behind eyes then roundly narrowing, subequal to eye length (Fig. 121). Occipital carina very narrow, 
less than a fifth diameter of an ocellus. Entirely shining with white pubescence and practically impunctate, with very few widely scattered fine punctures (Figs 120, 121). Mesosoma: Pronotum without anteriorly projecting tooth. Propleuron shining, impunctate. Mesonotum shining, mostly reticulate, mesoscutal middle lobe and mesoscutellum with faint transverse sculpturation at center; anterior lobes of mesoscutum roundly protuberant (Fig. 123). Pleura reticulate, posterior margin of mesopleuron narrowly scrobiculate (Fig. 122). Hind coxa nearly 3.0X longer than broad, smooth and shining. Hind basitarsus about 1.3X length of remaining tarsal segments combined. Tarsal claws with 5 teeth, lower tooth smallest, and with small basal lobe. Forewing with cells 1M and 1 Rs contiguous, not separated by vein Rs+M (as in Fig. 97); intercostal area about same width as stigma. Hind wing with veins distinct, cells $\mathrm{Cu}$ and $\mathrm{R} 1+\mathrm{Rs}$ separated by vein $\mathrm{M}$ (as in Fig. 104). Metasoma: Smooth, shining, with fine white pubescence on segments 3 to apex.

Holotype: Male, labeled "Mexico: Guerrero, 6 miles east of Xochipala, July 13, 1985, Jones, Schaffner" (TAMU).

Etymology: From the Latin, tenuis, referring to the slender appearance of the species.

\section{Remarks:}

This species resembles the male of $P$. decorus, but in $P$. tenuis the wings are clear, the coxae are long, nearly three times longer than broad, and the mesoscutal lobes are sculptured. The intercostal area is broad as in $P$. decorus, but it is about equal to the width of the stigma in $P$. tenuis whereas it is broader than the stigma in $P$. decorus.

\section{Pristaulacus decolorus Smith, new species}

(Figs 124-127)

\section{Diagnosis:}

Mesosoma and metasoma black. Wings hyaline, without black spots. Head shining. Mesosoma shining, with transverse carinae. Hind coxa shining, smooth, elongate. Anterior margin of pronotum with one tooth.

Female: Unknown.

Male:

Length, $6.5 \mathrm{~mm}$; forewing length, $4.5 \mathrm{~mm}$. Color: Antenna black with scape yellow. Head orange yellow with large area on vertex and frons black, black area from near occipital carina to upper inner orbits through ocelli to lower three-quarters of frons. Mesosoma black with propleuron orange yellow. Legs orange yellow with hind coxa and trochanter black, hind femur and hind tibia with black streak on outer surfaces, and hind tarsus brown. Metasoma black with second tergite with orange band and lateral orange areas on segments 3 and 4 . Wings hyaline, without black spots; veins and stigma brownish. Head: Antennal length 4.0X head width. Lower interocular distance subequal to eye height; malar space about $0.3 \mathrm{X}$ eye height (Fig. 124). From above head behind eyes roundly narrowing, about $0.6 \mathrm{X}$ eye length (Fig. 125). Occipital carina very small, less than a fifth diameter of an ocellus. Head smooth and shining with white pubescence, pubescence densest on lower frons, lower inner orbits, and malar area; practically impunctate, several small widely scattered punctures on frons (Figs 124, 125). Mesosoma: Pronotum with one anteriorly projecting tooth. Propleuron smooth and shining, few punctures on posterior half. Rest of mesonotum shining; mesoscutal middle lobe with about 6 transverse carinae; mesoscutal lateral lobe smooth, 


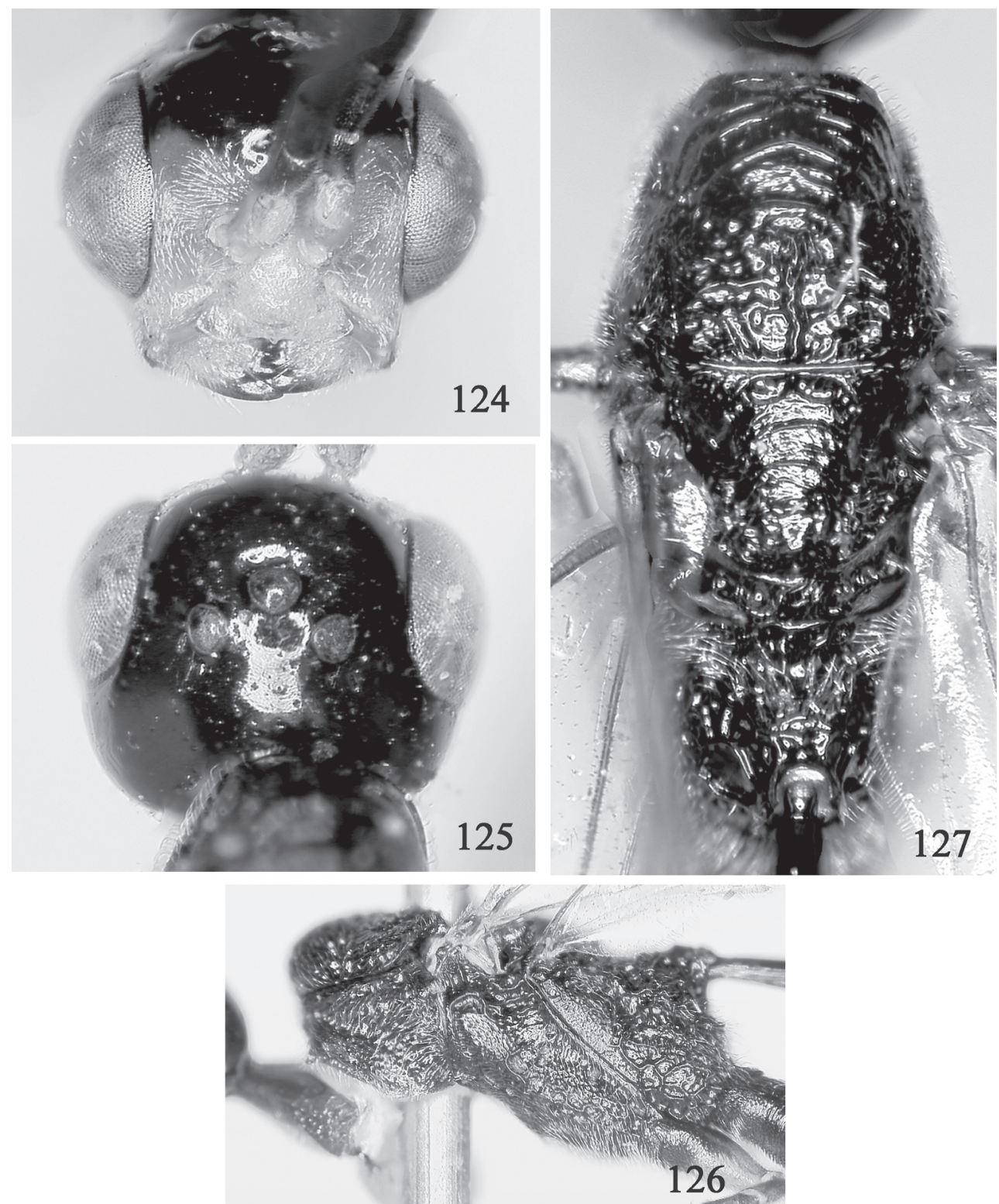

Figs 124-127: Pristaulacus decolorus. $124 \mathrm{Head}$, front. $125 \mathrm{Head}$, dorsal. 126 Mesosoma and head, lateral. 127 Mesosoma, dorsal.

shining, reticulate posteriorly; axillae somewhat reticulate; mesoscutellum with several transverse carinae at center; pleura mostly reticulate with dorsoanterior area on mesopleuron and anterior band on metapleuron finely punctate (Figs 126, 127). Hind coxa long, 3.2X longer than broad, smooth and shining. Tarsal claws with 4 teeth, basal tooth may represent small acute basal lobe. Hind basitarsus 1.1X length of following tarsal segments combined. Forewing with cells $1 \mathrm{M}$ and 1 Rs separated by short Rs+M vein (as in Fig. 91). Hind wing with veins faint to absent (as in Fig. 157). Metasoma: Segments 2 to apex with fine white pubescence and fine punctures. 
Types: Holotype: Male, labeled "Guanajuato, Guanajuato, Mex., VI-27-52, E. E. Gilbert, C. D. MacNeil, Collectors” (UCB). Paratypes: MEXICO: 4 mi NW Tepanco de Lopez, Puebla, VII.2.53, Univ. Kans Mex. Expedition (1 $0^{\star}$, UKAN); Oaxaca, Crawford (1 $0^{\star}$, USNM); 14 mi. W. Ojuelos de Jalisco, 7360 ft., July 7, 1972, B. \& C. Dasch (1 o, AEI).

Etymology: From the Latin adjective decolor, meaning without color, referring to the lack of black spots on the wings.

\section{Remarks:}

The forewing is entirely clear, without dark spots. I have not seen females with which this species can be associated.

\section{Pristaulacus singulus SMITH, new species}

(Figs 128-131)

\section{Diagnosis:}

Head, mesosoma, and legs orange, metasoma black. Forewing with one black apical spot. Head shining. Mesosoma with transverse carinae. Hind coxa smooth, shining, elongate. Anterior margin of pronotum without tooth.

Female: Unknown.

Male:

Length, $15.0 \mathrm{~mm}$; forewing length $11.5 \mathrm{~mm}$. Color: Antenna with scape orange, pedicel and basal 6 flagellomeres black (segments beyond 6 missing). Head orange with brownish band bordering occiput. Mesosoma orange with mesoscutal middle lobe blackish. Legs orange (hind legs missing beyond coxae). Metasoma black. Wings hyaline with black spot at apex of forewing; veins and stigma black. Head: Lower interocular distance shorter, about $0.8 \mathrm{X}$, eye height; malar space about $0.2 \mathrm{X}$ eye height (Fig. 128). Occipital carina narrow, less than a fifth diameter of an ocellus. From above, straight then roundly narrowing behind eyes, distance behind eyes about 0.7 eye length (Fig. 129). Front ocellus in distinct depression (Fig. 128). Head smooth and shining, vertex and gena with widely spaced punctures, interspaces much longer than puncture diameters; frons with widely scattered somewhat larger punctures, separated by distances more than puncture diameters, interspaces with fine microsculpture (Figs 128, 129). Mesosoma: Pronotum without anteriorly projecting tooth. Propleuron shining, almost impunctate. Mesonotum shining, without sculpture on front downturned portion of mesoscutal middle lobe, with coarse transverse carinae dorsally; pronotum almost impunctate, large smooth shining area at center, slight reticulations on posterior margin; mesopleuron almost impunctate, microsculptured with some large reticulations ventroanteriorly and dorsoposteriorly; metapleuron microsculptured with 5 or 6 carinae ventrally; propodeum microsculptured but more reticulate around metasomal insertion and posteriorly (Figs 130, 131). Hind coxa long, about 3.3X longer than broad, smooth and shining. Tarsal claws with 4 teeth. Forewing with cells $1 \mathrm{M}$ and 1 Rs separated by long Rs+M vein (as in Fig. 91). Hind with veins faint to absent (as in Fig. 157). Metasoma: Smooth, shining; fine white pubescence at apex of segment 2 to apex, especially laterally.

Holotype: Male, labeled "Sendero, Pailas, Catarata, Prov. Guan., Costa Rica, 800 m, 11-12 Ene 1994, M. Zumbado, LN 306300_388600 \#2666," “Costa Rica INBIO CRI001 725804” (INBio) ("Guan" = Guanacaste). 


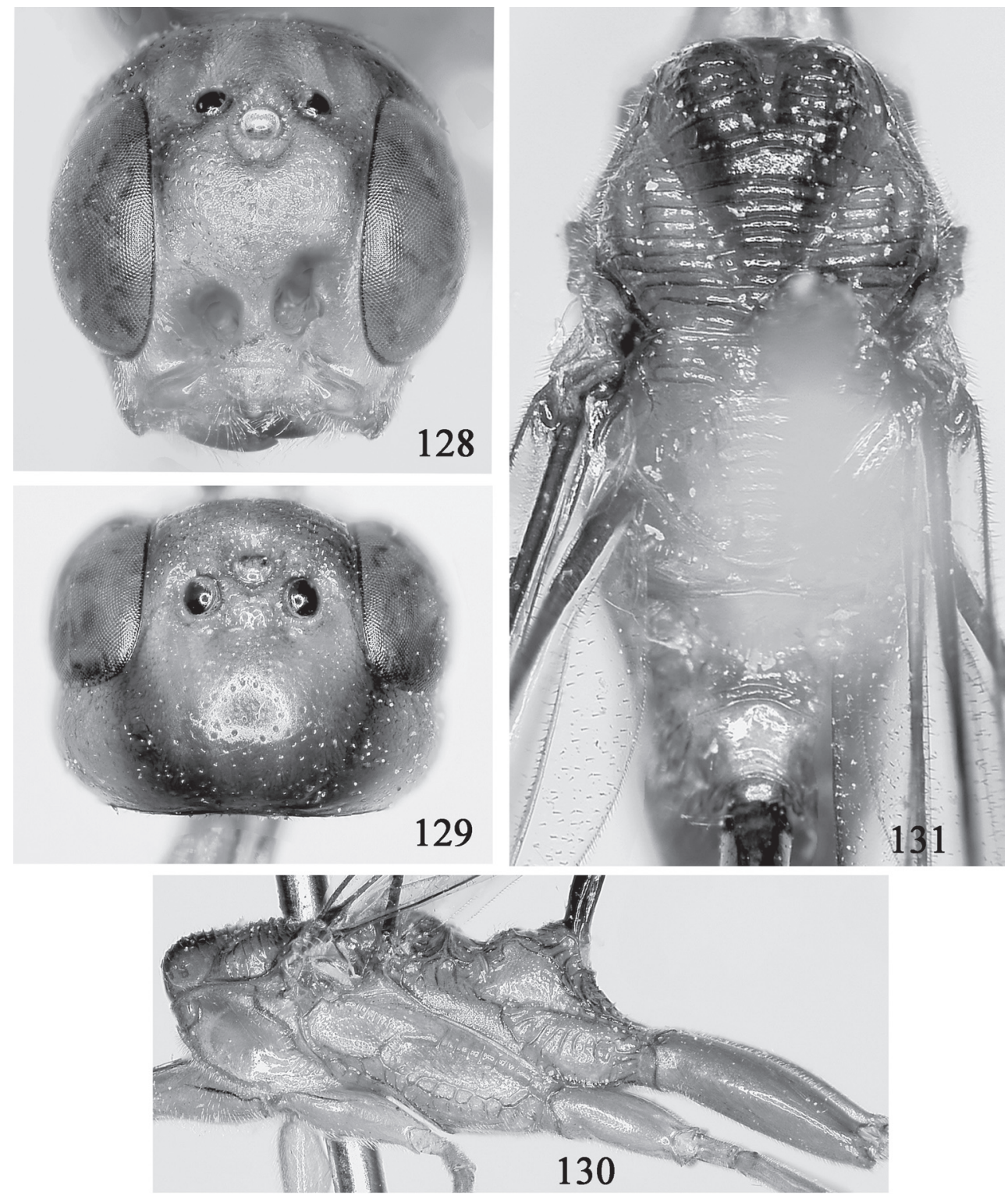

Figs 128-131: Pristaulacus singulus. 128 Head, front. 129 Head, dorsal. 130 Mesosoma, lateral. 131 Mesosoma, dorsal.

Etymology: From the Latin singulus, meaning single spot, referring to the single black spot at the apex of the forewing.

\section{Remarks:}

I have not seen females with which this species can be associated. 


\section{Pristaulacus candidus SMITH, new species}

(Figs 132-135)

\section{Diagnosis:}

Entirely orange. Forewing black at apex only (though a very small indistinct spot under stigma). Head shining. Mesoscutum with transverse carinae. Hind coxa smooth, shining. Anterior margin of pronotum with one anteriorly projecting tooth.
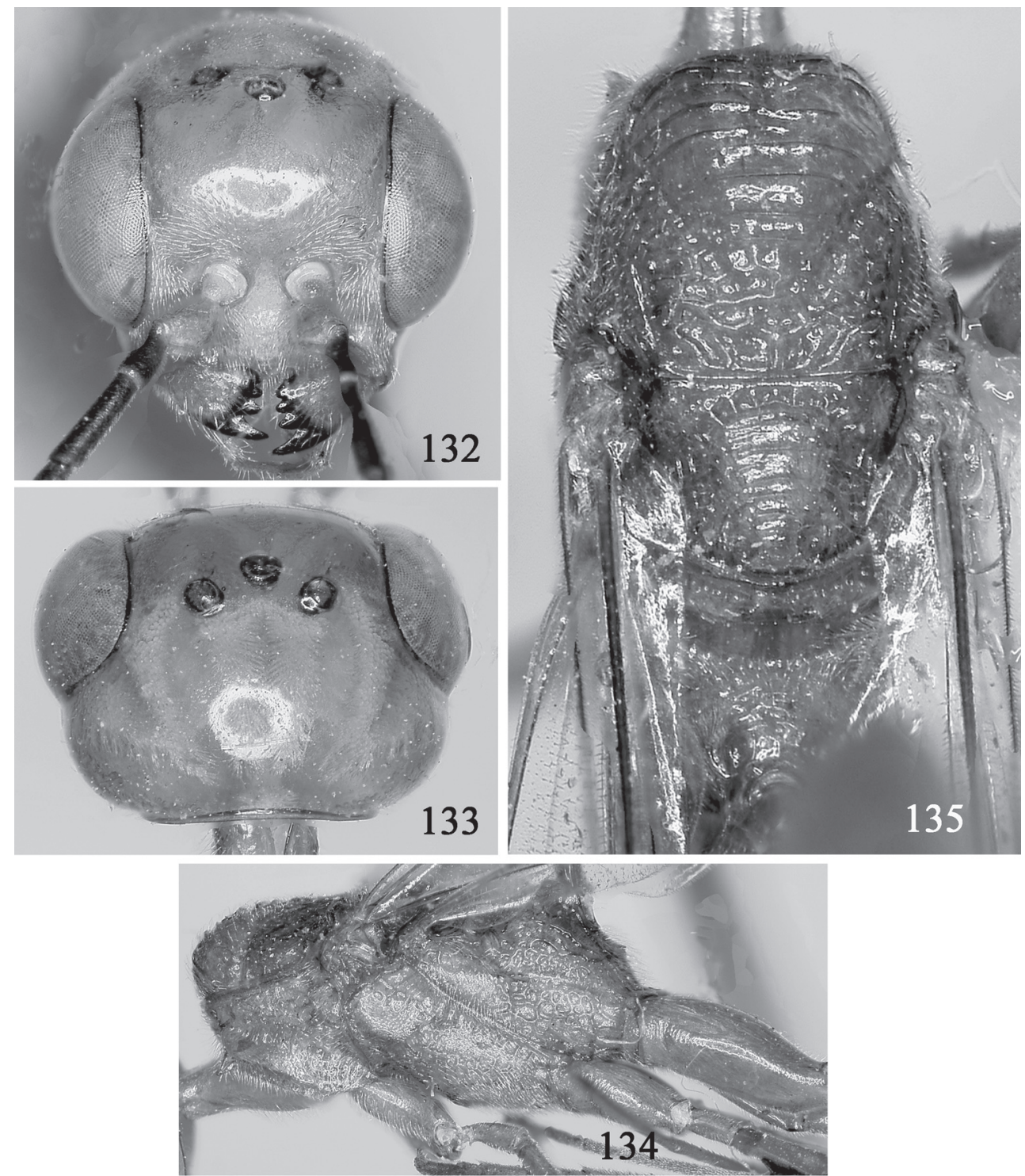

Figs 132-135: Pristaulacus candidus. 132 Head, front. 133 Head, orsal. 134 Mesosoma, lateral. 135 Mesosoma, dorsal. 


\section{Female:}

Length, $8.0 \mathrm{~mm}$; forewing length, $6.5 \mathrm{~mm}$; ovipositor length, $6.5 \mathrm{~mm}$. Color: Orange; antennal flagellum and ovipositor sheath black. Wings hyaline; forewing with black spot at apex; veins and stigma amber. Head: Antennal length 3.5X head width. Lower interocular distance subequal to eye height; malar space about $0.25 \mathrm{X}$ eye height (Fig. 132). From above, head behind eyes roundly narrowing but long, about $0.8 \mathrm{X}$ eye length (Fig. 133). Occipital carina very narrow, less than a fifth diameter of an ocellus. Smooth and shining, practically impunctate, with white pubescence, pubescence densest above antennae, and on inner orbits and malar area (Figs 132, 133). Mesosoma: Pronotum with anteriorly projecting tooth. Propleuron smooth, shining, impunctate. Mesoscutal middle lobe with about 6 transverse carinae; mesoscutal lateral lobes reticulate; axillae slightly reticulate; mesoscutellum with about 6 transverse carinae at center; pronotum reticulate, except ventroanteriorly with fine punctures; mesopleuron finely punctured, reticulate anteroventrally and on posterior margin; metapleuron finely punctured dorsally, rest reticulate; propodeum reticulate (Figs 134, 135). Hind coxa about $3 \mathrm{X}$ longer than broad, smooth and shining. Hind basitarsus $1.3 \mathrm{X}$ length of remaining tarsal segments combined. Tarsal claws with 4 teeth. Forewing with cells $1 \mathrm{M}$ and 1 Rs separated by short vein Rs+M (as in Fig. 91). Hind wing veins absent (as in Fig. 157). Metasoma: Segments 2 to apex with fine white pubescence and fine punctures. Ovipositor length subequal to forewing length.

Male: Length, $7.5 \mathrm{~mm}$; forewing length, $5.0 \mathrm{~mm}$. Color and structure similar to female.

Types: Holotype: Female, "Mexico, Oaxaca, 16 mi N. of Juchitan, 2 July 1955, R.E. Beer \& party (UKAN). Paratypes: MEXICO: Same data as holotype except 13 July 1989, \#036 (1 ð’, UKAN); Sin., Mazatlan, 31 July 1964, W.R.M. Mason (1 +, CNC); Jalisco, Chamela Bio. Stn., 10 July 1989, A. Roig Alsina, C. Michener, R. Brooks, ex. malaise trap \#002” (1 ð’, UKAN).

Etymology: From the Latin candidus, meaning bright, shining, referring to the texture of the head.

\section{Remarks:}

The entirely orange color, shining head and hind coxae, and presence of a tooth on the anterior margin of the pronotum separate this species from other mostly orange Pristaulacus.

\section{Pristaulacus omninoniger SMITH, new species}

(Figs 136-139)

\section{Diagnosis:}

Entirely black. Forewing with black spot below stigma and black spot at apex. Head shining. Mesoscutum with transverse carinae. Hind coxa smooth, shining. Anterior margin of pronotum with anteriorly projecting tooth.

Female: Unknown.

\section{Male:}

Length, $7.5 \mathrm{~mm}$; forewing length, $5.0 \mathrm{~mm}$. Color: Black with antennal scape (antenna missing beyond segment 8 ), spot on posterior margin of vertex, first metasomal segment, and legs beyond trochanters dark orange; hind femur, hind tibia, and hind tarsus brownish to black. Wings hyaline; forewing with black spot under stigma and black spot at apex; veins and stigma black. Head: Lower interocular distance subequal to eye height; malar space about $0.3 \mathrm{X}$ eye height (Fig. 136). From 


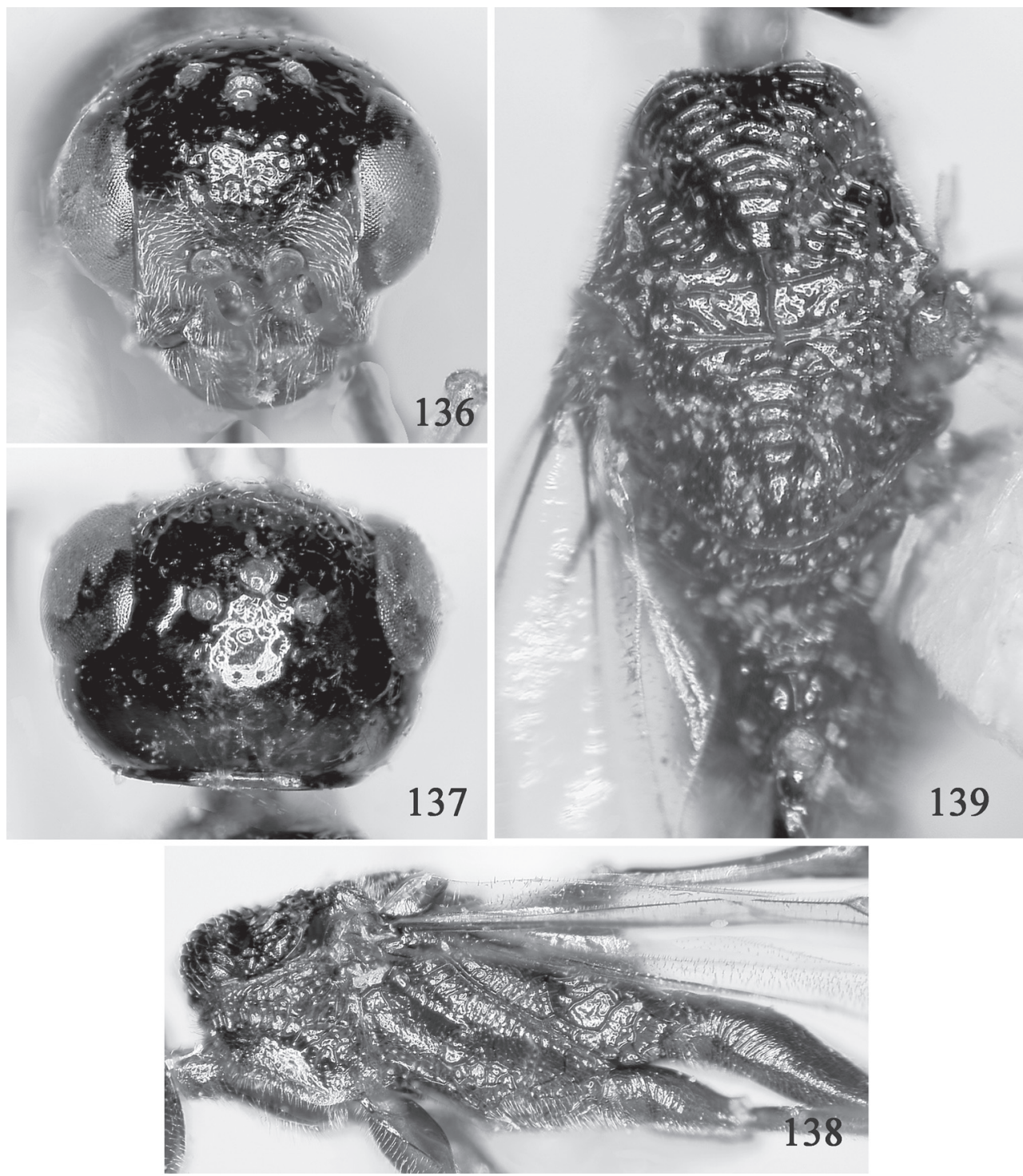

Figs 136-139: Pristaulacus omninoniger. $136 \mathrm{Head}$, front. $137 \mathrm{Head}$, dorsal. 138 Mesosoma, lateral. 139 Mesosoma, dorsal.

above, roundly narrowing behind eyes, about $0.7 \mathrm{X}$ eye length (Fig. 137). Occipital carina broad, nearly half diameter of an ocellus. Shining with fine white pubescence, pubescence densest on lower frons, lower inner orbits and malar area; vertex with very widely scattered punctures, much farther apart than puncture diameters; frons with punctures, those at center close together, otherwise similar to vertex (Figs 136, 137). Mesosoma: Pronotum with anteriorly projecting tooth. Propleuron shining, without sculpture. Mesoscutal middle lobe with somewhat transverse carinae, rest of mesonotum reticulate. Pleura mostly reticulate with ventroanterior portion of pronotum and upper portion of mesopleuron finely punctate and posterior margin of mesopleuron somewhat scrobiculate (Figs 138, 139). Hind coxa about $3 \mathrm{X}$ longer than broad, shining, with very fine transverse carinae, especially 
evident on sides. Tarsal claws with 4 teeth, basal tooth very small, possibly representing small acute basal lobe. Hind basitarsus 1.2X length of remaining tarsal segments combined. Forewing with cells $1 \mathrm{M}$ and 1 Rs separated by very short vein Rs+M (as in Fig. 91). Hind wing veins faint to absent (as in Fig. 157). Metasoma: Segment 2 to apex with fine pubescence and finely punctate.

Types: Holotype: Male, labeled "Mexico, Tamaulipas, Atlas Cumbres, $12 \mathrm{mi}$. W. Cd. Victoria, February 18, 1986, R. Jones (1, TAMU). Paratype: MEXICO: Rancho del Ciclo, Tamaulipas, May 1954, J. Heckenla:ble [?, not legible] (1 ơ, UMINN).

Etymology: From the Latin omnino (entirely) and niger (black), referring to the entirely black color of this species.

\section{Remarks:}

This species cannot be associated with described females. The black color is similar to P. annulatus, but $P$. omninoniger lacks punctures on the head, has a black spot under the stigma of the forewing, and has most of the legs beyond the trochanters brown to dark orange.

\section{Pristaulacus townesi SMITH, new species}

(Figs 140-143)

\section{Diagnosis:}

Entirely black with metasoma red and apex black. Forewing with black spot below stigma and black spot at apex. Head shining. Mesonotum dull, with dense punctures, some fine transverse carinae. Hind coxa dull, with cross striations. Anterior margin of pronotum without anteriorly projecting tooth.

Female: Unknown.

\section{Male:}

Length, $14.0 \mathrm{~mm}$; forewing length, $9.5 \mathrm{~mm}$. Color: Black; metasoma with apical 2/3 of first segment and segments 2 and 3 orange. Wings hyaline; forewing with black spot under stigma and black spot at apex; veins and stigma black. Head: Antennal length 2.2X head width. Lower interocular distance longer, 1.1X, eye height; malar space about $0.3 \mathrm{X}$ eye height (Fig. 140). From above, head behind eyes sharply roundly narrowing, length behind eyes about $0.8 \mathrm{X}$ eye length (Fig. 141). Occipital carina narrow, less than a fifth diameter of an ocellus. Shining, rather evenly covered with white pubescence; vertex and gena with widely scattered punctures, separated by flat interspaces $2 \mathrm{X}$ or more puncture diameters; frons densely punctate with contiguous punctures; punctures of interantennal area and clypeus not as dense or close together as those on frons (Figs 140, 141). Mesosoma: Pronotum without anteriorly projecting tooth. Propleuron shining, with fine punctures. Mesonotum shining, almost evenly reticulate; pleura and propodeum reticulate with reticulations coarser on anteroventral portion of pronotum, and very fine on upper portion of metapleuron (Figs 142, 143). Hind coxa about 3.2X longer than broad; densely punctate, with transverse carinae. Tarsal claws with 5 teeth, lower tooth smallest and indistinct basal lobe. Forewing with cells $1 \mathrm{M}$ and $1 \mathrm{Rs}$ contiguous not separated by vein Rs+M (as in Fig. 97). Hind wing with veins distinct, cells $\mathrm{Cu}$ and $\mathrm{R} 1+\mathrm{Rs}$ separated by vein $\mathrm{M}$ (as in Fig. 104). Metasoma: Smooth, shining, with fine white pubescence on segments 3 to apex.

Holotype: Male, labeled "San Pedro Iturbide, 32£ Km W. Linares, X.6.62, N.L., Mex., H. \& M. Townes" (AEI). 


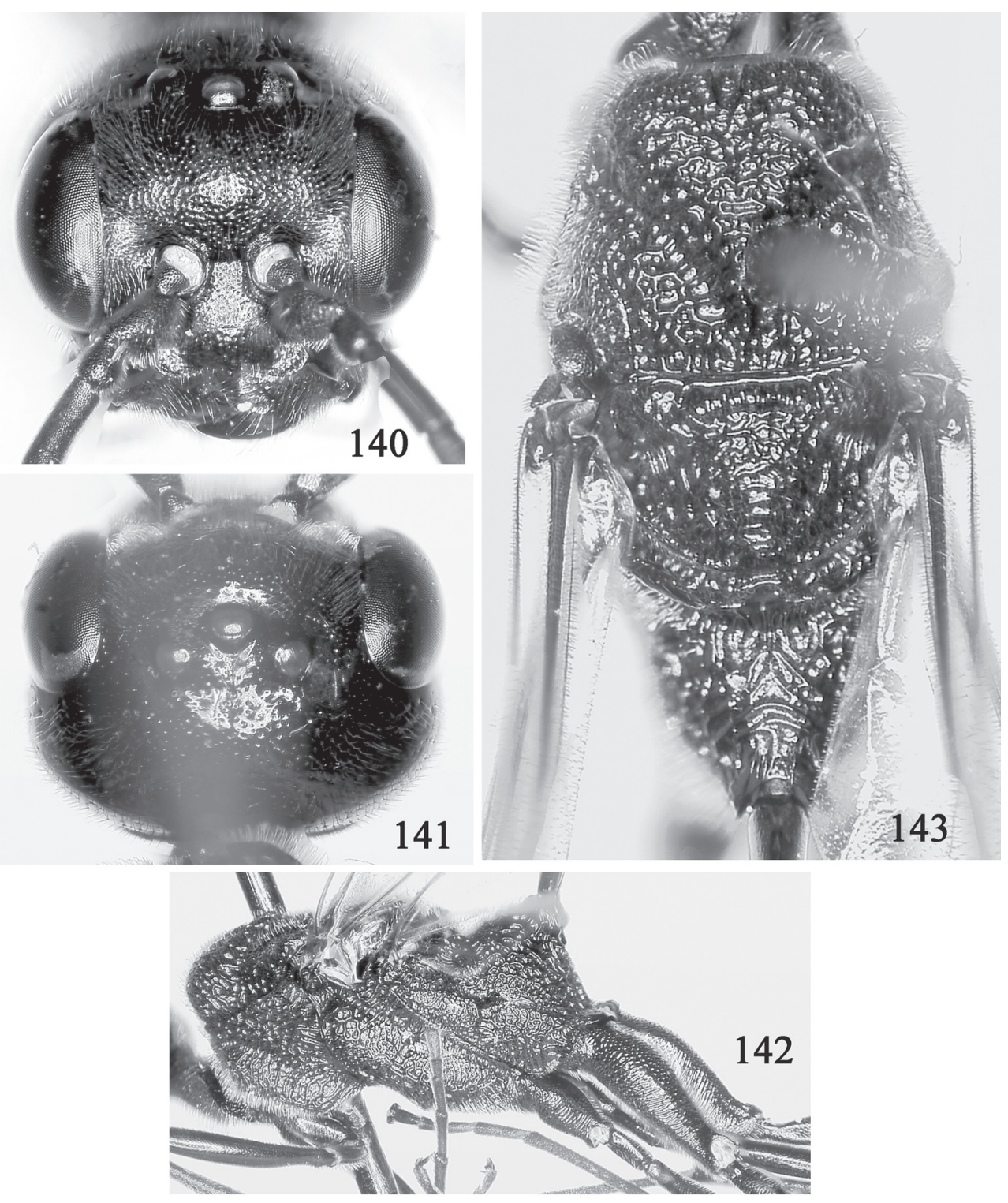

Figs 140-143: Pristaulacus townesi. 140 Head, front. 141 Head, dorsal. 142 Mesosoma, lateral. 143 Mesosoma, dorsal.

Etymology: Named for the late Henry K. Townes, who revised the Nearctic species of Aulacidae.

\section{Remarks:}

The color is similar to $P$. arizonicus and $P$. rufitarsus, both known from females. Pristaulacus townesi differs by the hyaline forewing with black below the stigma and at the apex, shining head, and narrow occipital carina. 
Beitr. Ent. 58 (2008) 2

\section{Pristaulacus arizonicus (TownEs)}

(Figs 144-147)

Aulacostethus arizonicus Townes 1950: 98.-Townes 1951: 657.

Pristaulacus arizonicus: CARLSON 1979: 1112.-SMITH 2001: 278.

\section{Diagnosis:}

Head and mesosoma black; mesoscutal middle lobe with transverse carinae; occipital carina flangelike; head punctate, frons with closely set punctures.

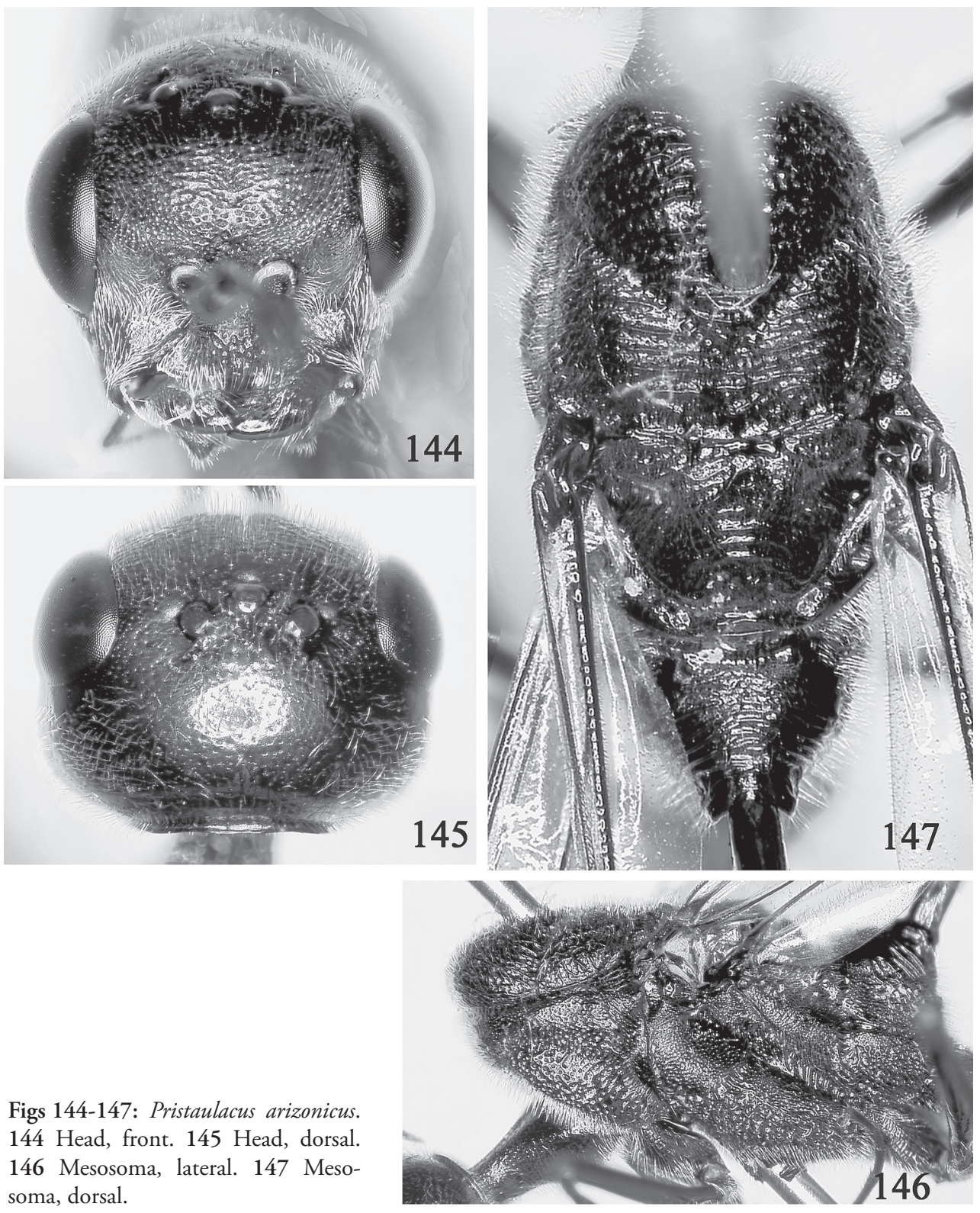




\section{Female:}

Length, 13.5-15.0 mm; forewing length, 12.5-13.5 mm; ovipositor length 18.0-20.0 mm. Color: Black; first metasomal except streak at base and segments 2 and 3 and basal part of 4 orange. Wings slightly dusky; forewing with black spot under stigma and at apex; veins and stigma black. Head: Lower interocular distance $1.4 \mathrm{X}$ eye height; malar space neatly $0.5 \mathrm{X}$ eye height (Fig. 144). Head from above, sharply narrowing behind eyes, distance behind eyes subequal to eye length (Fig. 145). Occipital carina broad, flangelike, more than half diameter of an ocellus (Fig. 145). Shining; gena and vertex with large punctures, mostly separated by flat, shining interspaces $2 \mathrm{X}$ or more puncture diameters; frons with closely set punctures, interspaces ridgelike, mostly equal to puncture diameters; with fine white pubescence, densest on lower inner orbits, malar area, and clypeus (Figs 144, 145). Mesosoma: Pronotum without anteriorly projecting tooth. Propleuron punctate. Mesoscutum with transverse carinae; axillae and sides of mesoscutellum reticulate, center of mesoscutellum with transverse carinae; propleuron shining, punctate; pronotum mostly punctate, punctures finer dorsoposteriorly; mesopleuron finely punctate on upper half, reticulate mixed with punctures on lower half; metapleuron mostly reticulate; propodeum finely punctate to reticulate, shining with few carinae near metasomal insertion (Figs 146, 147). Hind coxa with transverse carinae. Tarsal claws with 4 teeth. Hind basitarsus slightly longer than remaining tarsal segments combined. Forewing with long vein Rs+M separating cells $1 \mathrm{M}$ and $1 \mathrm{Rs}$ (as in Fig. 157). Hind wing veins distinct, cells $\mathrm{Cu}$ and $\mathrm{R} 1+\mathrm{Rs}$ contiguous (as in Fig. 110). Metasoma: Smooth, shining, with fine white pubescence on segments 4 to apex. Ovipositor length about $1.5 \mathrm{X}$ forewing length.

Male: Unknown.

Holotype: Female is at OSU, labeled "Chiricahua M., Ar, VII-26-87,” "D.J. \& J.N. Knull Collrs," "Holotype" [red], "Pristaulacus arizonicus Tow. type" [Townes' name label].

Specimens examined: UNITED STATES. ARIZONA: Cochise Co., Cave Cr. Canyon, Chiricahua Mts., Southwestern Research Station, 5350', 81 ${ }^{\circ} 53^{\prime} \mathrm{N}, 109^{\circ} 12^{\prime} \mathrm{W}, 22 . \mathrm{VI}-1999$ (1 $q$, USNM); Chiricahua M., VIII-2-52 (1 + , USNM); Mt. Lemmon, Sta. Catalina Mts., 3-4.VIII.67 (1 ㅇ, CNC); Apache Co., Hawley L., 8300', 8.5.82 (2 ㅇ ㅇ․ CAS), same except VIII-1-82 (1 + , CAS); Williams, VII-22-50 and VIII-2-52 (6 ㅇ ㅇ, OSU); 5 mi NW Flagstaff, Coconimo Co., 7000 ft., July 29, 1950 (1 ㅇ, AMNH).

\section{Remarks:}

This large black species with the metasoma partly orange has been found only in Arizona.

\section{Pristaulacus rufitarsis (CRESSON)}

(Figs 148-151)

Aulacus rufitarsis Cresson 1864: 134 (see SMITH 2001 for synonymy and subsequent references).

\section{Diagnosis:}

Wings uniformly lightly infuscate, without dark spots; head and mesosoma black, hind tarsus white to reddish, always paler than hind femur and tibia; head with widely scattered punctures; mesoscutum with transverse carinae. Tarsal claws with 3 teeth. 

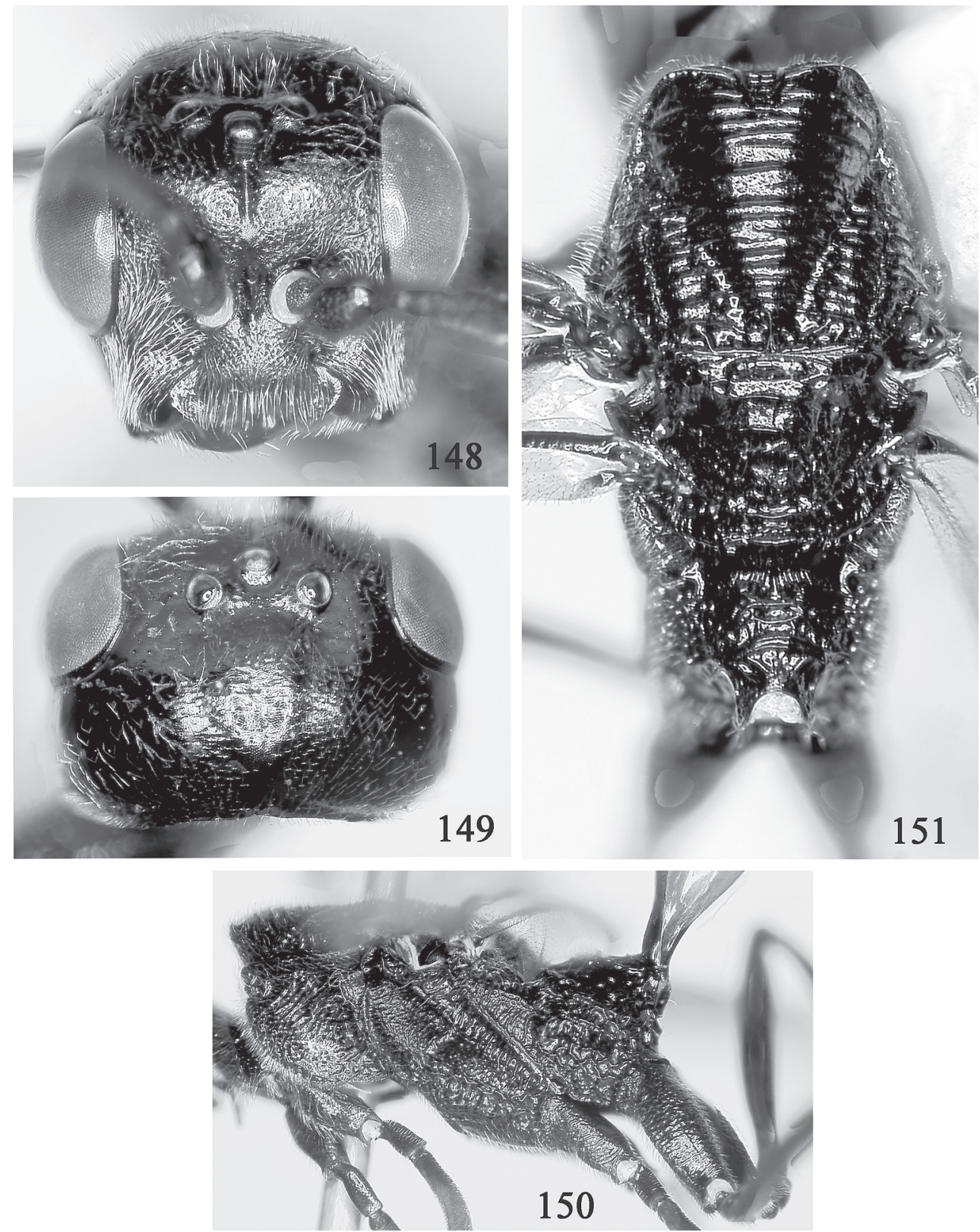

Figs 148-151: Pristaulacus rufitarsis. $148 \mathrm{Head}$, front. $149 \mathrm{Head}$, dorsal. $150 \mathrm{Mesosoma,} \mathrm{lateral.}$ 151 Mesosoma, dorsal.

\section{Female:}

Length 10.0-12.0 mm; forewing length, 8.0-9.5 mm; ovipositor length 9.5-10.5 mm. Color: Black; base of first metasomal segment red. Legs black with fore- and mid femora and tibiae brown, all tarsi reddish brown to white. Wings uniformly lightly infuscate, forewing without black spots; veins and stigma black. Head: Lower interocular distance about 1.3X eye height; 
malar space $0.4 \mathrm{X}$ eye height (Fig. 148). Head from above, straight, then roundly narrowing behind eyes, distance behind eyes about equal to eye length (Fig. 149). Occipital carina narrow, less than a fifth diameter of an ocellus (Fig. 149). Shining; gena and vertex almost impunctate with fine widely scattered punctures, separated by broad shining flat interspaces several times puncture diameters; frons with more closely set punctures, separate by a distance of about puncture diameter; with fine white pubescence, densest and longest on lower inner orbits, malar area, and clypeus (Figs 148, 149). Mesosoma: Pronotum without anteriorly projecting tooth. Propleuron punctate. Mesoscutum with transverse carinae; axillae and mesoscutellum mostly punctate to reticulate, several transverse carinae indicated at center of mesoscutellum; propleuron shining, with few scattered punctures; pronotum mostly punctate, slightly reticulate dorsoposteriorly; mesopleuron punctate on dorsal third, reticulate ventrally, with narrow scrobiculate band posteriorly; metapleuron mostly reticulate, dorsal portion with few carinae; propodeum coarsely reticulate (Figs 150,151). Hind coxae punctate, with distinct transverse carinae. Tarsal claws with 3 teeth. Hindbasitarsus slightly longer than length of remaining tarsal segments combined. Forewing with cells $1 \mathrm{M}$ and $1 \mathrm{Rs}$ separated by vein Rs+M (as in Fig. 157). Hind wing with veins distinct, cells $\mathrm{Cu}$ and $\mathrm{R} 1+\mathrm{Rs}$ contiguous (as in Fig. 110). Metasoma: Smooth, shining, with fine white pubescence on segments 3 to apex. Ovipositor length subequal to forewing length.

Male: Length, 9.0-12.0 mm; forewing length, 7.5-9.5 mm. Color and structure similar to female except apical metasomal segments, usually from 5 to apex, usually black.

Type: Female (ANSP) from "Colo." Cresson (1864) described the species from "Rocky Mountains, Colorado Territory."

Specimens examined: Numerous specimens, transcontinental in Canada and northern United States extending south to Georgia in the East and to New Mexico, Arizona, and California in the West. UNITED STATES. ARIZONA: Jacob Lake, Coconimo Co., VII-24-1952 (1 ㅇ, AMNH); Rustler Park, Chiricahua Mts., Cochise Co., July 17, 1957 (1 + , AMNH); Rustlers Park, Chir., Mts., 8400', VI-25-1956 (1 ㅇ, CNC). NEW MEXICO: Emory Pass, Sierra Co., 7200-8178 ft., July 18, 1964 (1 $\circ$, AMNH).

Hosts: Buprestidae and Cereambycidae, mostly from conifers; reared from Chrysobothris caurina Horn (Buprestidae) in Pinus ponderosa Dougl. ex Laws.; from Melanophila fulvoguttata (Harris) (Buprestidae) in Tusga canadensis (L.) CARR.; from Melanophila drummondi (KIRBY) (Buprestidae) in Abies concolor (GoRD. \& GLEN.) Lindl.; from Sapeda calcarata SAY (Cerambycidae) in Populus tremuloides Michx.; from Graphisurus sp. (Cerambycidae); Chrysophana placida (LeConte) (Buprestidae); in cone of Pinus attenuate Lemm.; reared from Pinus arizonica Engelm., P. lambertiana Dougl., P. flexilis James; Libodedrus decurrens Torr., Tsuga mertensiana (Bong.) Carr. (Townes 1950, Smith 2001).

\section{Remarks:}

This is a widespread and common species in the coniferous forests of North America. The specimens from the mountains of southern Arizona and New Mexico are the southernmost known records, though it is likely to occur in Mexico. It can be separated from the other Nearctic species using the keys in Townes (1950) and SMITH (1996). Distribution records also are given in those publications. 


\section{Pristaulacus ruficruris SMITH, new species}

(Figs 152-157)

\section{Diagnosis:}

Black with legs a contrasting red. Forewing with black spot below stigma and black spot at apex. Head shining, elongate behind eyes. Mesonotum densely reticulate to punctate. Hind coxa shining, with cross striations. Anterior margin of pronotum with one tooth.

\section{Female:}

Length, $9.0 \mathrm{~mm}$; forewing length, $7.0 \mathrm{~mm}$; ovipositor length, $9.0 \mathrm{~mm}$. Color: Black with base of antennal scape, mandible except apex, clypeus and outer edge of malar space, spot at sides of first metasoma segment dark orange. Legs bright orange to brown; hind coxa may be dark brown, apical tarsal segment of tarsi black. Ovipositor sheath black. Wings hyaline; forewing with black spot under stigma and black spot at apex (Fig. 157); veins and stigma black. Head: Antennal length 3.3X head width. Lower interocular distance subequal to eye height; malar space about $0.25 \mathrm{X}$ eye height (Fig. 152). From above, head long behind eyes, straight then roundly narrowing, about subequal to slightly longer than eye length (Fig. 153); in lateral aspect, eye far removed from posterior margin of head (Fig. 154). Occipital carina narrow, about $0.2 \mathrm{X}$ diameter of an ocellus. Shining with fine white pubescence, pubescence densest on lower frons, inner orbits and malar area; gena and vertex shining, almost impunctate; lower frons, interantennal area, and clypeus finely punctate (Figs 152-154). Mesosoma: Pronotum with anteriorly projecting tooth. Propleuron finely punctate. Mesosoma reticulate with center of mesoscutal middle lobe, posterior portions of mesoscutal lateral lobes and center of mesoscutellum with more transverse sculpturation; pleura and propodeum reticulate; anteroventral portion of pronotum and upper area on mesopleuron more finely punctured, narrow posterior margin of mesopleuron scrobiculate (Figs 155, 156). Hind coxa about $2.4 \mathrm{X}$ longer than broad, shining, with transverse carinae, with diagonal ovipositor guide near apex on inner surface. Tarsal claws with 5 teeth, inner tooth small and indistinct, and indistinct basal lobe. Hind basitarsus 1.2X length of remaining tarsal segments combined. Forewing with cells $1 \mathrm{M}$ and 1 Rs touching or separated by very short vein Rs+M (Fig. 157). Hindwing veins faint to absent (Fig. 157). Metasoma: Segments 2 to apex with fine white pubescence and fine punctures. Ovipositor length 1.3X forewing length.

Male: Length, $8.5 \mathrm{~mm}$; forewing length, $7.0 \mathrm{~mm}$. Color and structure similar to female.

Types: Holotype: Female, labeled "Tex., San Patricio Co., Welder Wildlife Refuge, em. 21-31 Oct. 1981, R. Turnbow; ex Acacia farnesiana (L.) Willd.” (UGA). Paratypes: MEXICO: Chis: Mirador Chicoasen, nr Tuxtia Gut., 24 Oct. 86, E. Fisher, D. Thomas (1 ․ CDA); Morelos: Cuantla, IX-7-1922, C. C. Hoffman (2 $\left.\sigma^{\star} \sigma^{\star}, A M N H\right)$; Tamps Ca. San Antonio, Ruta 101 W. Co. Victoria, 24, 26-VI-81, B. Miller, C. Porter, L. Stange, C. Porter Collection (1 ơ , FSCA); La Ventosa, 72 mi. E. Oax., VII-21-68, J. Doyen, Collector (1 + , UCB); Teocaltiche, Jal., 5600', VIII-26-1979, B. Villegas (1 9 , UCD) [broken]. UNITED STATES: TEXAS: Same data as holotype (1 $\left.\sigma^{*}, \mathrm{UGA}\right)$; same data as holotype except em. 10-20 May 1980, ex Acacia rigidula Benth (1 o, UGA); Live Oak Co., 1 mi ne Three Rivers, V-8-1987, D. J. Heffern, coll. (1 9 , CSU); McMullen Co., 5 mi. W Tilden, 1 May 1982, R. Turnbow (1 + , UGA); Jim Wells Co., Alice, 15-IV-1986, S. G. Wellso (1 오 MSU).

Etymology: From the Latin rufi (red) and cruris (leg), referring to the entirely red legs.

Host: One specimen was apparently reared from Acacia rigidula BENTH. (Fabaceae). 

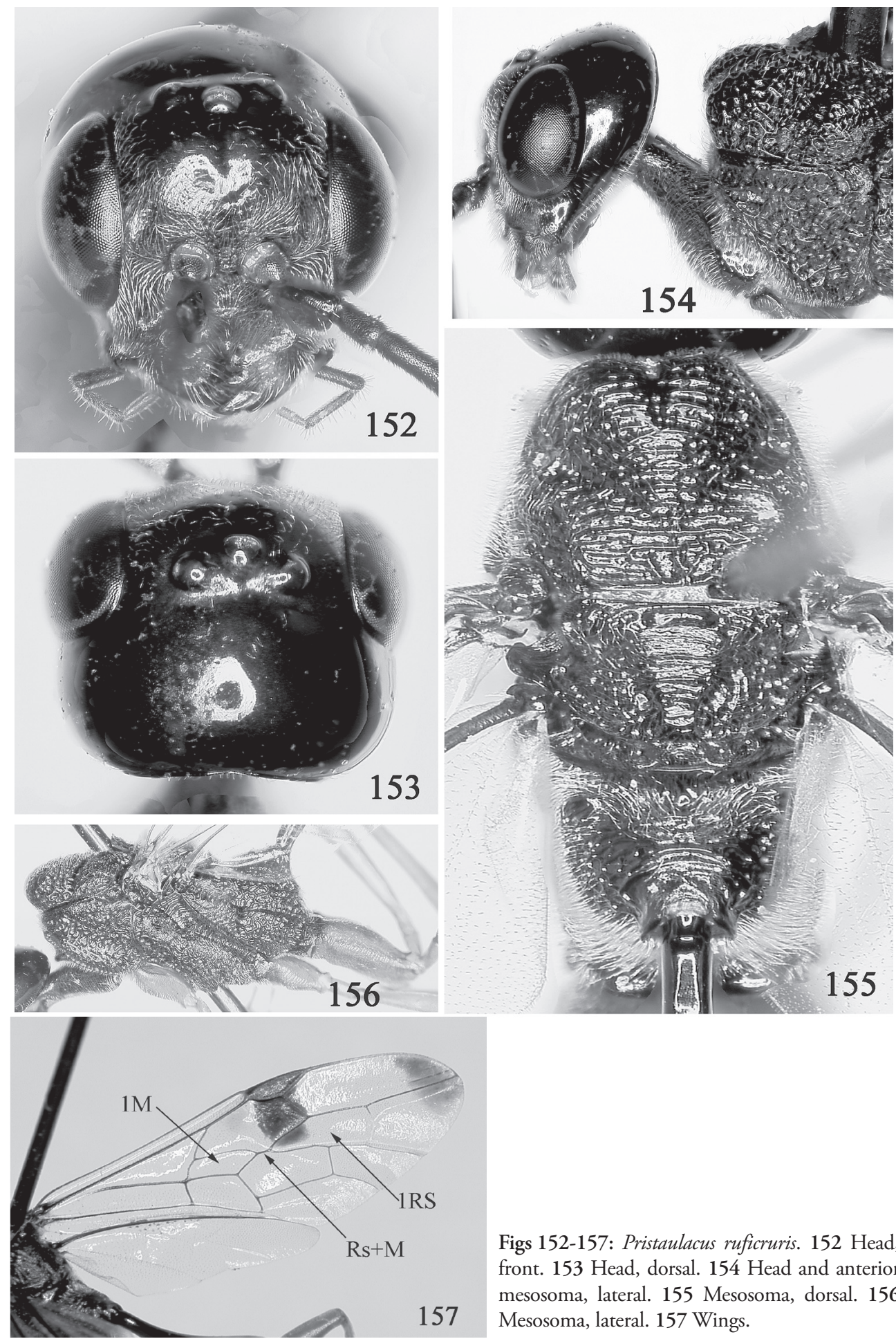

Figs 152-157: Pristaulacus ruficruris. $152 \mathrm{Head}$, front. 153 Head, dorsal. 154 Head and anterior mesosoma, lateral. 155 Mesosoma, dorsal. 156 Mesosoma, lateral. 157 Wings. 


\section{Remarks:}

The hind coxa of the male may be entirely orange to blackish. The black head and body with the contrasting bright orange legs, densely punctate-reticulate mesonotum, and the single tooth on the anterior margin of the pronotum are helpful in identifying P. ruficruris.

\section{Pristaulacus parkeri SMITH, new species}

(Figs 158-163)

\section{Diagnosis:}

Entirely orange. Forewing with black spot under stigma and black at apex. Head shining. Mesonotum reticulate to punctate. Propleuron and hind coxa smooth, shining. Anterior margin of pronotum without tooth.

\section{Female:}

Length, $14.0 \mathrm{~mm}$; forewing length, $10.0 \mathrm{~mm}$; ovipositor length, $9.0 \mathrm{~mm}$. Color: Orange; ovipositor sheath black. Wings lightly infuscate; forewing with dark spot under stigma and at apex; veins and stigma black (Fig. 163). Head: Lower interocular distance subequal to eye height; malar space about $0.25 \mathrm{X}$ eye height (Fig. 158). Occipital carina narrow, about $0.3 \mathrm{X}$ or less diameter of an ocellus. From above long and narrowing behind eyes, length behind eyes subequal to eye length (Fig. 159). Shining with fine white pubescence, pubescence densest on lower inner orbits, malar area, interantennal area, and clypeus. Vertex and gena smooth and shining, impunctate (Figs 159, 160); frons with small punctures about as close together as puncture diameters (Fig. 158). Mesosoma: Pronotum without anteriorly projecting tooth. Propleuron shining, almost impunctate. Mesonotum (Fig. 161) shining; mesoscutal middle lobe with transverse carinae, lateral lobes reticulate; axillae and mesoscutellum mostly finely reticulate to punctate; pleura and propodeum (Fig. 162) almost evenly reticulate, small more punctate areas on upper portion of meso- and metapleura. Hind coxa smooth and shining. Tarsal claws with 5 teeth. Hind basitarsus subequal in length to length of remaining tarsal segments combined. Cells $1 \mathrm{M}$ and $1 \mathrm{Rs}$ of forewing almost contiguous, vein Rs+M separating them very short (Fig. 163). Hind wing with veins distinct, cells $\mathrm{Cu}$ and $\mathrm{R} 1+\mathrm{Rs}$ separated by vein M (as in Fig. 104). Metasoma: Segments 2 to apex with fine white pubescence and fine punctures. Ovipositor about $0.9 \mathrm{X}$ length of forewing.

Male: Unknown.

Types: Holotype: Female, labeled "6 mi. south Temixco, Mor., Mex., VII-16-1963, F. D. Parker, L.A. Stange, Collectors” (UCD). Paratypes: MEXICO: GUERRERO: $18.2 \mathrm{mi}$. S. Iguala, VII-5-1987, 3000 ft., R. Wharton (1 + , TAMU). JALISCO: Chamela Biol. Stn., 16 July 1989, R. Brooks, C. Michener, A. Roig Alsina \#054, ex Malaise trap (1 + , UKAN), same except A. Roig Alsina, C. Michener, R. Brooks (1 +, UKAN); same except 11 July 1989, A. Roig Alsina, C. Michener, R. Borroks \#018 (1 +. UKAN); Chamela Res. Sta., 25 Aug. 1986, M. Sanchez - M.T. (1 9 , USU), same except 4 Aug. 1986 (1 ㅇ, USU). MORELOS: Same data as holotype (1 ๆ, UCD); Yautepec, VII-31-1963, F.D. Parker, L.A. Stange, Collectors (1 ㅇ, UCD).

Other specimens: MEXICO: Oaxaca, 5 km N Huajapan de León, 5-X-1986, R. Miller \& L. Stange (1 [metasoma missing], FSCA).

Etymology: Named for Frank D. Parker, who collected the holotype and some paratypes of this species. 


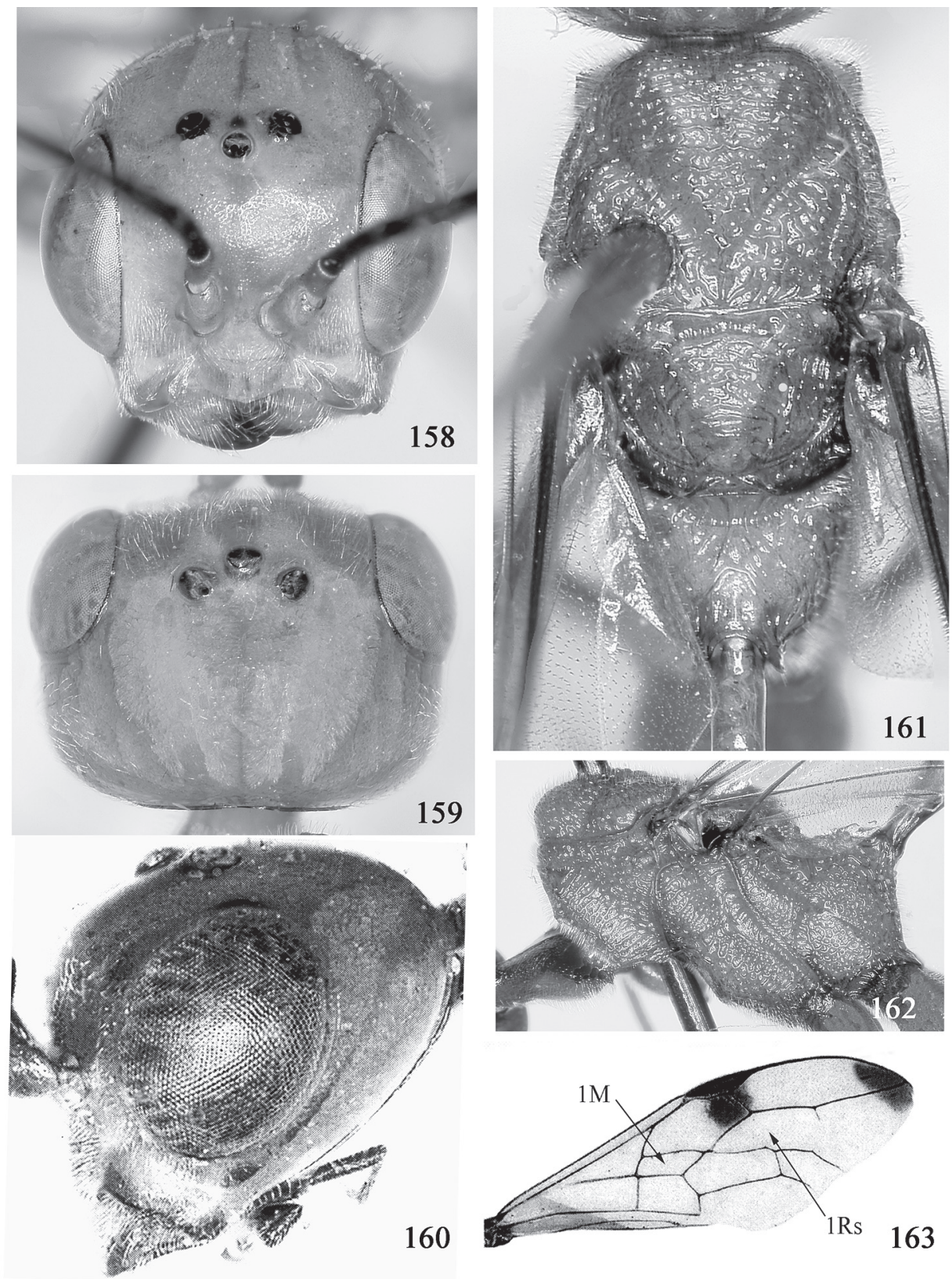

Figs 158-163: Pristaulacus parkeri. 158 Head, front. 159 Head, dorsal. $160 \mathrm{Head}$, lateral. 161 Mesosoma, dorsal. 162 Mesosoma, lateral. 163 Forewing.

\section{Remarks:}

The orange color and size are similar to $P$. totoferrugineus. Pristaulacus parkeri has the head and hind coxae smooth and shining as opposed to the punctate frons and punctate and striate hind coxae of $P$. totoferrugineus. 
Beitr. Ent. 58 (2008) 2

\section{Pristaulacus mexiuni SMITH, new species}

(Figs 164-168)

\section{Diagnosis:}

Head orange; mesosoma orange in front of transscutal articulation, black behind; metasoma black. Forewing with black spot under stigma and black at apex. Head shining, strongly narrowing behind eyes. Mesoscutum with transverse carinae. Hind coxa smooth, shining. Anterior margin of pronotum with one anteriorly projecting tooth.
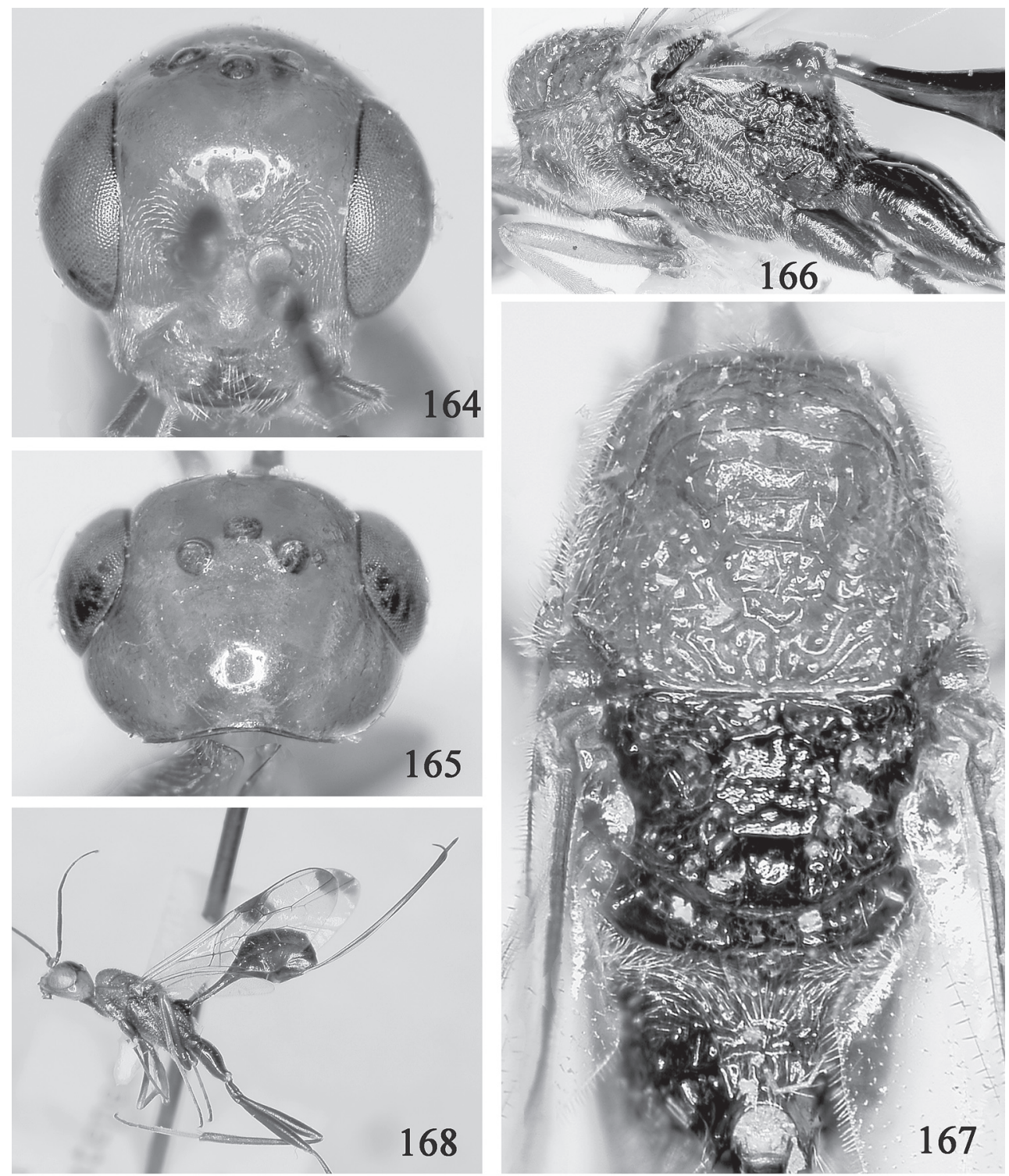

Figs 164-168: Pristaulacus mexiuni. $164 \mathrm{Head}$, front. 165 Head, dorsal. 166 Mesosoma, lateral. 167 Mesosoma, dorsal. 168 Lateral. 


\section{Female:}

Length, $7.5 \mathrm{~mm}$; forewing length, $6.5 \mathrm{~mm}$; ovipositor length, $7.0 \mathrm{~mm}$. Color: Head orange, sometimes small black spots around or anterior to ocelli on frons; mesosoma black, usually propleuron, pronotum, and mesoscutum orange, propleuron may be black or partly black and sometimes black spot on lower pronotum. Legs black with fore- and midfemora and tibiae orange, hind tarsus white. Ovipositor sheath black. Wings hyaline, veins and stigma black; forewing with black spot under stigma and black spot at apex (Fig. 168). Head: Lower interocular distance subequal to eye height; malar space about $0.25 \mathrm{X}$ eye height (Fig. 164). From above, narrowing behind eyes, length of head about $0.6 \mathrm{X}$ eye length (Fig. 165). Occipital carina narrow, $0.2 \mathrm{X}$ or less diameter of an ocellus. Smooth and shining with white pubescence, pubescence densest on lower frons, lower inner orbits, and malar area. Gena and vertex impunctate (Fig. 165); frons practically impunctate, few very widely scattered punctures on lower half (Fig. 164). Mesosoma: Pronotum with anteriorly projecting tooth. Propleuron smooth and shining, impunctate. Mesonotum (Fig. 167) shining, mostly reticulate, sculpturation more transverse on mesoscutal middle lobe and middle of mesoscutellum; pronotum (Fig. 166) smooth and shining with few widely scattered punctures, more reticulate on posterior third; mesopleuron, metapleuron, and propodeum (Fig. 166) reticulate with upper portion of metapleuron with small finely punctate area. Hind coxa about $3 \mathrm{X}$ longer than broad, smooth and shining. Tarsal claws with 5 teeth, lower tooth smallest. Hindbasitarsus slightly longer than length of remaining tarsal segments combined. Forewing with cells $1 \mathrm{M}$ and 1 Rs separated by short vein Rs+M (as in Fig. 157). Hind wing with veins faint to absent (as in Fig. 157). Metasoma: Smooth and shining; first segment long, etiolate. Ovipositor length 1.1X longer than forewing length (Fig. 168).

Male: Unknown.

Types: Holotype: Female, labeled “Tex., Cameron Co., 10 mi. E. jct. hwy. 4 \&1419, emerged 11-20 June 1979, R. Turnbow" (UGA). Paratypes: COSTA RICA: Escazu, May 27, 1987, H. \& M. Townes (1 + , AEI). MEXICO: CHIHUAHUA: 6 MI. s. Villa Mtamoros, VIII-8-1967, R. C. Gardner, C. R. Kovacic, K. Lorenzen (1 ㅇ, UCD). JALISCO: 14 MI. w, 7360 ft., Ojelos de Jalisco, July 7, 1972, B. \& C. Dasch (3 우 ㅇ, AEI); PUEBLA: 4.4 mi. SW. Acatepec, July 9, 1981, Bogar, Schaffner, Friedlander (1 ㅇ, TAMU). TAMAULIPAS: Gomez Farias: 900 m, Alta Cima, T. Malaise, 19-26.vi.1999, Col. Sonia Hernandez A. (1 ㅇ, USNM), same except 29.v-5.vi.1999 (1 \%, USNM). UNITED STATES: ARIZONA: Onion Saddle, 7600', Chiricahua Mts., Cochise Co., VIII-24-1967, E. I. Schlinger, Univ. Calif. Riverside Ent. Res. Museum, UCRC ENT 88952 (1 우 UCRC). TEXAS: Cameron Co., 4 mi W Boca Chica, R'd Ebony, 1-7 July 2003, J. E. Wappes (2 우 오 FSCA).

Etymology: From the first syllables of Mexico and the United States, referring to the occurrence of this species in both countries; a noun in apposition.

\section{Remarks:}

Some specimens have black areas on the vertex to frons. 
Beitr. Ent. 58 (2008) 2

\section{Pristaulacus totoferrugineus SMITH, new species}

(Figs 169-172)

\section{Diagnosis:}

Entirely orange. Forewing with black spot below stigma and black at apex. Head shiny. Mesosoma reticulate, with some fine transverse carinae. Hind coxa with cross striations. Propleuron punctate. Anterior margin of pronotum without anteriorly projecting tooth.

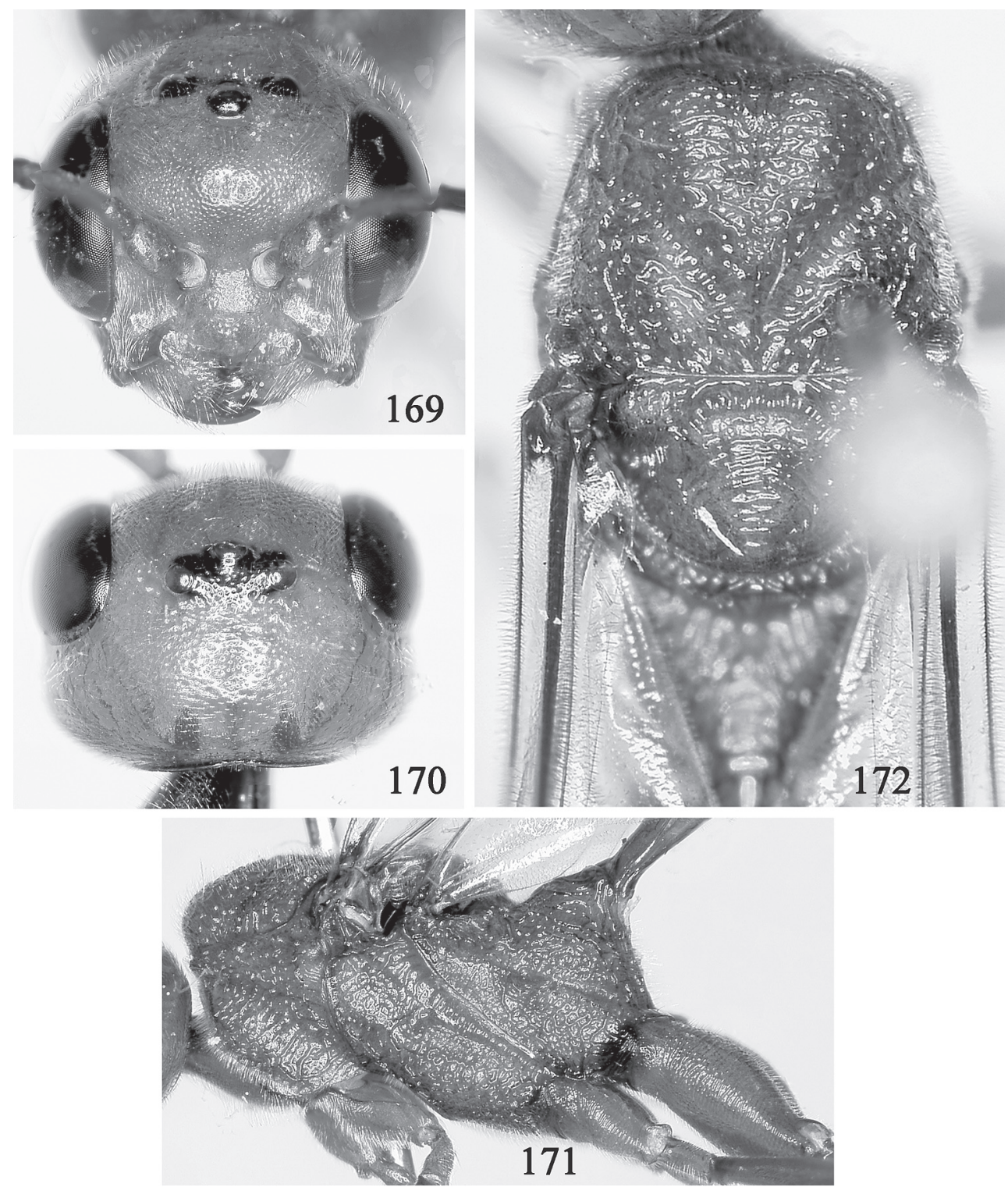

Figs 169-172: Pristaulacus totoferrugineus. 169 Head, front. 170 Head, dorsal. 171 Mesosoma, lateral. 172 Mesosoma, dorsal. 


\section{Female:}

Length, $11.0 \mathrm{~mm}$; forewing length, $9.5 \mathrm{~mm}$; ovipositor length, $8.0 \mathrm{~mm}$. Color: Orange. Ovipositor sheath black. Wings hyaline, veins and stigma black; forewing with black spot under stigma and black spot at apex. Head: Antennal length 2.1X head width. Lower interocular distance about 1.2X eye height; malar space about $0.3 \mathrm{X}$ eye height (Fig. 169). Occipital carina broad, nearly half diameter of an ocellus. From above, straight, then narrowing behind eyes, head behind eyes about $0.6 \mathrm{X}$ eye length (Fig. 170). Smooth and shining, with scattered fine white pubescence; vertex and gena with fine punctures, separated by distance of more than puncture diameters (Fig. 170); fine punctures on frons denser than those on vertex and separated by puncture diameters or less (Fig. 169). Mesosoma: Pronotum without anteriorly projecting tooth. Propleuron shining, punctate. Mesonotum (Fig. 172) mostly reticulate; mesoscutellum sculpture in transverse pattern; pleura and propodeum (Fig. 171) mostly reticulate, anterior margin of pronotum and small area on upper metapleuron less reticulate and finely punctate. Hind coxa dull, with transverse carinae, about 2.2X longer than wide (Fig. 171). Tarsal claws with 5 teeth and small basal lobe. Hind basitarsus 1.1X length of remaining tarsal segments combined. Forewing with cells $1 \mathrm{M}$ and 1 Rs separated by short Rs+M vein (as in Fig. 157). Hind with veins faint, cells $\mathrm{Cu}$ and $\mathrm{R} 1+\mathrm{Rs}$ separated by vein M (as in Fig. 104). Metasoma: Smooth, shining, with fine white pubescence on segments 3 to apex. Ovipositor length about $0.8 \mathrm{X}$ forewing length.

Male: Unknown.

Types: Holotype: Female, labeled "San Pedro Iturbide, 32+ Km. W. Linares, X.6.62, N.L., Mex., H. \& M. Townes” (AEI). Paratypes: MEXICO: JALISCO: 14 km. N. Guadalajara, Ruta 54, Posada San Isidro, 22-IX-1986, R. Miller \& L. Stange (1 as holotype (2 우 오, AEI).

Etymology: From the Latin toto (all) and ferrugineus (rusty), referring to the entirely reddishorange coloration of this species.

\section{Remarks:}

See remarks under $P$. parkeri.

\section{Pristaulacus hespenheidei SMITH, new species}

(Figs 173-176)

\section{Diagnosis:}

Head and mesosoma orange with pleura and sterna black, legs orange with coxae and femora black; metasoma mostly black. Forewing with black spot below stigma and black at apex. Head smooth, shiny. Mesoscutum with transverse carinae. Hind coxa shining. Anterior margin of pronotum with one anteriorly projecting tooth.

\section{Female:}

Length, $7.0 \mathrm{~mm}$; forewing length, $5.0 \mathrm{~mm}$; ovipositor length, $4.5 \mathrm{~mm}$. Color: Antenna black; scape and pedicel dark orange. Head and mesosoma orange with venter of propleuron, mesosternum, and lower lateral margins of propodeum black. Legs orange; coxae black, venter of forecoxa orange in one specimen; hindleg black with basal fifth of tibia and tarsus white. Metasoma with apical two-thirds of first segment and second segment mostly orange; basal third of first segment and segments 3 to apex black. Ovipositor sheath black. Head: Antennal length 

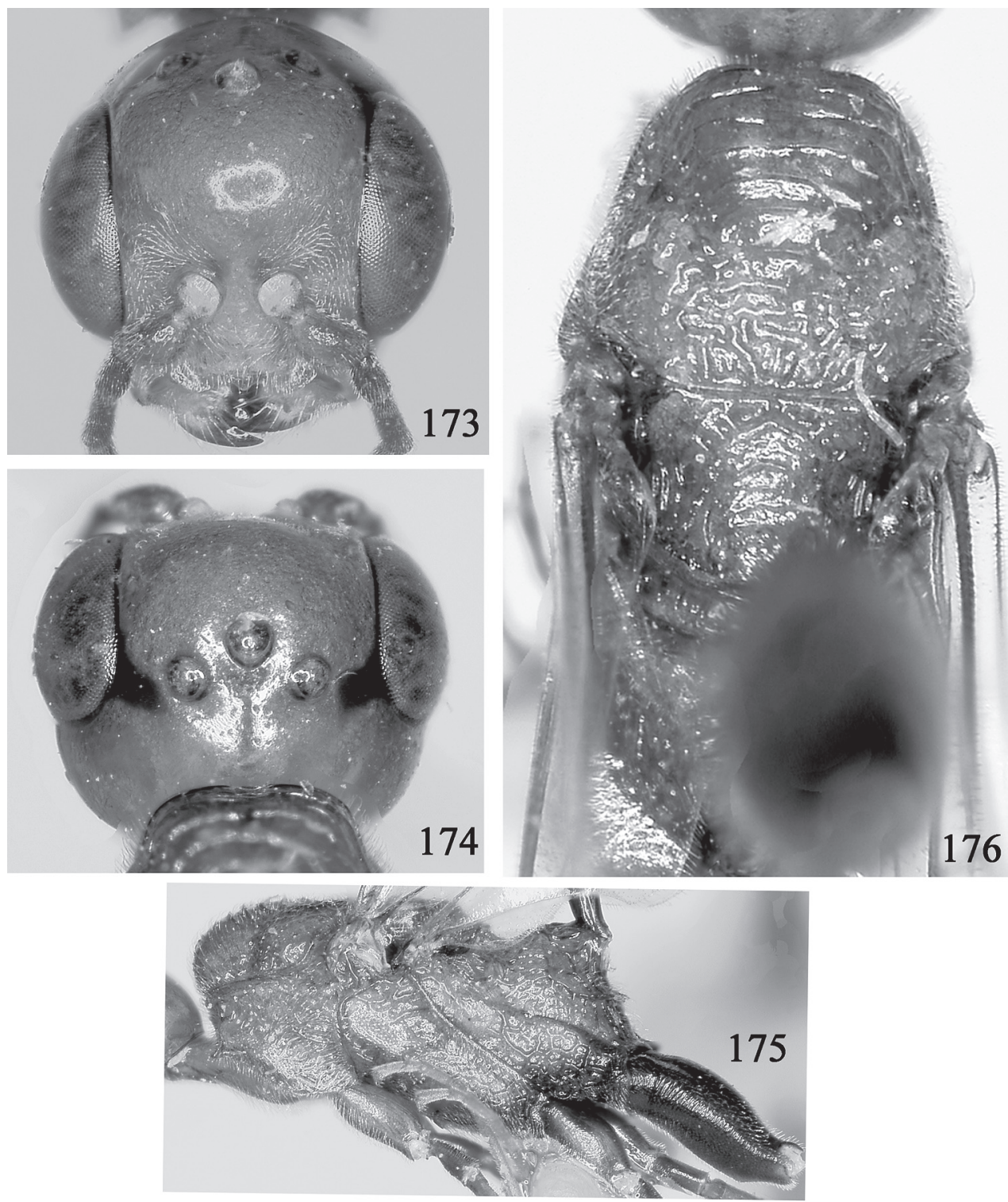

Figs 173-176: Pristaulacus hespenheidei. 173 Head, front. 174 Head, dorsal. 175 Mesosoma, lateral. 176 Mesosoma, dorsal.

1.8X head width. Lower interocular distance subequal to eye height; malar space about $0.25 \mathrm{X}$ eye height (Fig. 173). Occipital carina narrow, less than a fifth diameter of an ocellus. From above, head narrowing behind eyes, about 0.6X eye length (Fig. 174). Smooth, shining, with white pubescence, pubescence densest above antennae, on lower inner orbits, and malar area (Fig. 173); gena and vertex with few, very widely scattered punctures, much farther apart than puncture diameters; frons with somewhat denser punctation than vertex (Fig. 173). Mesosoma: Pronotum with anteriorly projecting tooth. Propleuron shining, finely punctate. Mesoscutal middle lobe with 6 or 7 transverse carinae; mesoscutal lateral lobes reticulate; axillae with few punctures; 
mesoscutellum with few transverse carinae at center Fig. 176); pronotum mostly reticulate, anteroventral margin finely punctate; mesopleuron reticulate with area on upper portion finely punctate; metapleuron and propodeum reticulate (Fig. 175). Hind coxa about 2.7X longer than broad smooth and shining above, transverse carinae on sides and ventrally. Tarsal claws with 4 teeth, basal most tooth very small and with small basal lobe. Hind basitarsus slightly longer than length of remaining tarsal segments combined. Forewing with cells $1 \mathrm{M}$ and 1 Rs separated by short vein Rs+M (as in Fig. 157). Hind wing with veins faint to absent (as in Fig. 157). Metasoma: Smooth, shining, with fine white pubescence on segments 3 to apex. Ovipositor length about $0.9 \mathrm{X}$ forewing length.

Male: Unknown.

Types: Holotype: Female, labeled "México: Veracruz, Est. Biol. de Los Tuxtlas, 18³5'N, 9505'W," “25-IV-1991, H. A. Hespenheide” (USNM). Paratype: UNITED STATES: ARIZONA: Prescott, VII-25-50, D.J. \& J.N. Knull, Collrs (1 + , OSU).

Etymology: Named for Henry Hespenheide, University of California, Los Angeles, who colleted the paratype.

\section{Remarks:}

This species and P. tamaulipas are similar. Pristaulacus hespenheidei has the coxae and hind femur black, the ovipositor length slightly shorter than the forewing length, and coarser reticulations on meso- and metapleura and propodeum than on the pronotum (compare Figs 175, 176, 179, 180).

\section{Pristaulacus tamaulipas SMITH, new species}

(Figs 177-180)

\section{Diagnosis:}

Head and most of mesosoma orange; legs orange; metasoma orange with black apex. Forewing with black spot below stigma and black at apex. Head shiny. Mesoscutum with transverse carinae. Hind coxa smooth, shining. Anterior margin of pronotum with one anteriorly projecting tooth.

\section{Female:}

Length, $9.0 \mathrm{~mm}$; forewing length, $7.0 \mathrm{~mm}$; ovipositor length, $7.0 \mathrm{~mm}$. Color: Orange; mandible except apex, scape, frons from ocelli to clypeus, and malar area more orange yellow. Pedicel, flagellum, apex of mandible, labial palpus, first two segments of maxillary palpus, ventral surface of propleuron, mesosternum, ventral surface of forecoxa, foretrochanter, base of first metasomal segment, posterior dorsal spots on metasomal segments 1-3, metasomal segments 4 to apex, and ovipositor sheath black. Wings hyaline; forewing with spot below stigma and apex black, veins and stigma black. Head: Antennal length 3.2X head width. Lower interocular distance subequal to eye length; malar space about $0.25 \mathrm{X}$ eye length (Fig. 177). Occipital carina narrow, less than a fifth diameter of an ocellus. From above, head narrowing behind eyes, about $0.6 \mathrm{X}$ eye height (Fig. 178). Smooth and shining, with fine white pubescence, pubescence densest on lower inner orbits and malar area; gena, vertex, and frons smooth, shining, impunctate (Figs 177, 178). Mesosoma: Pronotum with one anteriorly projecting tooth. Propleuron smooth, shining, impunctate. Mesoscutal middle lobe with 8-10 transverse carinae; mesoscutal lateral lobes reticulate, axillae reticulate, center of mesoscutellum without reticulations, finely punctate; 


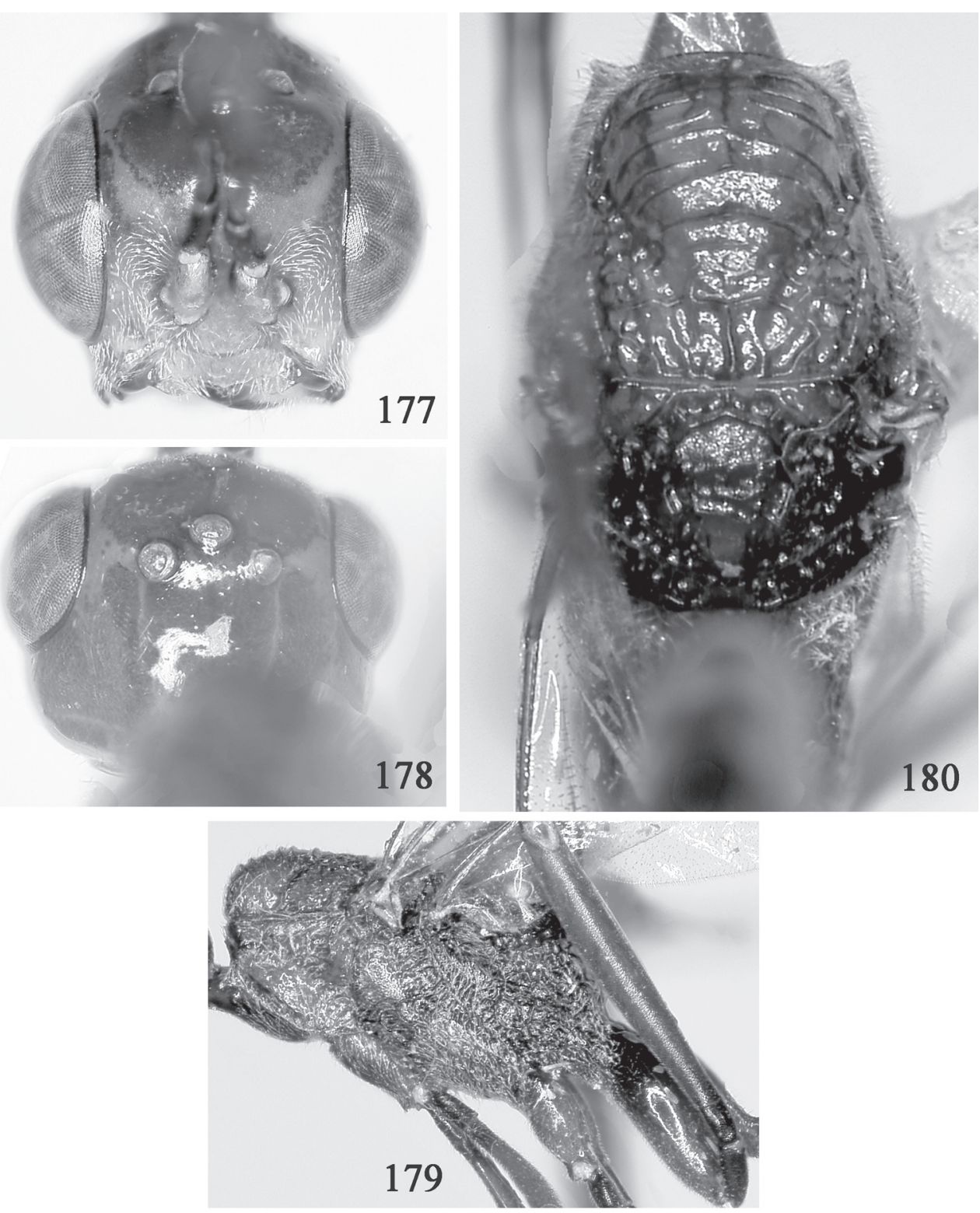

Figs 177-180: Pristaulacus tamaulipas. $177 \mathrm{Head}$, front. $178 \mathrm{Head}$, dorsal (partially obscured by mesosoma). 179 Mesosoma, lateral. 180 Mesosoma, dorsal.

pleura and propodeum almost evenly reticulate (Figs 179, 180). Hind coxa about $3 \mathrm{X}$ longer than broad, smooth and shining. Tarsal claws with 4 teeth and small basal lobe. Hind basitarsus 1.2X longer than following tarsal segments combined. Forewing with cells $1 \mathrm{M}$ and $1 \mathrm{Rs}$ separated by vein Rs+M (as in Fig. 157). Hind wing with veins absent (as in Fig. 157). Metasoma: Fine white pubescence on segments 2 to apex. Ovipositor length subequal to forewing length.

Male: Unknown. 
Types: Holotype: Female, labeled "Mexico, Tamaulipas, Gomez Farias: 900 m, Alta Cima, Malaise, 17-24.vii.1999, Col. Sonia Hernandez A.” (USNM). Paratypes: MEXICO: TAMAULIPAS: Same data as holotype except 7-14.viii.1999 (1 ㅇ, USNM); same data as holotype except 14-24. viii.1999 (1 ㅇ, USNM).

Etymology: Named for the State of Tamaulipas where this species was collected.

\section{Remarks:}

The metapleuron is blackish in one paratype. See remarks under $P$. hespenheidei.

\section{Pristaulacus annulatus KIEFFER}

(Figs 181-183)

Psilaulacus annulatus KIEFFer 1911: 230.

Pristaulacus annulatus: KiefFer 1912: 381, 404.-Hedicke 1939: 5.-Sмiтн 2001: 278.

\section{Diagnosis:}

Black; whitish spot a middle on each side of first metasomal segment; white band on ovipositor. Forewing with black spot at apex. Head shining with large scattered punctures. Mesoscutum with transverse carinae. Hind coxa smooth, shining. Anterior margin of pronotum without anteriorly projecting tooth.
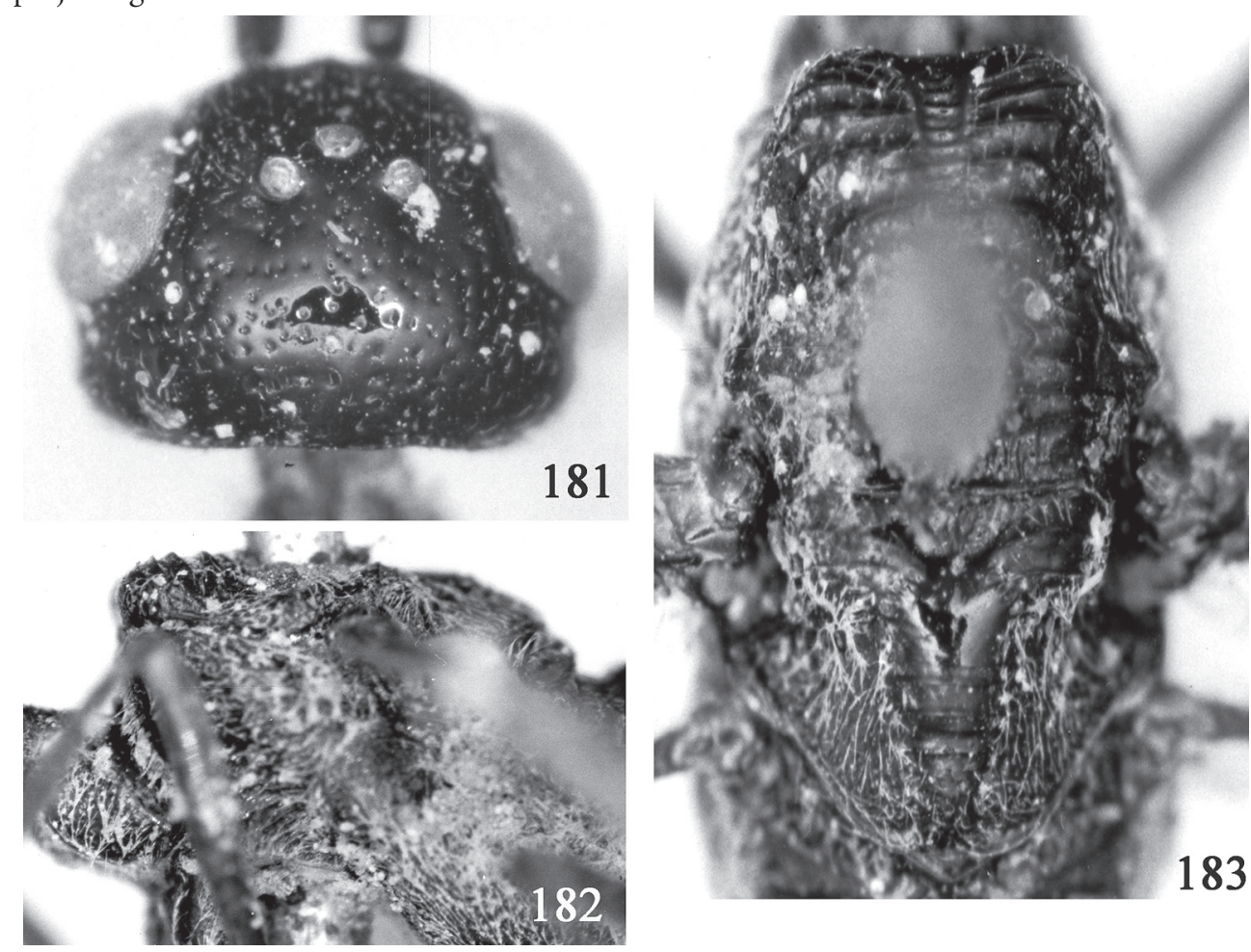

Figs 181-183: Pristaulacus annulatus. $181 \mathrm{Head}$ and anterior mesosoma, dorsal. 182 Mesosoma, lateral. 183 Mesosoma, dorsal. Note: Figures taken with another photomicroscope and not of similar quality as other figures; specimen not reborrowed for further pictures. 


\section{Female:}

Length, $11.5 \mathrm{~mm}$; forewing length, $9.0 \mathrm{~mm}$; ovipositor length $15.0 \mathrm{~mm}$. Color: Black; whitish spot at middle on each side of first metasomal segment; ovipositor with white band near apical third; legs somewhat brownish. Wings hyaline, veins and stigma black; forewing with dark spot at apex. Head: Antenna apex missing. Lower interocular distance subequal to eye height; malar space equal to first antennal segment. Occipital carina narrow, less than a quarter diameter of an ocellus. Head from above straight then narrowing behind eyes, distance behind eyes about $0.6 \mathrm{X}$ eye length (Fig. 181). Shining with large punctures on vertex and frons separated by distances two or more times puncture diameters (Fig. 181), punctures on frons slightly denser than those on vertex. Mesosoma: Pronotum without anteriorly projecting tooth. Propleuron shining, finely punctate. Anterior lobes of mesonotum rounded. Mesoscutal middle lobe transversely carinate, lateral lobes more reticulate; axillae reticulate; mesoscutellum shining, with 3 medial transverse ridges at center, reticulate laterally; pronotum, mesopleuron, metapleuron, and propodeum shining, mostly reticulate (Fig. 182). Hind coxa shining, without sculpture. Hind basitarsus 1.3X longer than remaining tarsal segments combined. Tarsal claw with 3 large subequal teeth and basal lobe; third tooth slightly smaller that two outer teeth. Metasoma: Basal two segments shining, glabrous; apical segments with fine white pubescence. Ovipositor length 1.7X forewing length.

Male: Unknown.

Type: Female (BMNH) labeled “Type,” "B.M. type Hym. 3.a.102,”B.M. type Hym. Psilaulacus annulatus Kieffer 1911," "Pristaulacus annulatus K.", "56 143" above and "Mex." below on one label, "Determined by Dr. Kieffer," "Aulacus bimaculatus Smith [purple label]." I regard this as a syntype; though undoubtedly the only specimen KIEFFER had, he did not mention the number of specimens.

\section{Remarks:}

This species is known only from the holotype. Its large size, black color, punctate head, and unusually long ovipositor should make this species readily recognizable. Females of all other Pristaulacus I have examined have the ovipositor length $1.5 \mathrm{X}$ or less the forewing length.

\section{Incertae Sedis}

\section{Aulacus hyalinipennis WESTWOOD}

Aulacus hyalinipennis Westwood 1841: 538.-WeStwood 1843: 265.-CAMERON 1887: 423.-SCHLETTERER 1890: 518 (= Aulacinus pediculatus Schletterer).-Kieffer 1912: 371, 373.-Hedicke 1939: 18.Sмiтн 2001: 271.

Aulacinus hyalinipennis: KIEFFER 1902: 12.

\section{Remarks:}

I was unable to locate the type. It was not found at the BMNH or at the Hope Entomological Collections, Oxford University, where Westwood's collections are apt to be found. Westwood's description is not adequate to place this species to genus. He described the species from a male from "Mexico." The following is from Westwood: Black, very slender. Face, lower and behind part of head red brown, head small. Palpi black brown. Scape red brown. Neck lengthened, ventral red brown. Wings clear, distal end blackish, stigma black. Front and mid legs red brown, hind legs with coxa and femur blackish, knees red brown, tibia rusty, tarsus red brown with blackish distal end. Metasoma laterally compressed. 


\section{Acknowledgements}

My sincere thanks to all those listed in Materials and Methods for lending specimens. Christopher O'Toole kindly searched the Hope Entomological Collections, Oxford University, U.K., for the type of Aulacus hyalinipennis. I appreciate the comments and suggestions of the following reviewers: ANDREW R. DEANS, North Carolina State University, and S. M. McKamey and T. J. Henrr, Systematic Entomology Laboratory, U. S. Department of Agriculture, Washington, DC.

\section{Literature Cited}

Bradley, J. C. 1908: The Evaniidae, ensign-flies, an archaic family of Hymenoptera. - Transactions of the American Entomological Society 34: 101-194, plates V-XV.

Cameron, P. 1887: Insects. Hymenoptera (Families Tenthredinidae - Chrysididae). Vol. I. - In: Godman and Salvin, Biologia Centrali-Americana, 1883-1900: 473 pp., 20 pls.

Carlson, R. W. 1979: Aulacidae, pp. 1111-1115. - In: Krombein, K. V.; Hurd, P. D., Jr.; Smith, D. R. \& Burks, B. D. (eds.): Catalog of Hymenoptera in America North of Mexico. Volume 1. Symphyta and Apocrita (Parasitica). - Smithsonian Institution Press, Washington, DC: xvi + 1198 pp.

Cresson, E. T. 1864: Descriptions of North American Hymenoptera in the collection of the Entomological Society of Philadelphia. - Proceedings of the Entomological Society of Philadelphia 3: 131-196.

Dalla Torre, C. G. DE 1902: Catalogus Hymenopterorum hucusque descriptorum systematicus et synonymicus. - Volumen III: Trigonalidae, Megalyridae, Stephanidae, Ichneumonidae, Agriotypidae, Evaniidae, Pelecinidae. Pars II., pp.: 543-1141. Lipsiae.

Fernández, F. \& Sharkey, M. J. (eds.) 2006: Introducción a los Hymenoptera de la Región Neotropical. Sociedad Colombia de Entomología y Universidad Nacional de Colombia, Bogotá D.C.: xxx + $894 \mathrm{pp}$.

Gauld, I. D. \& Hanson, P. E. 2006: Capítulo 8. Evaniomorpha, pp. 210-212. - In: Hanson, P. E. \& Gauld, I. D. (eds): Hymenoptera de la Región Neotropical. - Memoirs of the American Entomological Institute, Vol. 77: 994 pp.

Hanson, P. E. \& Gauld, I. D. (eds.). 2006: Hymenoptera de la Región Neotropical. - Memoirs of the American Entomological Institute, Vol. 77: 994 pp.

He, J.-H., X.-X. Chen \& MA, Y. 2002: Two new species of Aulacidae from Zhejian Province, China. - Acta Zootaxonomica Sinica 27: 149-152.

Hedicke, H. 1939: Aulacidae. - In: Hedicke, H. [ed.] Hymenopterorum Catologus, Pars 10. Dr. W. Junk, Gravenhage: 28 pp.

Jennings, J. T. \& Austin, A. D. 2006: Aulacid wasps (Hymenoptera: Aulacidae) of New Guinea, with descriptions of five new species. - Zootaxa 1365: 19-35.

Jennings, J. T.; Austin, A. D. \& Stevens, N. B. 2004a: The aulacid wasp fauna of Western Australia with descriptions of six new species. - Records of the Western Australian Museum 22: 115-128.

Jennings, J. T.; Austin, A. D. \& Stevens, N. B. 2004b: Species of the wasp genus Aulacus Jurine (Hymenoptera: Aulacidae) endemic to South Australia. - Transactions of the Royal Society of South Australia 128: 13-21.

Jennings, J. T.; Austin, A. D. \& Stevens, N. B. 2004c: First record of Aulacidae (Hymenoptera: Evanioidea) from New Caledonia with descriptions of three new species of Aulacus Jurine. - Australian Journal of Entomology 43: 346-352.

Kieffer, J.-J. 1902: Hymenoptera, Fam. Evaniidae. - In: Wytsman, P. (ed.) Genera Insectorum, Fascicule 2, 13 pp., 1 plate. Bruxelles.

Kieffer, J.-J. 1903: Les Evaniiden. - In: André, E. Species des Hyménoptères d'Europe \& d'Algérie. Volume 7, part 2: pp. 347-482. Paris.

Kiefrer, J.-J. 1904: Description de Stephanides et d'evaniides nouveaus. - Bulletin de la Société d'Histoire naturelle de Metz 11: 1-30. 
KiefFer, J.-J. 1911: Étude sur les Evaniides exotiques (Hym.) du British Museum de Londres. - Annals Société Entomologique de France 80: 151-230.

Kiefrer, J.-J. 1912: Hymenoptera, Ichneumonidae, Evaniidae. - Das Tierreich, Berlin, Volume 30: I-XIX $+431 \mathrm{pp}$.

Mason, W. 2007: Capítulo 90, Superfamilia Evanioidea, pp. 793-794. - In: Fernández, F. \& Sharkey, M. J. (eds.) Introducción a los Hymenoptera de la Región Neotropical. Sociedad Colombia de Entomología y Universidad Nacional de Colombia, Bogotá D.C.: xxx + 894 pp.

Muesebeck, C. F. W. 1958: Gasteruptiidae, p. 88. - In: Krombein, K. W. (ed.). Hymenoptera of America North of Mexico, Synoptic Catalog (Agriculture Monograph 2). First Supplement. United States Department of Agriculture, Washington, DC: 305 pp.

Schletterer, A. 1889: Die Hymenopteren-Gruppe der Evaniiden. III. Abteilung. - Annalen des K. K. Naturhistorischen Hofmuseums, Wien 4: 373-546.

Sмith, D. R. 1996: Aulacidae (Hymenoptera) in the mid-Atlantic states, with a key to species of eastern North America. Proceedings of the Entomological Society of Washington 98: 274-291.

Sмiтh, D. R. 1998: A synopsis of the sawflies (Hymenoptera: Symphyta) of America south of the United States: Introduction, Xyelidae, Pamphiliidae, Cimbicidae, Diprionidae, Xiphydriidae, Siricidae, Orussidae, Cephidae. Systematic Entomology 13: 205-261.

Sмiтh, D. R. 2001: World catalog of the family Aulacidae (Hymenoptera). - Contributions on Entomology, International 4 (3): 263-319.

Smith, D. R. 2005: Aulacidae (Hymenoptera) of northern South America, emphasizing Colombia. Transactions of the American Entomological Society 131: 217-253.

Smith, D. R. 2006: 8.3. Familia Aulacidae, pp. 219-221. - In: Hanson, P. E. \& Gauld, I. D. (eds.). Hymenoptera de la Región Neotropical. Memoirs of the American Entomological Institute, Vol. 7: 994 pp.

Smith, D. R. 2007: Capitulo 92, Familia Aulacidae, pp. 803-805. - In: Fernández, F. \& Sharkey, M. D. (eds.). Introducción a los Hymenoptera de la Región Neotropical. Sociedad Colombia de Entomología y Universidad Nacional de Colombia, Bogotá D.C.: xxx +894 pp.

Sun, S.-P. \& Sheng, M.-L. 2007a: Aulacus Jurine (Hymenoptera: Aulacidae) from China with a new species parasitizing Xiphydria popovi (Hymenoptera: Xiphydriidae). - Proceedings of the Entomological Society of Washington 109: 121-124.

Sun, S.-P. \& Sheng, M.-L. 2007b: Genus Pristaulacus (Hymenoptera, Aulacidae) in Henan Province, China. - Acta Zootaxonomica Sinica 32: 216-220.

Townes, H. K. 1950: The Nearctic species of Gasteruptiidae (Hymenoptera). - Proceedings of the United States National Museum 100: 85-145.

Townes, H. K. 1951: Aulacinae, pp. 657-660. - In: Muesebeck, C. F. W.; Krombein, K. V. \& Townes, H. K. (eds.) Hymenoptera of America North of Mexico, Synoptic Catalog. United States Department of Agriculture, Agriculture Monograph No. 2: 1420 pp.

Turrisi, G. F. 2005: Description of Aulacus schoenitzeri spec. nov. (Hymenoptera, Evanioidea, Aulacidae) from China. - Linzer Biologische Beiträge 37: 797-803.

Turrisi, G. F. 2006: Revision of the Afrotropical species of Pristaulacus KiefFer, 1900 (Hymenoptera, Aulacidae). - Insect Systematics and Evolution 37: 27-38.

Turrisi, G. F. 2007: Revision of the Palearctic species of Pristaulacus Kiefrer, 1900 (Hymenoptera, Aulacidae). - Zootaxa 1433: 76 pp.

WAlKLeY, L. M. 1952: An unusual aulacine from New Mexico (Hymenoptera-Gasteruptiidae). - Proceedings of the Entomological Society of Washington 54: 185-186.

WAlkLeY, L. M. 1967: Evanioidea, pp. 284-285. - In: Krombein, K. V. \& Burks, B. D. (eds.). Hymenoptera of America North of Mexico, Synoptic Catalog (Agriculture Monograph No. 2), Second Supplement. United States Department of Agriculture, Washington, DC: 584 pp. 
Westwood, J. O. 1841: [Descriptions in entomological society proceedings.] - Proceedings of the Entomological Society of London 1841: 535-539.

Westwood, J. O. 1844 (1843): XXXVIII. On Evania and some allied genera of Hymenopterous insects.

- Transactions of the Entomological Society of London 3: 237-278, plates XIV-XV.

\section{Index}

Pages bold $=$ description, underlined $=$ image .

ambiguous (Schletterer), Pristaulacus 296

aneurus Walkley, Aulacus $267, \underline{292}$

annulatus Kieffer, Pristaulacus $267,268,274,333, \underline{\mathbf{3 5 0}}, 351$

anteala Smith, Pristaulacus $267,274,313, \underline{314}$

aquilus Smith, Pristaulacus $267,273,310,311,312$

arizonicus (Townes), Pristaulacus $267,268,275,334, \underline{\mathbf{3 3 5}}, 336$ argutus Smith, Pristaulacus $267,273,294, \underline{295}, 296$ auricomus Smith, Pristaulacus $267,273,302, \underline{303}, 304$ brasiliensis (Kieffer), Pristaulacus 296 candidus Smith, Pristaulacus $267,268,275, \underline{330}, 331$ costaricensis Smith, Aulacus $267,272,282, \underline{283}$ decemdentatus Kieffer, Pristaulacus 297 decolorus Smith, Pristaulacus $267,268,274,326, \underline{327}$ decorus Smith, Pristaulacus $267,268,273,306,308, \underline{309}, 310,326$ dispilis Townes, Aulacus $267,272,289,292, \underline{293}$ elongatus Smith, Aulacus $267,271,279, \underline{\mathbf{2 8 6}}, 287$ fascius Smith, Aulacus $267,272,279, \underline{280}$ femurrubrum Smith, Pristaulacus 296

haemorrhoidalis (Westwood), Pristaulacus 296 heredia Smith, Aulacus $267,269,272, \mathbf{2 8 4}, \underline{285}$ hespenheidei Smith, Pristaulacus $267,268,270,275,346, \underline{347}, 348,350$ hyalinipennis Westwood, Aulacus $267,268,269,351,352$ leon Smith, Aulacus $267,272,287, \underline{288}, 289,294$ maculatus (Schletterer), Pristaulacus $267,268,273,298, \underline{299}, 300,302$ maculosus Smith, Aulacus $267,271, \underline{\mathbf{2 7 6}}, 277$ mexiuni Smith, Pristaulacus $267,268,275, \underline{343}$ nigricoxae Smith, Pristaulacus $267,268,274,313,317, \underline{318}$ ochreus Smith, Aulacus $267,268,271,277, \underline{278}$ omninoniger Smith, Pristaulacus $267,268,269,331, \underline{332}, 333$ parkeri Smith, Pristaulacus $267,268,275,341, \underline{342}, 346$ 
postala Smith, Pristaulacus

$267,268,274,321, \underline{322}$

punctatus Smith, Pristaulacus 296

punctum Smith, Pristaulacus

267, 273, 306, 307, 308, 310

ruficeps (Westwood), Pristaulacus 296

ruficollis (Cameron), Pristaulacus $267,268,273,296,300, \underline{301}, 302$

ruficruris Smith, Pristaulacus $267,268,275,339, \underline{340}, 341$

rufitarsis (Cresson), Pristaulacus $267,268,273,336, \underline{337}$ singulus Smith, Pristaulacus $267,268,270,275,328, \underline{329}$ stangei Smith, Pristaulacus $267,268,274, \underline{323}$ tamaulipas Smith, Pristaulacus $267,268,275,348, \underline{349}$ tenuis Smith, Pristaulacus $267,268,269,274,324, \underline{325}, 326$

torridus (Bradley), Pristaulacus $267,274,312,313,315,319$

totoferrugineus Smith, Pristaulacus $267,268,275,342, \underline{345}$ townesi Smith, Pristaulacus $267,268,269,275,333, \underline{334}$

tria Smith, Pristaulacus 267, 270, 273, 296, 297 triclora Smith, Pristaulacus $267,268,274,315, \underline{316}$ unimacula Smith, Pristaulacus $267,268,270,274,319, \underline{320}$ whartoni Smith, Aulacus $267,270,272,289, \underline{290}, 291$ veracruz Smith, Aulacus $267,272, \underline{\mathbf{2 8 1}}$ virga Smith, Pristaulacus $267,273,304, \underline{305}, 306$

Author's address:

DAVID R. SMith

Systematic Entomology Laboratory, PSI

Agricultural Research Service

U.S. Department of Agriculture c/o National Museum of Natural History

Smithsonian Institution

P.O. Box 37012, MRC 168

Washington, D.C. 20013-7012

U.S.A.

e-mail: dave.smith@ars.usda.gov
Subject editor:

Dr. S. M. BLANK 